Step-Induced pH Gradients Generated with Mixed Resin Beds for Protein Chromatography

A Dissertation
Presented to
the faculty of the School of Engineering and Applied Science
University of Virginia
in partial fulfillment
of the requirements for the degree
Doctor of Philosophy

by

Tarl Albert Vetter

December

2014 
APPROVAL SHEET

The dissertation

is submitted in partial fulfillment of the requirements

for the degree of

Doctor of Philosophy

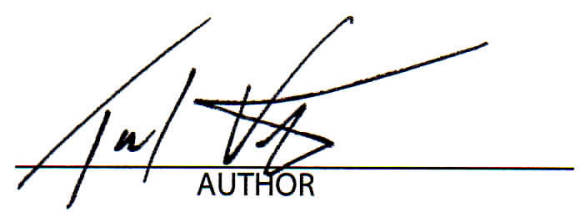

The dissertation has been read and approved by the examining committee:

Giorgio Carta

Advisor

Roseanne Ford

Geoffrey Geise

James Demas

Gisela Ferreira

Accepted for the School of Engineering and Applied Science:

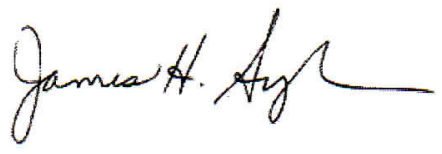

Dean, School of Engineering and Applied Science

December

2014 


\title{
Step-Induced pH Gradients Generated with Mixed Resin Beds for Protein Chromatography
}

\author{
A Dissertation \\ Presented to \\ the faculty of the School of Engineering and Applied Science \\ University of Virginia
}

\begin{abstract}
in partial fulfillment
of the requirements for the degree

Doctor of Philosophy (Chemical Engineering)
\end{abstract}

By

Tarl A. Vetter

December 2014 


\begin{abstract}
This work develops a new approach for the purification of proteins and protein charge variants using step-induced $\mathrm{pH}$ gradients generated on mixed-bed columns of strong and weak base ion exchange resins. The mixed-bed approach requires a weak base resin with small pores that will allow for the generation of an induced $\mathrm{pH}$ gradient, but prevent interaction with proteins, and a strong base exchanger with charged groups that are independent of $\mathrm{pH}$, and with large pores that facilitate protein mass transfer. Mixedbeds consisting of AG 4-X4 (Bio-Rad Laboratories, Hercules, CA), a weak base exchanger with a high weak ligand capacity and a size exclusion limit $<2 \mathrm{~nm}$, and SOURCE 30Q (GE Healthcare, Piscataway, NJ), a strong base exchanger with a size exclusion limit $>40 \mathrm{~nm}$, were used to purify a native $\mathrm{mAb}$ from a deamidated variant making up about $25 \%$ of the mAb sample.
\end{abstract}

The proper selection of exchange materials effectively partitions the two functions of $\mathrm{pH}$ gradient generation and protein retention into two separate phases which can then be optimized and modeled independently. A local equilibrium model was used to describe the generation of step-induced $\mathrm{pH}$ gradients in mixed-beds using experimentally determined parameters for the weak base resin. Protein retention as a function of $\mathrm{pH}$ and ionic strength was modeled using the steric mass action (SMA) and a linear driving force model (LDF) was used to describe adsorption kinetics. The models for these two functions were combined and solved numerically using a backwards finite differences discretization of the ensuing system of differential equations.

Experimental results show that mixed-bed columns with ratios of AG 4-X4 as low as $10 \%$ are capable of creating $\mathrm{pH}$ gradients of useful durations that can resolve charge 
variants with $0.2 \mathrm{pH}$ units difference in $\mathrm{pI}$. At higher loads, the apparent resolution decreases, but good recovery of purified material is achieved by cutting the elution peak appropriately. In all cases, the retention model showed good predictive agreement with the experimental results, indicating that the model could be used to optimize a separation process, and minimize the number of experiments required. 


\section{Acknowledgements}

This document is the culmination of countless hours of work and stress, and would have never been completed if not for the support of a few individuals that I must acknowledge. First and foremost I have to thank Prof. Carta for sharing his vast knowledge and experience with me. One could not ask for a more dedicated advisor. I would like to thank Prof. Ford, Prof. Demas, Prof. Geise, and Prof. Kwon for their helpful input as members of my committee. The insights provided by Gisela and David at MedImmune were also greatly appreciated and managed to keep this work grounded in the realities of industry.

A great deal is owed to all the members of the Carta lab group, both past and present, but I'd particularly like to recognize Ernie, Joe B., Jason, Arch, Frank and Yige for everything they've done over the years. Additionally, I'd like to thank several classmates, including Simpson, Ed, Jacob, Juan, Joe C., and Brittany, for their support and camaraderie. I would also like to thank Vickie, Teresa, and Ricky. They're the ones that know how to get things done, and I appreciate all their help.

I would be remiss if I didn't acknowledge all the love and support that I've received over the years from our families, who were willing to let their son, daughter, and granddog Newman move half way across the country to pursue a dream. This brings me to the most important person I need to recognize. This work is dedicated to my wonderful wife Joy; my best friend and the sunshine in my sky. Kid, I love you, and I never could have done it without you. 


\section{Table of Contents}

\section{Motivation and background}

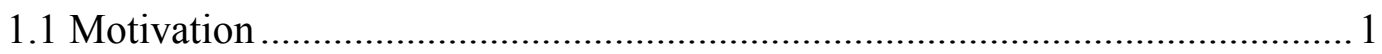

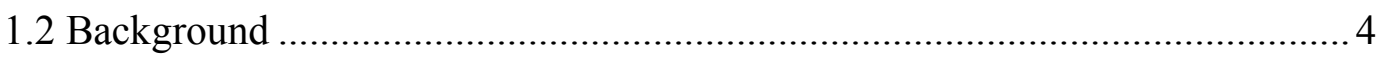

1.2.1 Ion exchange chromatography $-\mathrm{pH}$ versus salt gradients ................. 4

1.2.2 Externally generated versus induced $\mathrm{pH}$ gradients ...........................

1.2.3 Mixed-bed approach for induced $\mathrm{pH}$ gradient separations ............... 13

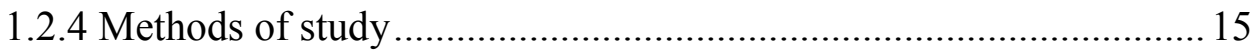

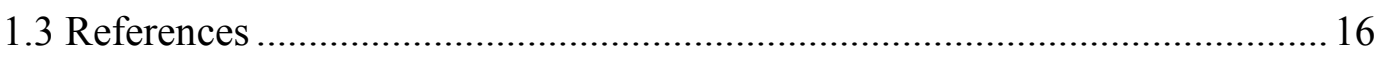

2 Generating step-induced $\mathrm{pH}$ gradients on mixed-beds of strong and weak anion exchangers

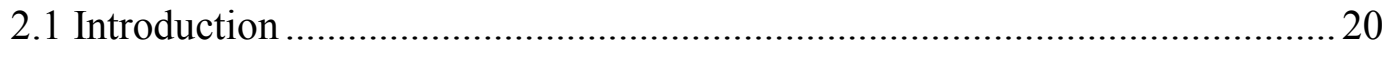

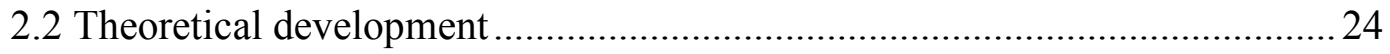

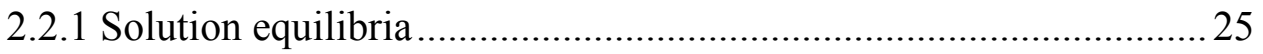

2.2.2 Ion exchange equilibria .................................................................2

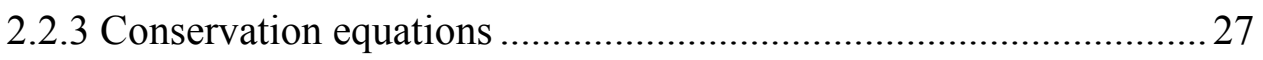

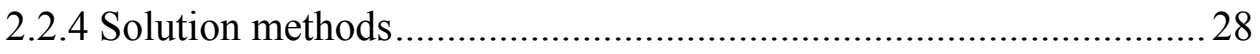

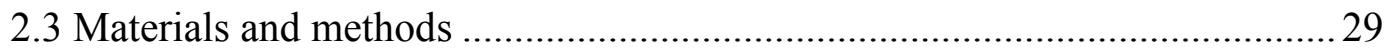

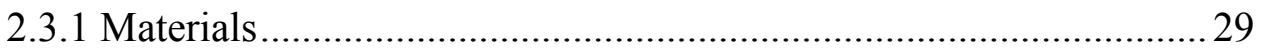

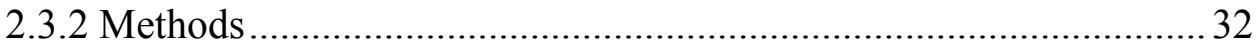

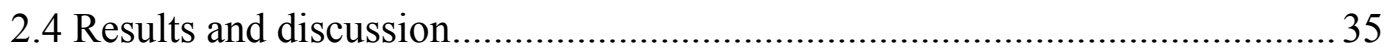

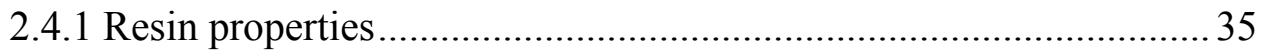

2.4.2 Mixed-bed packing characterization ................................................ 38 


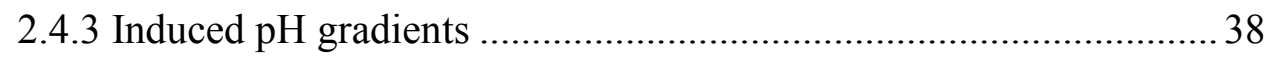

2.4.4 Separation of mAb charge variants .................................................. 49

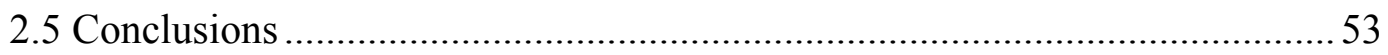

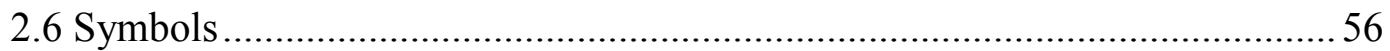

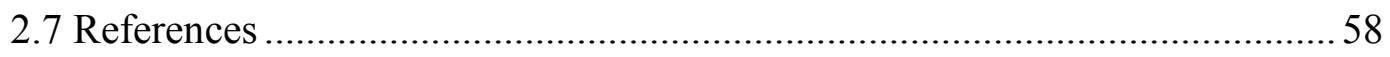

3 Predicting the resolution of mAb charge variants using mixed-beds of strong and weak anion exchange resins created with step-induced $\mathrm{pH}$ gradients at low protein loads

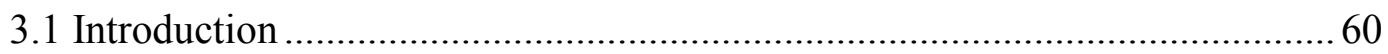

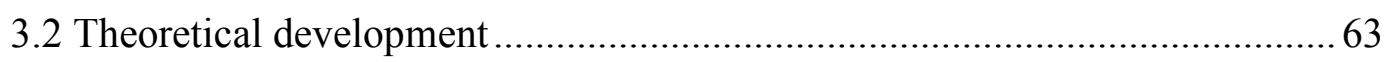

3.2.1 Prediction of induced $\mathrm{pH}$ gradients in mixed-bed columns .............. 63

3.2.2 Prediction of protein retention and band broadening in mixed-bed

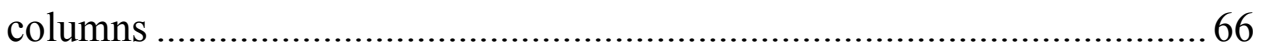

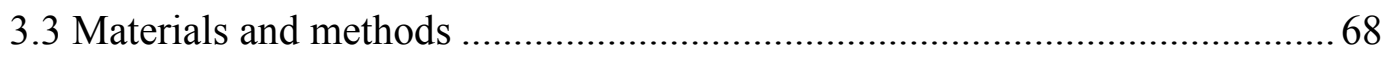

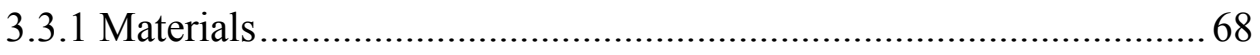

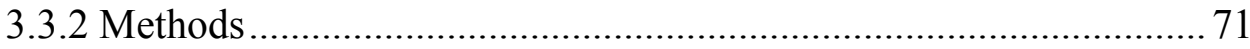

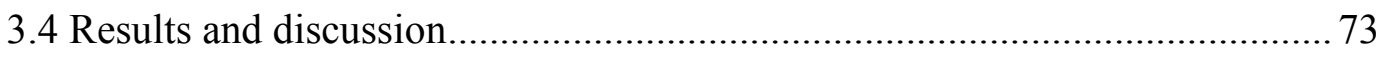

3.4.1 Protein retention as a function of $\mathrm{pH}$ and mobile phase composition .73

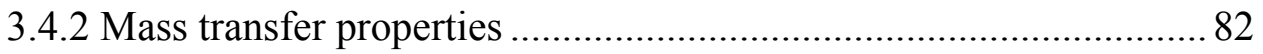

3.4.3 Separations with induced $\mathrm{pH}$ gradients ........................................... 84

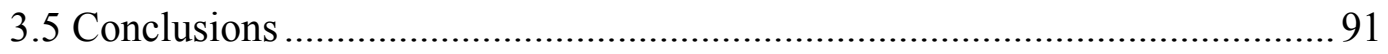

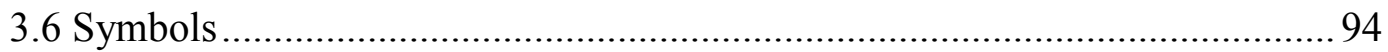


3.7 References

4 Resolution of Protein Charge Variants in Mixed-Bed Chromatography Columns with Step-Induced pH Gradients at High Protein Loads

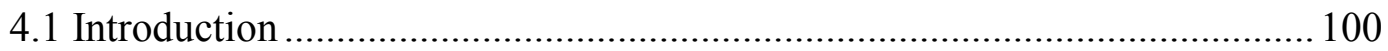

4.2 Theoretical development .............................................................. 103

4.2.1 Prediction of induced $\mathrm{pH}$ gradients ......................................... 104

4.2.2 Prediction of protein binding and elution................................. 106

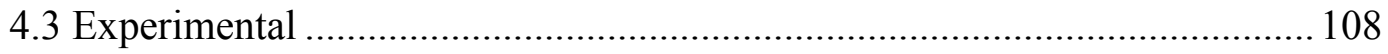

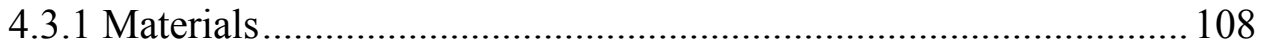

4.3.2 Methods ......................................................................... 112

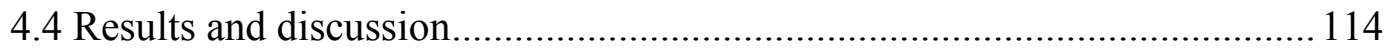

4.4.1 Adsorption isotherms ...................................................... 114

4.4.2 Mixed-bed $\mathrm{pH}$ gradient based separations ............................... 117

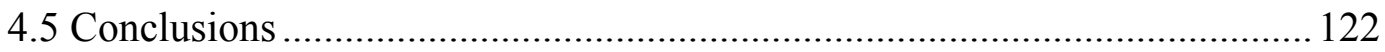

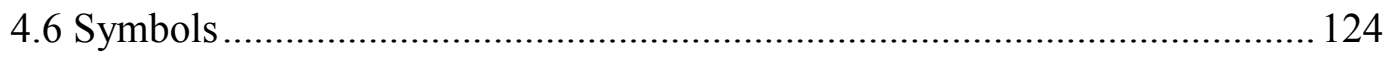

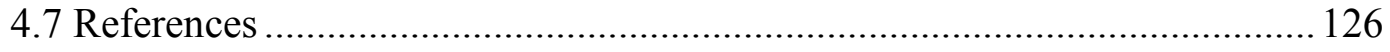

\section{Conclusions and recommendations}

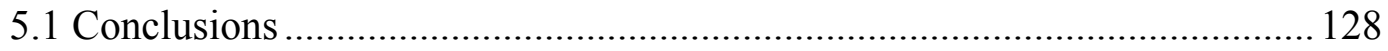

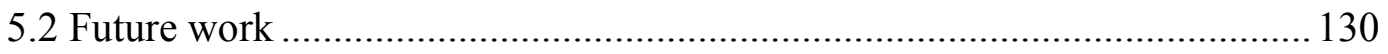

\section{Appendix 1}

Evaluation of stationary phases for mixed-bed applications............................ 132

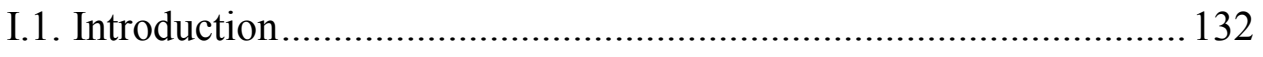

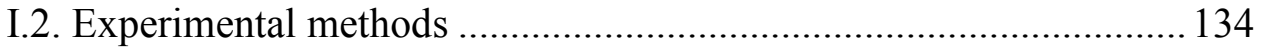




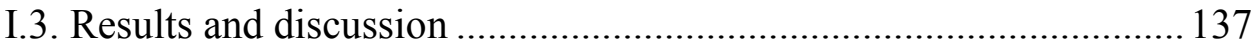

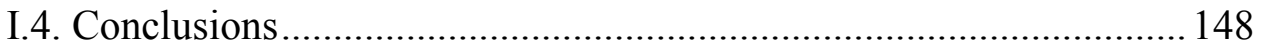

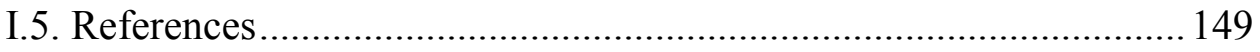

\section{Appendix 2}

Comparison of mixed-bed and layered-bed columns................................. 150

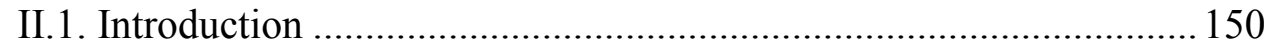

II.2. Experimental methods ....................................................... 151

II.3. Results and discussion ................................................... 153

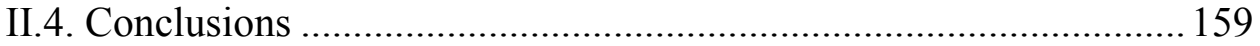

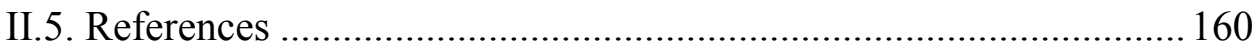




\section{List of Figures}

Figure 1.1 - Structural representation of an antibody (A) with a magnified view (B) of the antigen binding site. White regions are electrostatically neutral while the blue and red represent positively and negatively charged regions. Adapted from Ref. (21)................. 6

Figure 1.2 - Schematic comparing the retention factor of a native (N) and deamidated (D) protein based on elution with a change in salt concentration (a) or $\mathrm{pH}$ (b).

Figure 1.3 - Schematic illustrating the conceptual differences between an externally applied $\mathrm{pH}$ gradient on a strong exchanger (a) and an induced $\mathrm{pH}$ gradient created by a step change in buffer on a weak exchanger (b).

Figure 2.1 - Schematic of mixed-bed approach for protein separations by anion exchange with induced $\mathrm{pH}$ gradients. The weak and strong resin components serve the independent functions of generating a $\mathrm{pH}$ gradient in response to a step change at the column entrance and of interacting with proteins, respectively. The sketches on the left-hand side show from top to bottom the inlet $\mathrm{pH}$, the $\mathrm{pH}$ and protein concentration profiles along the column length at a particular time, and the outlet $\mathrm{pH}$, respectively. 22

Figure 2.2 - Potentiometric titration curves for the resins used in this work starting at $\mathrm{pH}$ 11 in $0.1 \mathrm{M} \mathrm{NaCl}$. The solid line is based on Eq. (12). The dashed line corresponds to titration of the blank solution without added resin.

Figure 2.3 - Microphotographs of longitudinally cut mixed-bed columns embedded in LRWhite resin showing the distribution of AG 4-X4 particles, stained dark, at different distances along the column length. Each image spans the column diameter $(4 \mathrm{~mm})$ and a vertical distance of $2 \mathrm{~mm}$ centered near the top $2-5 \mathrm{~mm}$, near the middle, and near the bottom $2-5 \mathrm{~mm}$ of each column. (a) $4 \times 36 \mathrm{~mm}$ column containing $10 \%$ AG $4-\mathrm{X} 4$ and $90 \%$ UNOsphere DQ; (b) $4 \times 20 \mathrm{~mm}$ column containing $10 \%$ AG $4-\mathrm{X} 4$ and $90 \%$ SOURCE 30Q.

Figure 2.4 - Results obtained with a mixed-bed column of AG 4-X4 and Q Sepharose FF with varying volumetric percentages of $\mathrm{AG} 4-\mathrm{X} 4$ with a $\mathrm{pH}$ step from 9 to 7 using ethanolamine buffers containing $50 \mathrm{mM}$ chloride at $300 \mathrm{~cm} / \mathrm{hr}$ for the 100 and $50 \%$ columns, and $150 \mathrm{~cm} / \mathrm{hr}$ for the $10 \%$ column. Column length $=5 \mathrm{~cm}$ for the $100 \%$ and $50 \%$ AG 4-X4 columns, and $20 \mathrm{~cm}$ for the $10 \%$ column. Symbols are experimental data and lines are model predictions. 41

Figure 2.5 - Results obtained with a mixed-bed column containing 10\% AG 4-X4 and $90 \%$ Nuvia Q with a $\mathrm{pH}$ step from 9 to 7 using ethanolamine/Tris buffer mixtures with varying composition each containing $15 \mathrm{mM}$ chloride at $150 \mathrm{~cm} / \mathrm{h}$. Column length $=20 \mathrm{~cm}$. Symbols are experimental data and lines are model predictions. 42 
Figure 2.6 - Results obtained with a mixed-bed column containing 14\% AG 4-X4 and $86 \%$ SOURCE 30 Q with a pH step from 9 to 7 using buffer mixtures containing 95\% ethanolamine and 5\% Tris with different chloride concentrations at $300 \mathrm{~cm} / \mathrm{h}$. Column length $=20 \mathrm{~cm}$. Symbols are experimental data and lines are model predictions.

Figure 2.7 - $\mathrm{pH}$ profile obtained with a mixed-bed column containing 14\% AG 4-X4 and $86 \%$ SOURCE $30 \mathrm{Q}$ with a $\mathrm{pH}$ step from 9 to 7 using buffer mixtures containing 93\% ethanolamine and $7 \%$ BisTris with $15 \mathrm{mM}$ chloride concentrations at $300 \mathrm{~cm} / \mathrm{h}$. Column length $=20 \mathrm{~cm}$. Symbols are experimental data and solid lines are model predictions based on the analytical solution $(\mathrm{N}=\infty)$ and the numerical solution for 50, 80, and 200 discretization points. Inset shows the region between 100 and $150 \mathrm{CV}$. The dashed line shows the simple wave profile calculated with eq. 16, which is unphysical as it predicts overlapping concentrations. 45

Figure 2.8 - Induced $\mathrm{pH}$ gradients for the conditions of Figure 6 predicted at 22, 24, and $26^{\circ} \mathrm{C}$ predicted by the model presented in this work accounting for the effects of temperature on the buffer $\mathrm{pKa}$ values based on the correlations in ref. (19). 48

Figure 2.9 - Separation of deamidated $\mathrm{mAb}$ mixture with a mixed bed column containing 14\%AG 4-X4 and 86\%SOURCE 30Q for the conditions of Figure 7. The protein load was $2 \mathrm{mg} / \mathrm{mL}$ packed bed volume. Fractions were collected as indicated by the vertical grey bars. Solid and dashed lines show the $\mathrm{pH}$ and UV trace at 280nm and the chloride concentration at the column outlet based on the conductivity trace. The figure at the bottom shows the IEF analysis results for the fractions along with pI values based on standard proteins. 50

Figure 3.1 - LGE chromatograms for SOURCE 30Q column at $\mathrm{pH}$ 8.0. (a) native mAb with ethanolamine- $\mathrm{HCl}$ gradients (solid lines) and with Tris- $\mathrm{HCl}$ gradients (dash-dotted lines); (b) major acidic variant with ethanolamine- $\mathrm{HCl}$ gradients; (c) native $\mathrm{mAb}$ with $\mathrm{NaCl}$ gradient in $10 \mathrm{mM}$ ethanolamine- $\mathrm{HCl}$. Normalized gradient slopes were $\gamma=3,4.5$, 6,9 , and $18 \mathrm{mM}$ chloride in all three cases with the gradient starting at $10 \mathrm{mM}$ chloride. Column volume $=0.98 \mathrm{~mL}, L=5 \mathrm{~cm}, u=150 \mathrm{~cm} / \mathrm{h}$. 74

Figure 3.2 - Log-log plot of the normalized gradient slope vs. the chloride concentration at elution for LGE experiments with a SOURCE 30Q column with gradients in ethanolamine- $\mathrm{HCl}$ at different $\mathrm{pH}$ values. Closed symbols and solid lines are for the native $\mathrm{mAb}$. Open symbols and dashed lines are for the major acidic variant. 78

Figure 3.3 - Retention factors for native $\mathrm{mAb}$ (solid lines) and major acidic variant (dashed lines) on SOURCE $30 \mathrm{Q}$ plotted as a function of chloride concentration in ethanolamine- $\mathrm{HCl}$ buffers at different $\mathrm{pH}$ values. 79

Figure 3.4 - Effective binding charge, $z$, and $A$-values as a function of $\mathrm{pH}$ for native $\mathrm{mAb}$ (solid symbols and lines) and major acidic variant (open symbols and dashed lines) on SOURCE $30 \mathrm{Q}$ in ethanolamine- $\mathrm{HCl}$ solutions. Lines are calculated as described in the text. 
Figure 3.5 - mAb isocratic elution peaks obtained for the SOURCE 30Q column at different mobile phase velocities under non-binding conditions (a) and corresponding van Deemter plot (b).

Figure 3.6 - Separation of mAb charge variants with a mixed-bed column containing 14\% AG 4-X4 using pH 9 to 7 steps with (a) 50, (b) 35, (c) 20, and (d) $15 \mathrm{mM}$ chloride concentration. Protein sample loads were $1 \mathrm{mg}$ for a and b, $11 \mathrm{mg}$ for c, and $2 \mathrm{mg}$ for $\mathrm{d}$. Thick solid lines and squares are experimental data. Thin lines are model predictions for total $\mathrm{mAb} \longrightarrow$, native $\mathrm{mAb}$-----, and major acidic variant . Column volume $=3.97$ $\mathrm{mL}, L=20.2 \mathrm{~cm}, u=300 \mathrm{~cm} / \mathrm{h}$.

Figure 3.7 - IEF analyses of fractions collected from the run in Figure $6 \mathrm{~d}$ at the CVvalues indicated for each lane. Lanes $b$ through $f$ used higher protein loads to improve visualization of the minor, lower $\mathrm{pI}$ variants..... 86

Figure 3.8 - Comparison of experimental and predicted elution $\mathrm{pH}$ as a function of buffer chloride concentration for the conditions of Figure 6. Elution $\mathrm{pH}$ for the major acidic variant could not be determined experimentally at chloride concentrations higher than 20 mM.

Figure 3.9 - Separation of mAb charge variants with a mixed-bed column containing $10 \%$ AG 4-X4 using a pH 9 to 7 step with $15 \mathrm{mM}$ chloride concentration. The protein load was $2 \mathrm{mg}$. Thick solid lines and squares are experimental data. Thin lines are model predictions for total $\mathrm{mAb}$, native $\mathrm{mAb}$, and major acidic variant. Column volume $=3.91$ $\mathrm{mL}, L=19.9 \mathrm{~cm}, u=300 \mathrm{~cm} / \mathrm{h}$.

Figure 4.1 - HPLC analysis of mAb feedstock with a ProPac WCX-10 pellicular CEX column. Three main peaks are identified as the native mAb (70\%), variants V1 $(23 \%)$, and V2 $(7 \%)$ of the total area.

Figure 4.2 - Adsorption isotherms for the crude mAb feedstock on SOURCE 30Q at $\mathrm{pH}$ 9.0 (a), 8.5 (b), 8.0 (c), and 7.5 (d) in 95/5 ethanolamine/Tris buffers containing different chloride concentrations. The total bound protein concentration shown on the y-axis, $\bar{q}$, is expressed in $\mathrm{mg}$ per $\mathrm{ml}$ of resin particle volume. Lines are based on the three-component SMA model Eq. (8) with parameters described in the text. 115

Figure 4.3 - Separation of mAb charge variants using the mixed-bed column with a 0.45 $\mathrm{mg} / \mathrm{ml}$ total protein load. Dots are experimental data and lines are model predictions. . 118

Figure 4.4 - Separation of mAb charge variants using the mixed-bed column with an 8.6 $\mathrm{mg} / \mathrm{ml}$ total protein load. Dots are experimental data and lines are model predictions. Purity values determined by HPLC are shown for fractions collected at various times along the $\mathrm{pH}$ gradient. 119 
Figure 4.5 - Separation of $\mathrm{mAb}$ charge variants using the mixed-bed column with a 15 $\mathrm{mg} / \mathrm{ml}$ total protein load. Dots are experimental data and lines are model predictions. Purity values determined by HPLC are shown for fractions collected at various times along the $\mathrm{pH}$ gradient. 120

Figure 4.6 - Separation of mAb charge variants using the mixed-bed column with a 21.5 $\mathrm{mg} / \mathrm{ml}$ total protein load. Dots are experimental data and lines are model predictions. Purity values determined by HPLC are shown for fractions collected at various times along the $\mathrm{pH}$ gradient. 121

Figure I.1 - Decision tree for evaluating resins for mixed-bed applications based on simple experiments. A "No" response excluded a material from further consideration for use in mixed-bed columns.

Figure I.2 - iSEC elution profiles for weak base exchange resins (a) A847, (b) AG 4-X4, and (c) DEAE Sepharose FF, tested with non-interacting dextran probes using $0.5 \mathrm{~cm} \mathrm{x}$ $5.0 \mathrm{~cm}$ columns and $20 \mathrm{mM}$ Tris $/ \mathrm{Cl}^{-}$buffer at $\mathrm{pH}$ 7.0. 138

Figure I.3 - iSEC elution profiles for strong base exchange resins (a) Nuvia Q, (b) SuperQ 650, (c) Q Sepharose FF, and (d) Q Sepharose HP, tested with non-interacting dextran probes using $0.5 \mathrm{~cm} \times 5.0 \mathrm{~cm}$ columns and $20 \mathrm{mM}$ Tris $/ \mathrm{Cl}^{-}$buffer at $\mathrm{pH} 7.0 \ldots 139$

Figure I.4 - iSEC elution profiles for strong base exchange resins (a) Macro-Prep High Q, (b) SOURCE 30Q, and (c) UNOsphere DQ, tested with non-interacting dextran probes using $0.5 \mathrm{~cm} \times 5.0 \mathrm{~cm}$ columns and $20 \mathrm{mM}$ Tris/ $/ \mathrm{Cl}^{-}$buffer at $\mathrm{pH} 7.0$...... 140

Figure I.5 - Potentiometric titrations for (a) weak and (b) strong anion exchange media 143

Figure I.6 - Particle size distributions determined by microphotograph analysis for (a) DEAE Sepharose FF, (b) Nuvia Q, (c) Q Sepharose FF, (d) Macro-Prep High Q, (e) SOURCE 30Q, and (f) UNOsphere DQ. 146

Figure II.1 - Image of a layered-bed column, with a $1.9 \mathrm{~cm}$ bed of AG 4-X4 packed on top of a $18.5 \mathrm{~cm}$ bed of SOURCE 30Q. The two sections are separated by a fiberglass frit to prevent resin mixing and ensure a flat transition between the two.

Figure II.2 - Comparison of the $\mathrm{pH}$ gradient elution behavior for a $\mathrm{mAb}$ in two columns with identical masses of two materials, $10 \%$ AG 4-X4 / 90\% SOURCE 30Q, with the materials mixed in one column and layered in the other. The induced $\mathrm{pH}$ gradient was created by a step change from $\mathrm{pH} 9$ to $\mathrm{pH} 7$ using a $35 \mathrm{mM}$ chloride buffer with $95 \%$ ethanolamine and $5 \%$ Tris. 
Figure II.3 - Comparison of the $\mathrm{pH}$ gradient elution behavior for a $\mathrm{mAb}$ in two columns with identical masses of two materials, 10\% AG 4-X4/90\% SOURCE 30Q, with the materials mixed in one column and layered in the other. The induced $\mathrm{pH}$ gradient was created by a step change from $\mathrm{pH} 9$ to $\mathrm{pH} 7$ using a $15 \mathrm{mM}$ chloride buffer with $95 \%$ ethanolamine and 5\% Tris.

Figure II.4 - Model predicted column $\mathrm{pH}$ profiles for a layered-bed (AG 4-X4 followed by SOURCE 30Q) and a mixed-bed using identical masses of each component resin. The $\mathrm{pH}$ waves are based on a $10 \%$ AG 4-X4 concentration in each column and occur after a pH 9 to $\mathrm{pH} 7$ step in $15 \mathrm{mM}$ chloride buffer with $95 \%$ ethanolamine and 5\% Tris. ...... 157 


\section{List of Tables}

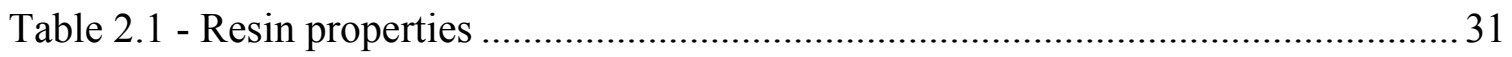

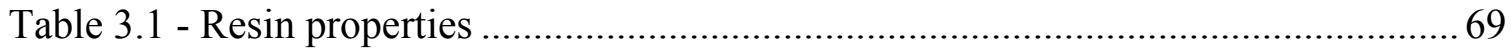

Table 4.1 - Summary of relevant resin properties .................................................. 110

Table I.1 - Dextran probes for iSEC experiments..................................................... 135

Table I.2 - Porosity and pore size as determined from iSEC studies ............................ 141

Table I.3 - Weak ligand concentrations and $\mathrm{pK}_{\mathrm{a}} \mathrm{s}$ determined by potentiometric titration 


\section{Motivation and background}

\subsection{Motivation}

Protein based pharmaceuticals like monoclonal antibodies (mAbs) are becoming a widespread method for treating both common and relatively rare ailments. As a result, over $300 \mathrm{mAbs}$ are currently in the production pipeline of biopharmaceutical companies around the world (1). The demand for increased production of these materials has led to the use of cell-lines with higher productivity, resulting in processes with ever higher titers. High product concentration and extended residence times can lead proteins to undergo post-translational modifications (PTMs) like enzymatic degradation, oxidation, or deamidation that can alter the native sequence and structure of the protein, creating variants (2-4). While in many cases a specific set of PTMs must occur to make a fully functional protein, systems with high protein expression rates often have incomplete or incorrect PTMs that create a heterogeneous mixture of protein variants that may have reduced functionality (5). One PTM of particular concern is deamidation, in which the amine group of a polar, uncharged amino acid residue (asparagine or glutamine) is converted to an acidic amino acid (aspartic acid or glutamic acid). Deamidation not only increases the negative charge on the protein, which could alter the function of the protein, but also may introduce D-type amino acids (isoaspartic acid) that are not normally present in human metabolism (6). Therefore, the removal of these variants may be required to produce a safe and effective product.

While current product development has attempted to minimize the impact of deamidation, either by eliminating susceptible molecules from consideration, or by 
optimizing purification trains, deamidation is still a significant complication for the production of pharmaceutical proteins. Extensive research has been conducted to establish methods for completing these difficult separations. While a significant fraction of research has been directed at analytical methods for the separation/identification of protein charge variants, using isoelectric focusing (IEF) (7), 2D electrophoresis (8), or chromatographic methods $(9,10)$, others have been working on methods for large-scale purification. Ebersold and Zydney, for example, showed that ultrafiltration was capable of separating a protein and variant with a single charge difference $(11,12)$, but in general research has focused on methods of operating chromatography columns to achieve the separation.

The application of salt gradients in ion exchange chromatography (IEC) can in some cases provide resolution of charge variants $(13,14)$, but requires long, shallow gradients that can be difficult to generate consistently, and create large pools of dilute protein which must be concentrated. Economical production of pharmaceutical proteins at the industrial scale relies on reproducible chromatography steps with suitably short load/elute cycles and high protein concentrations that minimize process volumes, making salt gradients poorly suited for the removal of charge variants on an industrial scale.

As an alternative, IEC using $\mathrm{pH}$ gradients has shown promise for the effective resolution of protein charge variants (15). $\mathrm{pH}$ gradients have the benefits of operating at low ionic strength and separating the native protein and variants near their pIs. Historically, the use of $\mathrm{pH}$ gradients has been limited by: (a) the complexity of mixing buffers to generate linear gradients (16), (b) the reproducibility of the $\mathrm{pH}$ gradients, and (c) the high costs associated with using proprietary ampholyte stationary and mobile 
phases. Induced $\mathrm{pH}$ gradients, generated by the protonation/deprotonation of weak base (or acid) IEC media, overcome many of the historical limitations of more classical $\mathrm{pH}$ gradient-based processes (17). Unlike the externally generated gradients, which require complex buffers and control systems, induced gradients use simple buffers and a step change in the mobile phase $\mathrm{pH}$ to generate smooth reproducible gradients through interactions with the stationary phase. Additionally, because induced $\mathrm{pH}$ gradients are an equilibrium response to a change in mobile phase composition, the axially generated $\mathrm{pH}$ gradient is steep and moves slower than the mobile phase velocity. This allows eluting proteins to focus at specific $\mathrm{pH}$ values along the wave, improving resolution.

Induced $\mathrm{pH}$ gradients also have several disadvantages that have precluded their use in large scale production. Both protein binding and $\mathrm{pH}$ gradient generation utilize the same weak exchange ligands, leading to variations in the $\mathrm{pH}$ gradients at high protein loads. Moreover, when the exchange ligands become deprotonated, they introduce hydrophobic interactions that are not readily quantified. Finally, protein retention is difficult to predict as both the protein and stationary phase have charges that change with $\mathrm{pH}$.

To overcome these limitations while maintaining the improved resolution of induced $\mathrm{pH}$ gradients, a novel mixed-bed approach has been developed and investigated in this work. The new approach combines a small-pore weak base exchanger with a large-pore strong base exchanger (18). The small pores of the weak base exchanger will prevent protein interactions, while providing ionizable ligands to generate an induced $\mathrm{pH}$ gradient. The large pores of the strong base exchanger will provide good mass transfer for proteins, but the strong base ligands are unaffected by $\mathrm{pH}$. The result is the effective 
partitioning of the two processes, binding/eluting protein and generating induced $\mathrm{pH}$ gradients, into two separate materials which can then be modeled and optimized individually.

The goal of this research is to investigate and develop a novel mixed-bed approach that enables the use of induced $\mathrm{pH}$ gradients as a means of predictable separation of protein charge variants. This work has been divided into three major sections: Chapter 2 describes the methods for characterization of the individual weak and strong ion exchangers, determines the packing quality achieved for mixed-bed columns, and develops a model for the prediction of induced $\mathrm{pH}$ gradients on mixed-bed columns using single and mixed buffers. Chapter 3 describes the methods for determining model parameters from simple experiments and the development of a model to predict protein retention in the linear limit of the protein isotherm. Finally Chapter 4 describes the methods for determining multicomponent model parameters and the extension of the previously developed model to the overloaded conditions expected at industrial scale.

\subsection{Background}

\subsubsection{Ion exchange chromatography $-\mathrm{pH}$ versus salt gradients}

Proteins bound to ion exchange media are frequently eluted by increasing the salt concentration at constant $\mathrm{pH}$. In this type of separation, the proteins are released from the resin by increasing the shielding of electrostatic interactions, which eventually overpowers the attraction between the stationary phase and the protein. Even relatively close to the pI, many proteins interact strongly with charged surfaces due to a heterogeneous distribution of charge over the protein surface (19). As a result, protein 
binding strength is a strong function of salt concentration and is similar for variants that differ by only one or two charged residues. Changes in $\mathrm{pH}$ can also be used to separate proteins on the same stationary phase by a different mechanism. For example, proteins at pHs above their pIs are negatively charged and can be bound to an anion exchange (AEX) resin. If the $\mathrm{pH}$ is then decreased, the net negative charge of the protein decreases, weakening the interaction and eventually causing elution. In general, elution is expected to be near the $\mathrm{pI}$ of each protein, but can differ due to the fact that binding usually occurs at specific regions of high charge density on the protein surface that vary between individual proteins (20). Figure 1.1, for example, shows the heterogeneous distribution of charged residues on an antibody. It is obviously possible for this protein to bind either to an anion exchanger or cation exchanger even if the net charge is zero. 
$\mathbf{A}$
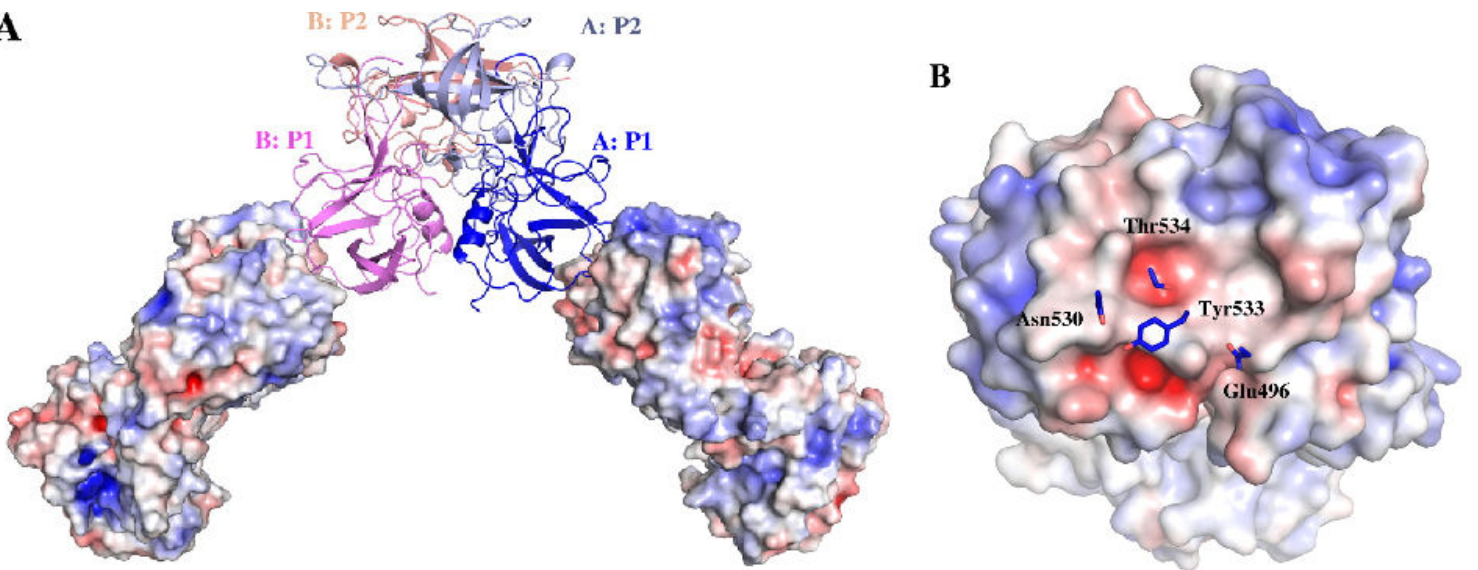

Figure 1.1 - Structural representation of an antibody (A) with a magnified view (B) of the antigen binding site. White regions are electrostatically neutral while the blue and red represent positively and negatively charged regions. Adapted from Ref. (21). 
For both salt and $\mathrm{pH}$, shallower gradients generally result in greater resolution. However, an argument can be made that $\mathrm{pH}$ gradients are intrinsically capable of greater resolution than salt gradients for the separation of charge variants. Consider, for instance, the hypothetical retention plots shown in Figure 1.2 for native $(\mathrm{N})$ and deamidated (D) isoforms of a protein on an anion exchange column versus salt at constant $\mathrm{pH}(1.2 \mathrm{a})$ and versus $\mathrm{pH}$ at constant salt (1.2b).

As shown in Figure 1.2a, for both the native and deamidated variant, the retention factor, k', which indicates the strength of protein binding, decreases rapidly with salt concentration. However, the variant curve is steeper because of a higher negative charge on the deamidated isoform. As a result, the selectivity is lower at the higher salt concentration needed to elute the proteins, which occurs at low $\mathrm{k}^{\prime}$. On the other hand, as shown in Figure 1.2b, for both native and variant form, $\mathrm{k}^{`}$ decreases as the $\mathrm{pH}$ is reduced because the charge associated with negative residues in the protein becomes increasingly balanced by protonation of basic residues (e.g. histidines), which acquire a positive charge. Since the deamidated isoform has more negatively charged residues, the $\mathrm{k}^{\prime}$ versus $\mathrm{pH}$ curve is shallower than for the native species. As a result, the selectivity increases under elution conditions (i.e. at lower $\mathrm{pH}$ ) giving, in principle, improved resolution. 

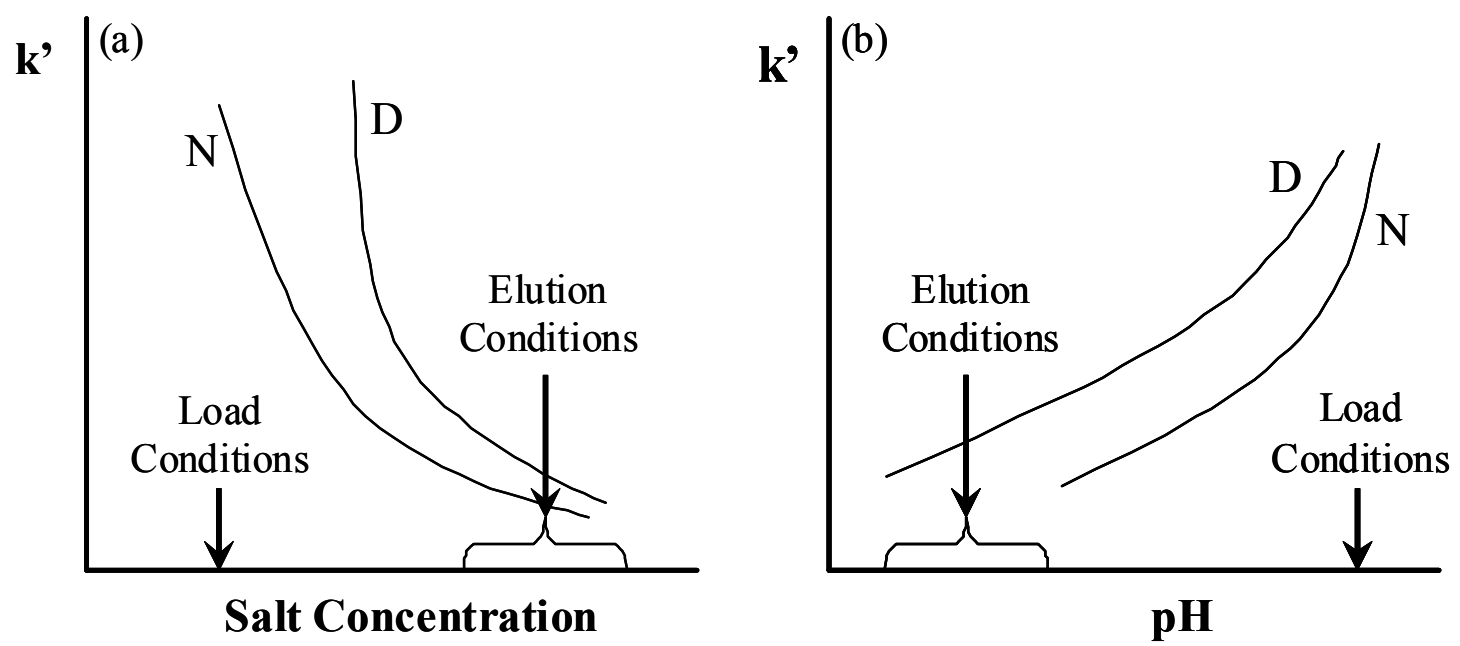

Figure 1.2 - Schematic comparing the retention factor of a native $(\mathrm{N})$ and deamidated (D) protein based on elution with a change in salt concentration (a) or $\mathrm{pH}(\mathrm{b})$. 


\subsubsection{Externally generated versus induced $\mathrm{pH}$ gradients}

Externally generated $\mathrm{pH}$ gradients are conceptually the simplest method of using $\mathrm{pH}$ gradients for protein separation, requiring the mixing of two buffers, with differing $\mathrm{pH}$, in the appropriate ratios to get a $\mathrm{pH}$ gradient at the column entrance. This method of $\mathrm{pH}$ gradient generation depends on a stationary phase with strong ion exchange groups that have no charge dependence on $\mathrm{pH}$. While theoretically simple, a number of problems arise with the application of this method that makes it a less practical separation tool for industrial applications. For example, to prevent interaction with the exchange resin, externally generated gradients are created with unretained buffering species that travel at the mobile phase velocity. For these conditions, any given point in the $\mathrm{pH}$ gradient will have a residence time of about $1 \mathrm{CV}$. As a result, the axial $\mathrm{pH}$ gradient will be shallow and travel faster than the large proteins released from the resin (Figure 1.3a). Because of this difference in rates, attempts to make steep external gradients will result in loss of resolution, while shallower gradients will lead to broad peaks that greatly dilute the eluting protein products.

Buffers used to create external gradients usually consist of a mixture of different buffer species to provide a buffering capacity through the range of the gradient (16). A number of researchers have looked at combinations of simple buffers to accomplish this goal, including Schroeder and Robberson (22) who used multiple buffers to separate peptides, Duhamel et al. (23) who used $\mathrm{pH}$ gradients to separate different classes of antibodies on protein A columns, and Farnan and Moreno (24) and Rea et al. (25) who used $\mathrm{pH}$ gradients to separate mAb charge variants. Despite being able to create relatively linear gradients, externally generated gradients do not focus the eluting proteins. 

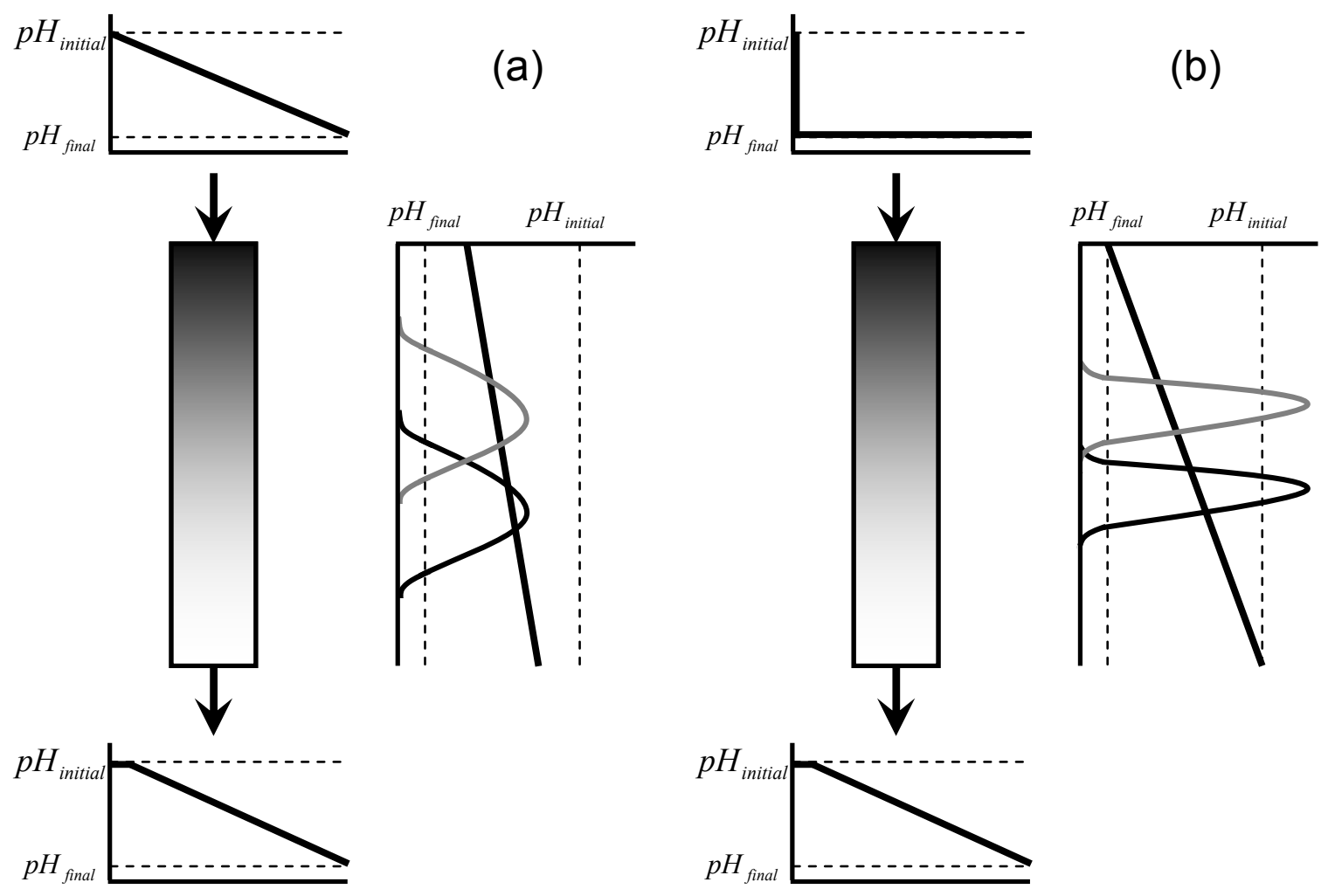

Figure 1.3 - Schematic illustrating the conceptual differences between an externally applied $\mathrm{pH}$ gradient on a strong exchanger (a) and an induced $\mathrm{pH}$ gradient created by a step change in buffer on a weak exchanger (b). 
Moreover, the increased complexity of the buffers can lead to reproducibility issues. Alternatively, a number of proprietary amphoteric buffers may be used for this purpose, but they tend to be expensive and the unknown compositions make modeling the system difficult.

The second method for generating $\mathrm{pH}$ gradients, an induced gradient, is created by making a step change in the mobile phase composition at the column entrance and taking advantage of interactions between the column packing and the mobile phase components to generate a $\mathrm{pH}$ gradient within the column. Resins containing either weakly acidic or weakly basic exchange ligands can be used for this purpose, because, unlike strong acid or base groups, the ionizable weak ligands can interact with $\mathrm{H}^{+}$and $\mathrm{OH}^{-}$ions (26). A weak exchanger at a given $\mathrm{pH}$ will have an amount of $\mathrm{H}^{+}$or $\mathrm{OH}^{-}$bound that is in equilibrium with the $\mathrm{pH}$ of the mobile phase. A change in the $\mathrm{pH}$, whether as a step or gradient, requires the exchange of counterions with the ionizable exchange groups to achieve equilibrium. The result is a slow moving $\mathrm{pH}$ wave with a large difference between the $\mathrm{pH}$ at the inlet and outlet of the column (Figure 1.3b).

Movement of the ensuing $\mathrm{pH}$ wave through the column occurs at a relatively slow rate, resulting in an axial $\mathrm{pH}$ gradients over the column length that are much sharper than those obtained with externally generated gradients. This makes induced $\mathrm{pH}$ gradients well suited for the separation of protein species near their $\mathrm{pI}$, because the $\mathrm{pH}$ wave moves slower than the mobile phase velocity and proteins have a chance to become focused along the $\mathrm{pH}$ wave at a value where their chromatographic velocity is the same as the velocity of the $\mathrm{pH}$ wave. Focusing in this manner can provide improved resolution for 
challenging separations, like $\mathrm{mAb}$ charge variants, without resorting to very small chromatographic particles that cannot be used for large scale operations.

The concept of focusing individual proteins along a traveling $\mathrm{pH}$ wave has been known for some time. Sluyterman and Elgersma (27) and Sluyterman and Wijdenes (28) introduced the term "chromatofocusing" to describe protein chromatographic separations with a traveling $\mathrm{pH}$ wave generated either with buffering species that bind to a strong exchanger or with unretained buffering species and weak acids or weak base resins. More recently, Frey and co-workers developed a model based on local equilibrium describing $\mathrm{pH}$ gradients generated with analytical size, weak anion exchangers (29-31). $\mathrm{Ng}$, et al. investigated induced gradients created using weak cation exchangers (32), while Pabst et al. first studied $\mathrm{pH}$ excursions created by these materials with salt changes (33), and then developed a model to describe induced $\mathrm{pH}$ gradients with weak cation exchangers using single and multicomponent unretained buffers (34). These authors also demonstrated the application of these gradients to the separation of acidic proteins, including a strong focusing effect. In addition, Pabst et al. (35) extended this work to weak anion exchangers, using buffer mixtures to obtain relatively linear profiles that were able to complete two difficult separations - the separation of sialylated variants of bovine transferrin and the separation of mAb charge variants with less than $0.1 \mathrm{pH}$ units difference in pIs.

A significant limitation with the previous research is that most experiments were conducted using relatively low protein loads that would be impractical for large scale production. This is due in part to the system constraint that the ion exchange sites responsible for creating the $\mathrm{pH}$ gradient are also the point of binding for the adsorbed 
protein. This means that the binding capacity of the resin changes with $\mathrm{pH}$ and the resulting competition for sites makes it difficult to load large amounts of protein without altering the induced $\mathrm{pH}$ gradient. This limits both the capacity and reproducibility of this separation technique and also makes predictive modeling of the process exceedingly difficult as both the protein and the resin have a charge that depends on $\mathrm{pH}$.

\subsubsection{Mixed-bed approach for induced $\mathrm{pH}$ gradient separations}

As discussed in the previous section, induced $\mathrm{pH}$ gradients have inherent limitations that make them difficult to implement as a separation method for large-scale protein purification. This is due in large part to the unpredictable nature of using a single type of exchange ligand to both bind the protein and generate the induced $\mathrm{pH}$ gradient. During the loading step, protein occupies sites that would have been involved in generating the $\mathrm{pH}$ gradient. Then, a step change in inlet buffer $\mathrm{pH}$ initiates an induced $\mathrm{pH}$ gradient. As the protein begins to elute the newly empty sites absorb ions to return to equilibrium with the buffer, causing deviations in both the counterion and $\mathrm{pH}$ profiles. A novel method for overcoming this limitation is to employ a mixed-bed approach utilizing two materials that are each specifically selected to perform only one of the two column functions. The hypothesis is that by combining a weak ion exchanger with small pores and a strong ion exchanger with large pores in a single mixed-bed, it is possible to decouple the binding of protein and $\mathrm{pH}$ gradient generation. The small-pore weak exchanger will readily interact with the small counterions, but will exclude the much larger proteins, while conversely, the large-pore strong exchanger will have no $\mathrm{pH}$ dependent interaction with the counterions, but will have large pores that are well-suited 
to protein mass transport. In this way, the strong resin can be loaded with protein, but an induced $\mathrm{pH}$ gradient generated within the weak resin will be unaffected.

It is hypothesized that separating the functional groups responsible for protein binding from those that are responsible for $\mathrm{pH}$ gradient generation into two phases not only will improve loadability, but also will allow for greater design flexibility and easier predictive modeling. Because the two functions are independent, any combination of weak and strong materials can be utilized in the ratio that best balances the needs for gradient generation and protein binding. As a result, stationary phases can be evaluated independently to determine the best protein/resin and $\mathrm{pH}$ gradient/resin combinations for the target separation. Additionally, by separating the functions into two non-interacting phases, simple models can be used to describe each component individually.

The general concept of mixed-beds itself is not novel, with a number of previous studies having looked at mixed-bed chromatography columns as a means to improve separations (36). El Rassi and Horvath used mixed-beds of strong cation and anion exchangers in HPLC columns to improve protein separations (37). Investigations in this area also include using mixed-beds of cation and anion exchange media to separate inorganic metal ions by Pietrzyk et al and Bruzzoniti et al. $(38,39)$. Motoyama utilized mixed-beds of cation and anion exchangers to separate peptides (40), while Maa et al. and Hou et al both investigated mixed-beds of weak ion exchangers to purify proteins $(41,42)$. However, these works have generally focused on isocratic or salt gradient elution. No literature was found pertaining to the use of mixed-beds containing strong and weak ion exchange groups as a means of improving separation of proteins by generating induced $\mathrm{pH}$ gradients. 


\subsubsection{Methods of study}

Chromatographic separations and predictive modeling require information on the specific properties of both the stationary phases and the proteins to be purified. In principle, because of the mixed-bed design, both protein and counterion interactions need to be characterized for both the weak and strong resin components.

The experimental techniques used in this work include:

- Potentiometric titrations to determine the buffering capacity of the resins

- Inverse size exclusion chromatography (iSEC) to determine the resin pore size and accessibility

- Optical microscopy to determine the distribution of resin components in the mixed-bed system

- Residence time distribution (RTD) studies to determine the packing quality and mass transfer characteristics for both the weak and strong resin components

- Isoelectric focusing (IEF) to determine the isoelectric point of target proteins and the purity of product fractions

- Salt gradient ion exchange chromatography to determine protein-resin interactions.

- Batch protein/resin isotherms to describe protein binding as a function of $\mathrm{pH}$ and conductivity.

The proteins investigated in this work were predominantly (a) a partially purified mAb containing a relatively low level of charge variants and (b) a sample of the same $\mathrm{mAb}$ for which the content of charge variants was increased by forced deamidation under alkaline conditions. Future work could benefit from the study of additional proteins. 


\subsection{References}

1. Reichert, J. M. (2013) Which are the antibodies to watch in 2013? MAbs, 5: 1-4.

2. Harris, R. J. et al. (2001) Identification of multiple sources of charge heterogeneity in a recombinant antibody. J. Chromatogr. B. Biomed. Sci. Appl., 752: 233-45.

3. Volkin, D. B.; Mach, H. \& Middaugh, C. R. (1997) Degradative covalent reactions important to protein stability. Mol. Biotechnol., 8: 105-22.

4. Geiger, T. \& Clarke, S. (1987) Deamidation, isomerization, and racemization at asparaginyl and aspartyl residues in peptides. J. Biol. Chem., 262: 785-794.

5. Hsu, Y. R. et al. (1998) Selective deamidation of recombinant human stem cell factor during in vitro aging: isolation and characterization of the aspartyl and isoaspartyl homodimers and heterodimers. Biochemistry, 37: 2251-2262.

6. Mamula, M.; Gee, R. \& Elliott, J. (1999) Isoaspartyl post-translational modification triggers autoimmune responses to self-proteins. J. Biol., 274: 2232122327

7. Drysdale, J.; Righetti, P. \& Bunn, H. (1971) The separation of human and animal hemoglobins by isoelectric focusing in polyacrylamide gel. Biochim. Biophys. Acta., 229: 42-50.

8. Görg, A. \& Wildgruber, R. (2000) Review The current state of two-dimensional electrophoresis with immobilized pH gradients. Electrophoresis, 21: 1037-1053.

9. Kaltenbrunner, O. \& Tauer, C. (1993) Isoprotein analysis by ion-exchange chromatography using a linear $\mathrm{pH}$ gradient combined with a salt gradient. $J$. Chromatogr. A, 639: 41-49.

10. Andersen, T.; Pepaj, M.; Trones, R.; Lundanes, E. \& Greibrokk, T. (2004) Isoelectric point separation of proteins by capillary $\mathrm{pH}$-gradient ion-exchange chromatography. J. Chromatogr. A, 1025: 217-226.

11. Ebersold, M. F. \& Zydney, A. L. (2004) Separation of protein charge variants by ultrafiltration. Biotechnol. Prog., 20: 543-549.

12. Ebersold, M. F. \& Zydney, A. L. (2004) The effect of membrane properties on the separation of protein charge variants using ultrafiltration. J. Memb. Sci., 243: 379388. 
13. Chicz, R. M. \& Regnier, F. E. (1989) Single Amino Acid Contributions to Protein Retention in Cation-Exchange Chromatography: Resolution. Anal. Chem., 61: 2059-2066.

14. Weitzhandler, M.; Farnan, D.; Rohrer, J. \& Avdalovic, N. (2001) Protein variant separations using cation exchange chromatography on grafted, polymeric stationary phases. Proteomics, 1: 179-185.

15. Mhatre, R. et al. (1995) Purification of antibody Fab fragments by cation-exchange chromatography and $\mathrm{pH}$ gradient elution. J. Chromatogr. A, 707: 225-231.

16. Celentano, F. C.; Tonani, C.; Fazio, M.; Gianazza, E. \& Righetti, P. G. (1988) pH gradients generated by polyprotic buffers. I. Theory and computer simulation. $J$. Biochem. Biophys. Methods, 16: 109-28.

17. Pabst, T. M. \& Carta, G. (2007) $\mathrm{pH}$ transitions in cation exchange chromatographic columns containing weak acid groups. J. Chromatogr. A, 1142: 19-31.

18. Vetter, T. A.; Ferreira, G.; Robbins, D. \& Carta, G. (2014) Mixed-Beds of Strong and Weak Anion Exchange Resins for Protein Separations with Step-Induced $\mathrm{pH}$ Gradients. Sep. Sci. Technol., 49: 477-489.

19. Kopaciewicz, W. \& Rounds, M. (1983) Retention model for high-performance ion-exchange chromatography. J. Chromatogr., 266: 3-21.

20. Yamamoto, S. \& Ishihara, T. (1999) Ion-exchange chromatography of proteins near the isoelectric points. J. Chromatogr. A, 852: 31-6.

21. Hansman, G. S. et al. (2012) Structural basis for broad detection of genogroup II noroviruses by a monoclonal antibody that binds to a site occluded in the viral particle. J. Virol., 86: 3635-3646.

22. Schroeder, W. \& Robberson, B. (1965) An Improved Gradient for Ion Exchange Chromatography of Peptides on Dowex-1. Anal. Chem., 37: 1583-1585.

23. Duhamel, R.; Schur, P.; Brendel, K. \& Meezan, E. (1979) pH gradient elution of human IgG1, IgG2 and IgG4 from protein A-sepharose. J. Immuno., 31: 211-217.

24. Farnan, D. \& Moreno, G. T. (2009) Multiproduct high-resolution monoclonal antibody charge variant separations by $\mathrm{pH}$ gradient ion-exchange chromatography. Anal. Chem., 81: 8846-8857. 
25. Rea, J. C.; Moreno, G. T.; Lou, Y. \& Farnan, D. (2011) Journal of Pharmaceutical and Biomedical Analysis Validation of a $\mathrm{pH}$ gradient-based ion-exchange chromatography method for high-resolution monoclonal antibody charge variant separations. J. Pharm. Biomed. Anal., 54: 317-323.

26. Helfferich, F. (1962) Ion Exchange. McGraw-Hill Book Company, Inc. New York, United States

27. Sluyterman, L. \& Elgersma, O. (1978) Chromatofocusing: Isoelectric Focusing on Ion-Exchange Columns I. General Principles. Chromatography, 150: 17-30.

28. Sluyterman, L. \& Wijdenes, J. (1978) Chromatofocusing: Isoelectric Focusing on Ion-Exchange Columns II. Experimental Verfication. Chromatography, 150: 3144.

29. Bates, R. C. \& Frey, D. D. (1998) Quasi-linear pH gradients for chromatofocusing using simple buffer mixtures: local equilibrium theory and experimental verification. J. Chromatogr. A, 814: 43-54.

30. Bates, R.; Kang, X. \& Frey, D. (2000) High-performance chromatofocusing using linear and concave $\mathrm{pH}$ gradients formed with simple buffer mixtures I. Effect of buffer composition on the gradient shape. J. Chromatogr. A, 890: 25-36.

31. Kang, X.; Bates, R. \& Frey, D. (2000) High-performance chromatofocusing using linear and concave $\mathrm{pH}$ gradients formed with simple buffer mixtures II. Separation of proteins. J. Chromatogr. A, 890: 37-43.

32. Ng, P. K.; He, J. \& Snyder, M. A. (2009) Separation of protein mixtures using pHgradient cation-exchange chromatography. J. Chromatogr. A, 1216: 1372-1376.

33. Pabst, T. M. \& Carta, G. (2007) $\mathrm{pH}$ transitions in cation exchange chromatographic columns containing weak acid groups. J. Chromatogr. A, 1142: 19-31.

34. Pabst, T. M.; Antos, D.; Carta, G.; Ramasubramanyan, N. \& Hunter, A. K. (2008) Protein separations with induced $\mathrm{pH}$ gradients using cation-exchange chromatographic columns containing weak acid groups. J. Chromatogr. A, 1181: 83-94.

35. Pabst, T. M. et al. (2008) Separation of Protein Charge Variants with Induced pH Gradients Using Anion Exchange Chromatographic Columns. Biotechnol. Prog., 24: 1096-1106.

36. Boschetti, E. \& Righetti, P. G. (2011) Mixed-bed chromatography as a way to resolve peculiar protein fractionation situations. J. Chromatogr. B, 879: 827-835. 
37. El Rassi, Z. \& Horváth, C. (1986) Tandem Columns and Mixed-Bed Columns in High-Performance Liquid Chromatography of Proteins. J. Chromatogr., 359: 255264.

38. Pietrzyk, D. J. \& Brown, D. M. (1986) Simultaneous separation of inorganic anions and cations on a mixed bed ion exchange column. Anal. Chem., 58: 25542557.

39. Bruzzoniti, M. C.; Cardellicchio, N.; Cavalli, S. \& Sarzanini, C. (2002) A study of the mechanisms involved in the separation of metal ions with a mixed-bed stationary phase. Chromatographia, 55: 231-234.

40. Motoyama, A.; Xu, T.; Ruse, C. I.; Wohlschlegel, J. A. \& Yates, J. R. (2007) Anion and cation mixed-bed ion exchange for enhanced multidimensional separations of peptides and phosphopeptides. Anal. Chem., 79: 3623-3634.

41. Maa, Y. F.; Antia, F. D.; el Rassi, Z. \& Horváth, C. (1988) Mixed-bed ionexchange columns for protein high-performance liquid chromatography. $J$. Chromatogr., 452: 331-45.

42. Hou, C. et al. (2010) Weak anion and cation exchange mixed-bed microcolumn for protein separation. J. Sep. Sci., 33: 3299-3303. 


\section{Generating step-induced $\mathrm{pH}$ gradients on mixed-beds of strong and weak anion exchangers}

\subsection{Introduction}

$\mathrm{pH}$ gradient based ion exchange chromatography has been shown effective for the separation of protein charge variants such as those arising from post translational modifications $(1,2,3)$. In addition to providing selectivities different from those attainable with salt gradients, $\mathrm{pH}$ gradients allow separation at low ionic strengths, which may simplify further downstream processing.

There are two fundamentally different ways of implementing such $\mathrm{pH}$ gradients. The first relies on an externally generated gradient obtained by mixing two mobile phases in a time-varying ratio at the column entrance. The second uses a gradient generated within the column as a result of interactions between mobile phase components and the stationary phase in response to a step change at the column entrance. Although induced $\mathrm{pH}$ gradients of this second type can be obtained either with a strong ion exchanger and a suitable mixture of retained buffering species or with a weak ion exchanger and nonretained buffering species, the latter is considered simpler and more easily predictable. In addition to the operational advantage of a simple step change compared to the timevarying mixing required with externally generated gradients, induced $\mathrm{pH}$ gradients result in a $\mathrm{pH}$ wave that propagates through the column at a rate slower than the mobile phase velocity. In this case, individual species can be focused along the traveling $\mathrm{pH}$ wave concentrating them at $\mathrm{pH}$ values where the $\mathrm{pH}$ wave velocity and the species chromatographic velocities are equal. 
Separations based on such "chromatofocusing" techniques were initially described by Sluyterman and Elgersma (4) and Sluyterman and Wijdenes (5). Practical aspects are discussed by Liu and Anderson (6). Frey and co-workers $(7,8,9)$ developed models to describe $\mathrm{pH}$ transitions in chromatography columns and described several protein separations using anion exchange resins, but primarily using stationary phases with small particles designed for analytical chromatography. Induced $\mathrm{pH}$ gradients have been shown by Pabst et al. $(10,11)$ to be effective at resolving charge variants for glycosylated proteins and for monoclonal antibodies, with both weak cation and weak anion exchange columns using low-pressure stationary phases.

Induced $\mathrm{pH}$ gradients generated with weak ion exchange columns also have some potential disadvantages, however, that can arise from the fact that the ligands responsible for generating $\mathrm{pH}$ gradients within the column are normally also responsible for the interactions that lead to protein separation. Firstly, it is difficult to predict protein retention since the stationary phase charge changes along with $\mathrm{pH}$. Secondly, protein binding itself can affect the $\mathrm{pH}$ gradient, leading to distortions of the induced $\mathrm{pH}$ profile that become more significant as the protein load increases. Thirdly, the resin can become uncharged at extreme $\mathrm{pH}$ values along the $\mathrm{pH}$ gradient introducing the possibility of undesirable nonspecific hydrophobic interactions between protein molecules and the resin surface. 


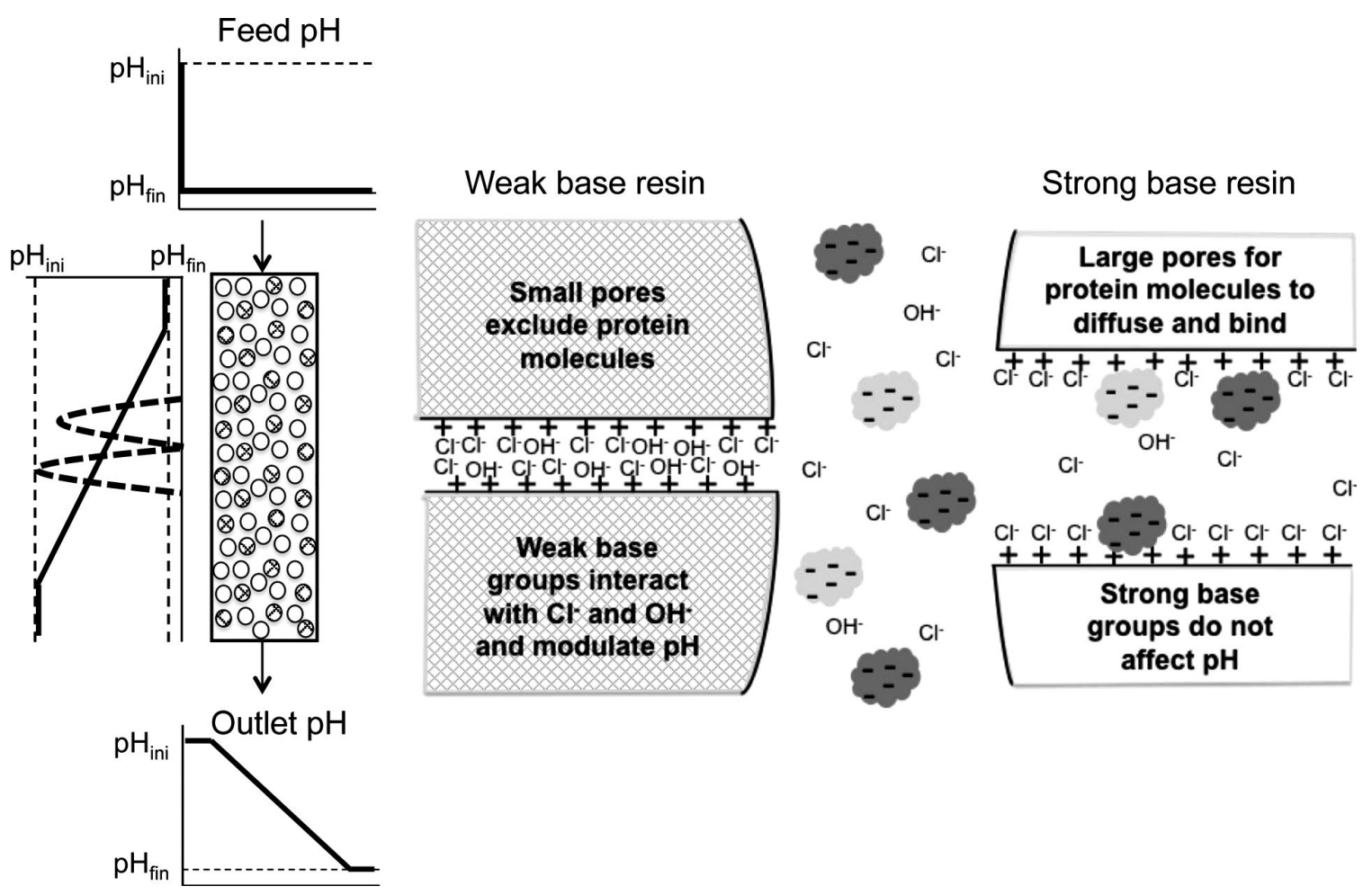

Figure 2.1 - Schematic of mixed-bed approach for protein separations by anion exchange with induced $\mathrm{pH}$ gradients. The weak and strong resin components serve the independent functions of generating a $\mathrm{pH}$ gradient in response to a step change at the column entrance and of interacting with proteins, respectively. The sketches on the left-hand side show from top to bottom the inlet $\mathrm{pH}$, the $\mathrm{pH}$ and protein concentration profiles along the column length at a particular time, and the outlet $\mathrm{pH}$, respectively. 
In order to overcome these limitations, in this work we examine the behavior of mixed-bed columns that utilize two different resins, each specially selected to perform independently one of the two functions required - ionic interactions with mobile phase components leading to the generation of $\mathrm{pH}$ gradients and interactions with protein species leading to their separation. The mixed-bed concept is shown schematically in Figure 2.1 with reference to the case of anion exchange with non-adsorbed buffering species. In this case, the column comprises a weak anion exchanger with pores small enough to completely exclude protein molecules and a strong anion exchanger with pores sufficiently large to allow protein diffusion and interaction with charged ligands on the resin. As in the case of a column containing a single weak anion exchanger, the $\mathrm{pH}$ gradient is induced by a step change at the column entrance, which generates both an axial $\mathrm{pH}$ gradient along the column and a temporal gradient at the column outlet. In this case, however, the small-pore weak anion exchanger alone modulates the $\mathrm{pH}$, while the strong base resin alone is responsible for protein binding and separation. In principle, protein binding can still occur to some extent on the outer surface of the weak exchanger. However, since the external surface area of moderately sized resin beads is negligible compared to the area within the resin's pores, protein binding on the weak exchanger is likely insignificant, approximating an ideal system where $\mathrm{pH}$ gradient generation and protein binding are effectively decoupled. In turn, predictability is improved since each resin component can be studied independently, the effect of protein loading on the $\mathrm{pH}$ gradient can be virtually eliminated since protein binding occurs on ligands different from those used to modulate $\mathrm{pH}$, and the possibility of hydrophobic interactions at $\mathrm{pH}$ extremes can be greatly reduced since the strong anion exchanger, which contains 
virtually all of the protein accessible surface area, remains charged across broad ranges of $\mathrm{pH}$. Additionally, the same weak anion exchanger can be combined with different strong anion exchangers in proportions that best balance $\mathrm{pH}$ gradient generation and proteinligand interactions. Obviously, analogous effects can be obtained with the combination of a weak, small pore cation exchanger and suitably large-pore cation exchanger, or by combining weak and strong functionalities in a single bead whose architecture prevents proteins from interacting with the weak functional group. (12).

For this chapter, the objectives are thus fourfold. The first objective is to demonstrate that mixed-beds of weak and strong anion exchangers can be obtained with a uniform distribution of resin components along the column lengths and radius. The second is to demonstrate that these columns can be used to generate reproducible $\mathrm{pH}$ gradients with non-retained buffering species. The third is to provide a model to predict the $\mathrm{pH}$ gradients as a function of column and mobile phase compositions. The fourth is to demonstrate the mixed-bed column separation of the charge variants of a monoclonal antibody.

\subsection{Theoretical development}

The model used to describe $\mathrm{pH}$ gradients generated with non-retained buffering species in mixed-bed columns is an extension of the model developed by Pabst et al. (10) for weak anion exchange columns. The main assumptions are: (i) the mixed-bed has a spatially uniform composition; (ii) the buffering species are unretained; (iii) exchange of chloride and hydroxide ions occurs only on the weak anion exchanger while the strong anion exchanger remains in the chloride form; and (iv) mass transfer of counterions and buffering species is rapid so that local equilibrium exists for these species between the 
mobile phase and the stationary phase. The $\mathrm{pH}$ is then found by considering solution and ion exchange equilibria together with differential balances according to the relationships in the following sections.

\subsubsection{Solution equilibria}

Considering a system containing chloride as the counterion with a mixture of monobasic buffering species, the relevant solution equilibria are described by the following equations:

$$
\begin{gathered}
K_{a, B_{i}}=\frac{C_{B_{i}} C_{H^{+}}}{C_{B_{i} H^{+}}} \\
C_{B_{i}}^{0}=C_{B_{i}}+C_{B_{i} H^{+}} \\
K_{W}=C_{H^{+}} C_{O H^{-}} \\
C_{H^{+}}+\sum_{i} C_{B_{i} H^{+}}=C_{O H^{-}}+C_{C l^{-}}
\end{gathered}
$$

describing deprotonation of the amine buffers, a material balance on the total buffer species, water splitting into hydronium and hydroxide ions, and the solution electroneutrality condition, respectively. In these equations, $K_{a, B_{i}}$ is the deprotonation constant for buffering species i, $C_{B_{i}}^{0}$ the corresponding total concentration, $C_{B_{i}}$ and $C_{B_{i} H^{+}}$ the corresponding concentrations of the neutral and protonated forms, respectively, and $K_{w}$, the ionic product of water. Combining Eqs. (2.1), (2.2), and (2.3) with Eq. (2.4), yields the following relationship:

$$
C_{H^{+}}+\sum_{i} \frac{C_{B_{i}}^{0}}{1+\frac{K_{a, B_{i}}}{C_{H^{+}}}}=\frac{K_{w}}{C_{H^{+}}}+C_{C l^{-}}
$$


which can be solved for $C_{H^{+}}$for given values of $C_{C I}$ and $C_{B_{i}}^{0}$. The $\mathrm{pH}$ can then be calculated as:

$$
p H=-\log \left(\gamma_{H^{+}} C_{H^{+}}\right)
$$

where $\gamma_{H^{+}}$is the activity coefficient, which, in turn, can be estimated as a function of ionic strength from the following equation (13):

$$
\log \gamma_{H^{+}}=-\left(\frac{A \sqrt{I}}{1+\sqrt{I}}-0.1 I\right)
$$

$A$ is the Debye-Hückle constant, equal to 0.51 at $298 \mathrm{~K}$ (13), and I is the ionic strength of the solution in $\mathrm{mol} / \mathrm{L}$.

\subsubsection{Ion exchange equilibria}

Ion exchange equilibria on the weak base resin are described by the following relationships:

$$
\begin{gathered}
K_{a, R}=\frac{q_{R} q_{H^{+}}}{q_{R H^{+}}} \\
q_{R}^{0}=q_{R H^{+}}+q_{R} \\
q_{R H^{+}}+q_{H^{+}}=q_{C l^{-}}+q_{O H^{-}}
\end{gathered}
$$

subject to the Donnan equilibrium condition (14):

$$
q_{C l^{-}} q_{H^{+}}=C_{C l^{-}} C_{H^{+}}
$$

where $K_{a, R}$ is the deprotonation constant for the resin's weak base functional groups, $q_{R}^{0}$ their total concentration, $q_{R}$ and $q_{R H^{+}}$are the corresponding concentrations of deprotonated and protonated forms, and $q_{H^{+}}, q_{\mathrm{OH}^{-}}$, and $q_{\mathrm{Cl}^{-}}$are the resin-phase 
concentrations of hydrogen, hydroxide, and chloride ions, respectively. All $q$-values in these equations are expressed per unit volume of resin solid; i.e. excluding both extraparticle and intraparticle pore volumes.

Since, in practice, both $q_{H^{+}}$and $q_{\mathrm{OH}^{-}}$are much smaller than $q_{\mathrm{Cl}^{-}}$(14), combining Eqs. (2.8) through (2.11) yields:

$$
q_{C l^{-}}=\frac{1}{2}\left\{\frac{-C_{H^{+}} C_{C l^{-}}}{K_{a, R}}+\left[\left(\frac{C_{H^{+}} C_{C l^{-}}}{K_{a, R}}\right)^{2}+\frac{4 q_{R}^{0} C_{H^{+}} C_{C l^{-}}}{K_{a, R}}\right]^{\frac{1}{2}}\right\}
$$

As shown by Pabst et al. (10), analogous but more complicated relationships are obtained for weak base resins containing multiple functional groups with different $p K_{a, R}$ values or when deprotonation of one group affects deprotonation of the others. In this work we consider only the simplest case, which proved adequate for the weak anion exchanger used. We assume that no exchange of chloride occurs on the functional groups of the strong base resin as these groups are fully protonated and $\mathrm{Cl}^{-}$is in excess as long as the $\mathrm{pH}$ is less than 12.

\subsubsection{Conservation equations}

Neglecting axial dispersion, material balances for the conserved species, which are the total of each buffering species, $\mathrm{B}_{\mathrm{i}}$, and $\mathrm{Cl}^{-}$, are given by the following equations:

$$
\begin{gathered}
u \frac{\partial C_{B_{i}}}{\partial x}+\varepsilon_{t} \frac{\partial C_{B_{i}}}{\partial t}=0 \\
u \frac{\partial C_{C l^{-}}}{\partial x}+\varepsilon_{t} \frac{\partial C_{C l^{-}}}{\partial t}+(1-\varepsilon) \varphi_{w}\left(1-\varepsilon_{p, w}\right) \frac{\partial q_{C l^{-}}}{\partial t}=0
\end{gathered}
$$

In these equations, $u$ is the superficial mobile phase velocity, $x$ is the column axial coordinate, $t$ is time, $\varepsilon_{t}$ is the total column porosity, $\varphi_{w}$ is the volume fraction of the 
weak resin component of the mixed-bed, and $\varepsilon_{p, w}$ is the corresponding intraparticle porosity. The total column porosity is given by $\varepsilon_{t}=\varepsilon+(1-\varepsilon)\left[\varphi_{w} \varepsilon_{p, w}+\left(1-\varphi_{w}\right) \varepsilon_{p, s}\right]$ where $\varepsilon$ is the extraparticle porosity and $\varepsilon_{p, s}$ the intraparticle porosity of the strong base resin.

\subsubsection{Solution methods}

Two different methods were used to solve the conservation equations. An analytical solution was obtained by the method of characteristics. Accordingly, the characteristic velocities, obtained from Eqs. (2.13) and (2.14) are:

$$
v_{c, B_{i}}=\frac{u}{\varepsilon_{t}}
$$

for the unretained buffering species,

$$
v_{c, C C^{-}}=\frac{u}{\varepsilon_{t}+(1-\varepsilon) \varphi_{w}\left(1-\varepsilon_{p, w}\right) \frac{d q_{C l^{-}}}{d C_{C l^{-}}}}
$$

for simple chloride waves, and

$$
v_{s, C C^{-}}=\frac{u}{\varepsilon_{t}+(1-\varepsilon) \varphi_{w}\left(1-\varepsilon_{p, w}\right) \frac{\Delta q_{C l^{\top}}}{\Delta C_{C l^{\top}}}}
$$

for chloride shock waves. In Eq. (2.17), $\Delta$ represents the difference between values upstream and downstream of a shock. The values of $d q_{C l^{-}} / d C_{C l^{-}}$and $\Delta q_{C C^{-}} / \Delta C_{C l^{\prime}}$ are determined numerically from the combined solution and ion exchange equilibrium relationships, Eqs. (2.1) through (2.12). As discussed in $(15,16)$, for a step change in buffer composition from $C_{B_{i}}^{\text {initial }}$ to $C_{B_{i}}^{\text {final }}$ and $C_{C l^{-}}^{\text {inital }}$ to $C_{C l^{\prime}}^{\text {final }}$ the solution consists of two waves - a fast wave traveling at velocity $u / \varepsilon_{t}$ with $\Delta C_{B_{i}}=C_{B_{i}}^{\text {initial }}-C_{B_{i}}^{\text {final }}$ and 
$\Delta C_{C l^{-}}=C_{C l^{-}}^{\text {initial }}-C_{C l^{-}}^{\text {interm }}$ where $C_{C l^{-}}^{\text {interm }}$ is an intermediate chloride concentration determined by setting $\Delta q_{C l}=0$; and a slow wave with $C_{B_{i}}=C_{B_{i}}^{\text {final }}$ along which the chloride concentration changes from $C_{C l}^{\text {interm }}$ to $C_{C l}^{\text {final }}$. The slow wave can be a gradual wave, a shock wave, or a combination of both dependent on whether $v_{c, C T}$ increases, decreases, or has a minimum as a function of the axial coordinate $x$. Once the appropriate wave type and velocity is determined, the number of column volumes that correspond to a particular outlet chloride concentration and $\mathrm{pH}$ are calculated as either $C V=u / v_{c}$ or $C V=u / v_{s}$. In general, a simple wave, which corresponds to a smooth $\mathrm{pH}$ gradient, is obtained with buffers whose $p K_{a}$ is larger than the operating $\mathrm{pH}(10,11,16)$.

A numerical solution of the conservation equation was also obtained by discretizing the axial derivative by backwards-finite differences and solving the resulting ordinary differential equations in time using Gear's method with subroutine DVIPAG of IMSL $^{\circledR}$ Numerical Libraries (Rogue Wave Software, Boulder, CO, USA) as described by Pabst and Carta (15). The discretization introduces numerical dispersion, which simulates qualitatively the effects of axial dispersion in the column. Increasing the number of discretization points, $N$, reduces numerical dispersion giving a solution that should approximate the analytical result.

\subsection{Materials and methods}

\subsubsection{Materials}

The resins used in this work are AG 4-X4, Nuvia Q, and UNOsphere DQ from Bio-Rad Laboratories (Hercules, CA, USA), and Q Sepharose FF and SOURCE 30Q 
from GE Healthcare (Piscataway, NJ, USA). Their basic properties are summarized in Table 2.1. AG 4X-4 is a weak anion exchanger based on acrylic polymers with trimethylamine functional groups. The resin has $4 \%$ crosslinkage, 100-200 dry mesh size, and an irregular particle shape with hydrated size in the range 50-200 $\mu \mathrm{m}$. The supplier-reported size exclusion limit is 1,400 Dalton. As a result, the resin is expected to exclude most proteins. On the other hand, since diffusion of small counterions and buffering species through this resin is likely to be fast, neither the particle shape nor the exact size are expected to affect the results. The remaining four resins are strong anion exchangers with quaternary amine functional groups. Q Sepharose FF is agarose based, SOURCE $30 \mathrm{Q}$ is based on poly(styrene-divinyl benzene), and Nuvia Q is a polymer grafted matrix based on a large-pore polymeric backbone. UNOsphere DQ is an experimental open-pore strong anion exchanger based on a backbone matrix similar to that of Nuvia Q but without polymer grafts.

Chemicals used in buffer preparation were of ACS grade and were obtained from Thermo Fisher Scientific (Waltham, MA, USA). A purified monoclonal antibody (mAb) (IgG1, $M_{r} \sim 150 \mathrm{kDa}, \mathrm{pI} \sim 8.2$ ) was obtained from MedImmune (Gaithersburg, MD, USA). The mAb was found to be essentially $100 \%$ monomer by size exclusion chromatography with a Superdex 200 column from GE Healthcare (Piscataway, NJ, USA) and chromatographically pure by salt gradient elution cation exchange chromatography with a SOURCE 30S column (also from GE Healthcare) at pH 5. However, the mAb was found to contain two significant charge variants with lower pI values ( 8.0 and 7.8, accounting for about $20 \%$ and $5 \%$, respectively, of the total protein), which could be distinguished by isoelectric focusing with precast IsoGel ${ }^{\circledR}$ Agarose IEF 
Table 2.1 - Resin properties

\begin{tabular}{|l|l|c|c|c|}
\hline Resin & Functionality & $\begin{array}{c}\text { Mean particle } \\
\text { diameter }(\mu \mathrm{m})\end{array}$ & $\begin{array}{c}\text { Porosity, } \\
\varepsilon_{p}^{(b)}\end{array}$ & $\begin{array}{c}\text { Size exclusion } \\
\text { limit }(\mathrm{nm})^{(\mathrm{c})}\end{array}$ \\
\hline AG 4-X4 & Weak base & $50-200^{(\mathrm{a})}$ & 0.44 & $<2$ \\
\hline Q Sepharose FF & Strong base & 94 & 0.92 & 20 \\
\hline Nuvia Q & Strong base & 81 & 0.69 & 7 \\
\hline UNOsphere DQ & Strong base & 65 & 0.80 & $>40$ \\
\hline SOURCE 30Q & Strong base & 28 & 0.63 & $>40$ \\
\hline
\end{tabular}

(a) Range of longest dimensions observed for hydrated particles

(b) Based on glucose

(c) Hydrodynamic radius of dextran giving $K_{D}=0$ 
plates (pH 7-11) from Lonza, Inc. (Allandale, NJ, USA). In order to accentuate the effects of the charge variants, the mAb was also forcibly deamidated by incubating it at room temperature in a $1 \mathrm{M}$ Tris solution at $\mathrm{pH} 9$ for 7 days. The forced deamidation increased the fractions of the two original charge variants to $35 \%$ and $20 \%$ of the total $\mathrm{mAb}$, respectively, and generated significant amounts of an additional variant with an IEF band corresponding to a pI of about 7.6 , representing $10 \%$ of the total.

All experiments were conducted at room temperature, $24 \pm 2{ }^{\circ} \mathrm{C}$. Since temperature affects the $p K_{a}$ values of the amine buffers used, the temperature was carefully monitored with a thermocouple inserted in tee fitting at the column outlet.

\subsubsection{Methods}

\section{Resin properties}

Inverse size exclusion chromatography (iSEC) was used to determine the size exclusion limit and intraparticle porosity of each resin as suggested by Hagel et al. (17) using glucose and dextran standards with molecular masses between 4 and 2,000 kDa and corresponding estimated hydrodynamic radii between 1.7 and $40 \mathrm{~nm}$. A Model e2695 HPLC system from Waters Corporation (Milford, MA, USA) with a Model 2414 refractive index detector was used for this purpose. Solutions containing $5 \mathrm{~g} / \mathrm{L}$ of each standard were prepared in the $20 \mathrm{mM}$ Tris- $\mathrm{HCl} \mathrm{pH} 7.0$ running buffer. $30 \mu \mathrm{L}$ samples were injected at $150 \mathrm{~cm} / \mathrm{hr}$. The distribution coefficient was then calculated for each solute from the following expression:

$$
K_{D}=\frac{V_{R} / V_{c o l}-\varepsilon}{1-\varepsilon}
$$


where $V_{R}$ is the retention volume at the peak maximum, $V_{c o l}$ is the column volume, and $\varepsilon$ is the extraparticle porosity. The latter was determined from the retention volume of 2,000 $\mathrm{kDa}$ dextran for the smaller pore resins or from pressure-flow curves using the Kozeny-Carman equation for the larger pore resins UNOsphere DQ and SOURCE 30Q. The intraparticle porosity was taken to be equal to $K_{D}$ for glucose while the size exclusion limit was taken as the dextran hydrodynamic radius giving $K_{D}=0$.

Potentiometric titrations were used to determine the weak base content of each resin. For this purpose, a sample of each resin was packed in a $5 \times 50 \mathrm{~mm}$ column and equilibrated with a $0.1 \mathrm{M} \mathrm{NaCl}$ solution at $\mathrm{pH} 11$. After removing the column bottom adapter, the resin was then extruded into a beaker containing $25 \mathrm{~mL}$ of the equilibration solution and titrated potentiometrically with $0.05 \mathrm{M} \mathrm{HCl}$. The resin weak base content, $q_{R}^{0}$, and its apparent $p K_{a}$ were determined by fitting the resulting titration curves to Eq. (2.12). As discussed below, only AG 4-X4 showed significant weak base content between pH 6 and 11.

\section{Preparation and characterization of mixed-beds}

Mixed-bed and single resin columns were packed in $5 \times 50$ or 5x200 mm Tricorn columns from GE Healthcare (Piscataway, NJ, USA) using an ÄKTA Explorer 10 unit also from GE Healthcare. For columns packed with a single resin, a 50\% slurry was poured into the column fitted with a packing extender and then flow-packed at the velocities recommended by the resin suppliers. Mixed-beds of AG 4-X4 with a strong base resin were packed by first collecting samples of each hydrated resin in the desired volumetric ratio from slurries with known concentrations. The two mixed resins were then re-suspended in buffer to create a 50\% slurry which was then flow-packed as for the 
single resin columns. Mixed-bed columns with ratios on the order of 1:1 were packed at the manufacturer specified velocity for the material with lower mechanical strength. In the case of mixed-beds with ratios on the order of 1:10, the manufacturer specified packing velocity for the major component was used.

The distribution of AG 4-X4 in mixed-beds was visualized using optical microscopy with a procedure similar to that described by Corbett et al. (18). For this purpose, mixed resin samples were packed in $1 \mathrm{~mL}$ plastic syringe bodies $(4 \mathrm{~mm}$ internal diameter) fitted with a fiberglass frit to retain the resin to a depth of 2 to $3.6 \mathrm{~cm}$. Each packed column was then dehydrated by passing 10 to $20 \mathrm{~mL}$ each of $20 \%, 67 \%$ and $100 \%$ aqueous ethanol solutions and then saturated with LR White polyester resin (London Resin Company, London, UK) dissolved in ethanol with increasing concentration from zero to $100 \%$. After saturation with LR White, the column was sealed and placed in a $45^{\circ} \mathrm{C}$ oven for 3 days to cure. Once cured, the embedded column was cut longitudinally along the column center using a jeweler's saw. The cut faces were then polished with 4000 grit finishing cloth using a Buehler EcoMet 3000 polisher (Lake Bluff, IL, USA), stained using FD\&C Blue 1 dye (General Mills Inc., Minneapolis, MN, USA), which is negatively charged, and photographed at 40x magnification with a Nikon Eclipse E-200 microscope (Nikon Instruments, Inc., Melville, NY, USA).

\section{Induced $\mathrm{pH}$ gradients}

As in the case of columns containing a single weak base resin, $\mathrm{pH}$ gradients were generated within mixed-bed columns by applying step changes at the column entrance from $\mathrm{pH} 9$ to $\mathrm{pH} 7$ while keeping a constant chloride concentration at superficial velocities between 150 and $450 \mathrm{~cm} / \mathrm{hr}$ using an ÄKTA Explorer 10 unit. Ethanolamine, Tris, and BisTris were used as buffers for these experiments either alone or as a mixture. 
The corresponding $p K_{a}$ values are 9.50, 8.06, and 6.46, respectively, at $298 \mathrm{~K}$ (19). Corrections to these values for deviations from $298 \mathrm{~K}$ were made according to the parameters provided by Beynon and Easterby (19), namely: $-0.029,-0.028$, and -0.020 ${ }^{\circ} \mathrm{C}^{-1}$ for ethanolamine, Tris, and BisTris, respectively. These buffers were selected because they are either neutral or cationic, preventing interaction with the anion exchangers, and because their $p K_{a}$ values span across the range of initial and final $\mathrm{pH}$ used in our experiments. Buffer solutions containing mixtures of ethanolamine with Tris or BisTris were prepared by first adding weighed amounts of either Tris or BisTris in free-base form (calculated based on Eqs. (2.1-2.7)) to $\mathrm{HCl}$ solutions having a known chloride concentration and then titrating these solutions with ethanolamine until the desired $\mathrm{pH}$ was reached. Conductivity, which corresponds closely to the chloride concentration, and $\mathrm{pH}$ were monitored at the column outlet with in-line $\mathrm{pH}$ and conductivity probes. The effluent $\mathrm{pH}$ was also checked off-line by collecting fractions of the column effluent. Good agreement was found between in-line and off-line measurements.

\subsection{Results and discussion}

\subsubsection{Resin properties}

The intraparticle porosity and size exclusion limit determined for each of the resins used in this work are given in Table 2.1. AG 4-X4 excluded all of the dextran standards except for the $4 \mathrm{kDa}$ dextran while all of the strong base resins had relatively large exclusion limits. Among these, Nuvia Q is an exception having a relatively small size exclusion limit. However, this resin contains charged polymer grafts that have been 
shown for similar matrices to exclude neutral macrosolutes but still effectively bind oppositely charged proteins $(20,21)$.

Figure 2.2 shows the potentiometric titration curves for the resins used in this work. The sloped portion of these curves provides the $\mathrm{pH}$ range over which the resin has buffering capacity resulting from the protonation of weak base groups while the plateau provides the concentration of these groups. It is evident that among these resins only AG 4-X4 has significant buffering capacity over a useful $\mathrm{pH}$ range, while the strong base resins give titration curves close to the blank titration indicated by the dashed line. The solid line in Figure 2.2 is based on Eq. (2.12) with fitted values of $p K_{a, R}=9.75 \pm 0.01$ and $q_{R}^{0}=3.45 \pm 0.02 \mathrm{mmol}$ per $\mathrm{mL}$ of resin solid. This $q_{R}^{0}$ value can be converted to a bed volume basis multiplying it times the quantity $(1-\varepsilon)\left(1-\varepsilon_{p}\right)=(1-0.33)(1-0.44)=0.38$ giving a weak base group content of $1.31 \pm 0.01 \mathrm{mmol}$ per $\mathrm{mL}$ of packed bed. This value is about 10 times greater than that previously reported in Pabst et al. (10) for DEAE Sepharose FF and for ANX Sepharose FF, which were used for $\mathrm{pH}$ gradient based separations of protein charge variants. The high value obtained for AG 4-X4 suggests that a small percentage of this resin can be used in a mixed-bed with a strong base resin to obtain induced $\mathrm{pH}$ gradients similar to those of Pabst et al. (10). As seen in Figure 2.2, using a single $p K_{a}$ value for the resin's functional groups provides agreement within experimental error especially in the practical $\mathrm{pH}$ range of 7 to 9 indicating that a more complicated description of protonation of the resin, as suggested by Pabst et al. $(10,11)$, is not warranted in this case. 


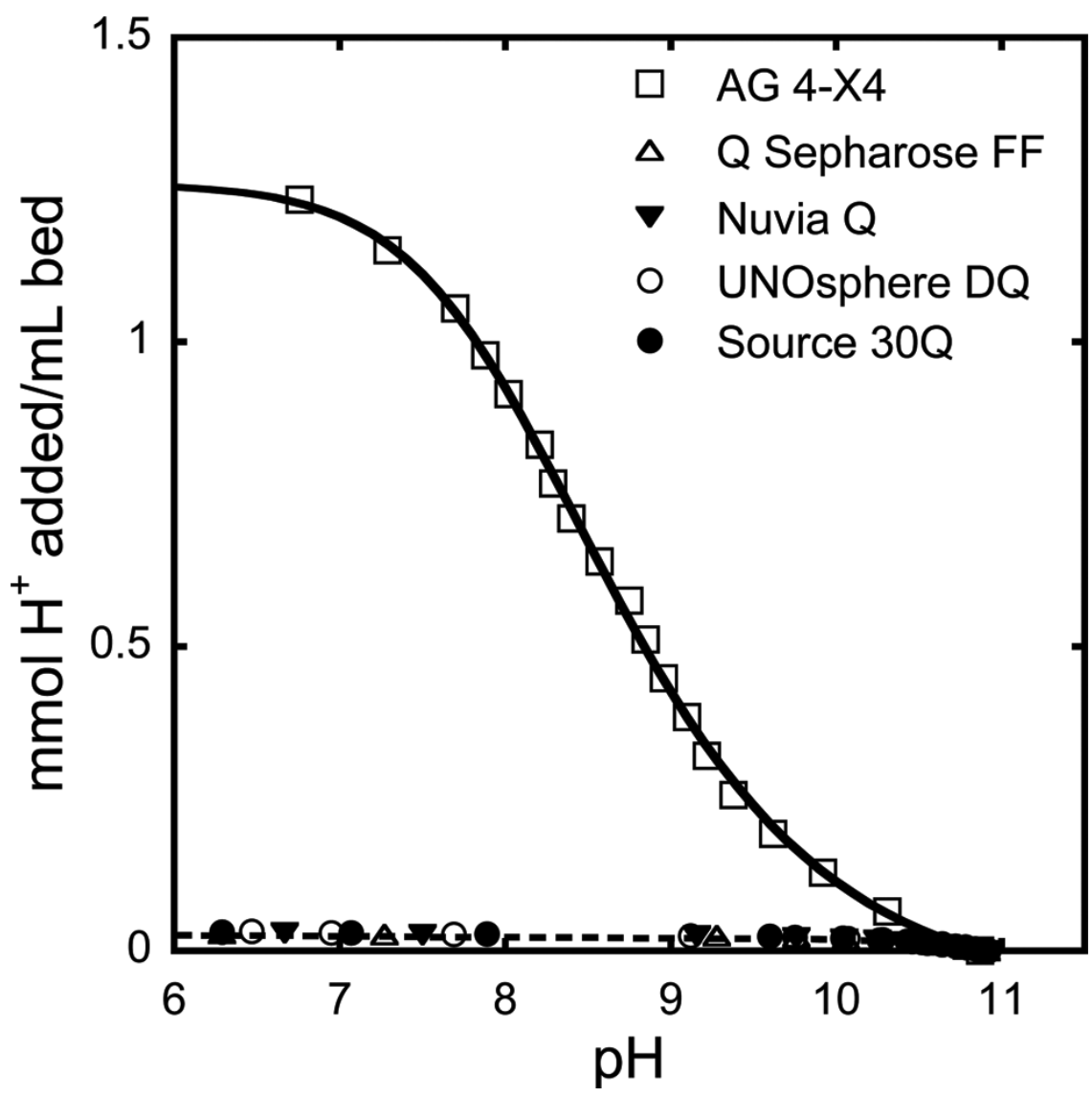

Figure 2.2 - Potentiometric titration curves for the resins used in this work starting at $\mathrm{pH} 11$ in $0.1 \mathrm{M} \mathrm{NaCl}$. The solid line is based on Eq. (12). The dashed line corresponds to titration of the blank solution without added resin. 


\subsubsection{Mixed-bed packing characterization}

Figure 2.3 shows microphotographs of mixed-bed columns containing $10 \%$ AG 4$\mathrm{X} 4$ that were embedded, cut longitudinally along the column center, and stained with FD\&C Blue 1 dye as described in the Methods section of this paper. Because of their large exchange ligand density, the AG 4-X4 particles are stained dark blue and are visible as irregular shapes against the background of UNOsphere DQ and SOURCE 30S which are only lightly stained. The images show that the AG 4-X4 particles are generally randomly distributed across both column length and diameter with no obvious agglomeration or preferential distribution. Similar results are obtained when mixing AG 4-X4 with either UNOsphere DQ or SOURCE 30Q, despite the large difference in particle size, size distribution, and shape. Thus, the assumption that the mixed-bed columns are composed of two well-dispersed materials appears appropriate.

\subsubsection{Induced pH gradients}

In order to demonstrate the versatility of the mixed-bed approach, results are presented in Figures 2.4 through 2.7 for AG 4-X4 in combination with different strong base resins varying the percentage of AG 4-X4, the buffer chloride concentration, and the buffer type and composition. In each case, the experimental $\mathrm{pH}$ and chloride concentration profiles, obtained from the in-line $\mathrm{pH}$ and conductivity probes as described by Pabst et al. (10), are compared with predictions based on the analytical solution of the model equations, Eqs. (2.1) through (2.14), obtained by the method of characteristics. 
(a)
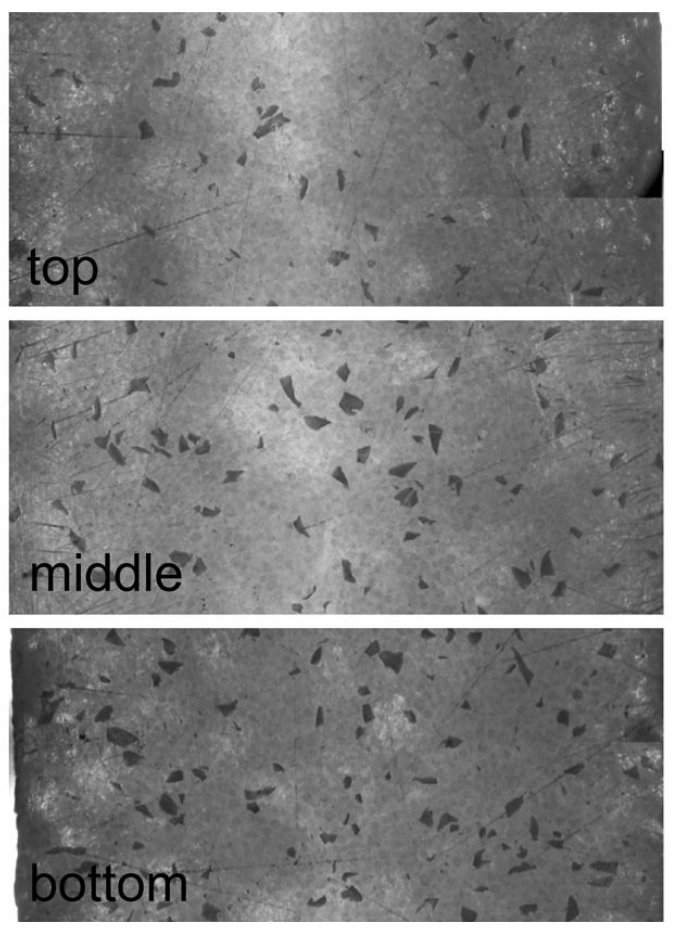

(b)
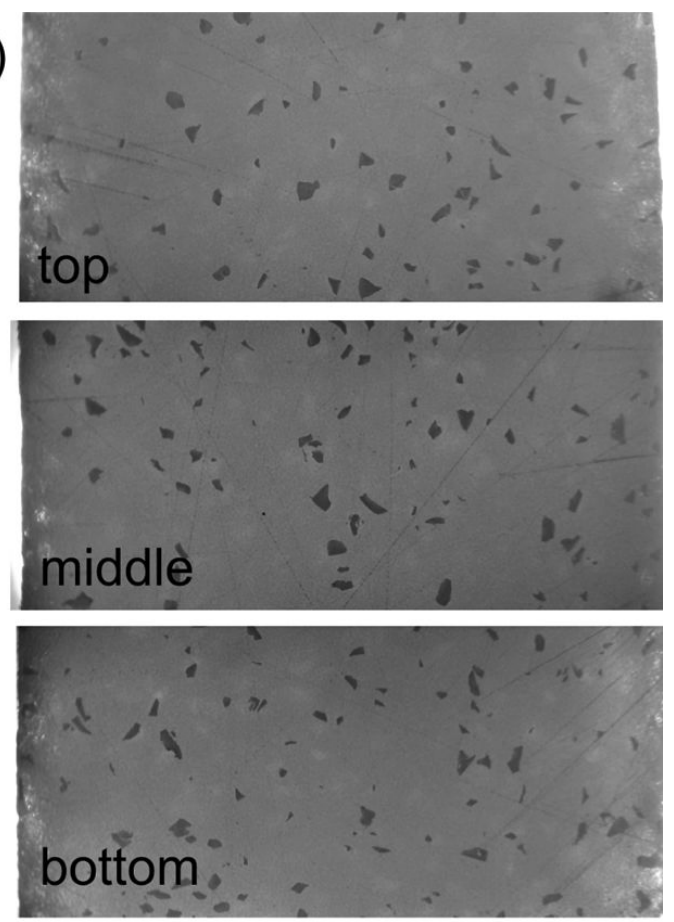

Figure 2.3 - Microphotographs of longitudinally cut mixed-bed columns embedded in LR White resin showing the distribution of AG 4-X4 particles, stained dark, at different distances along the column length. Each image spans the column diameter $(4 \mathrm{~mm})$ and a vertical distance of $2 \mathrm{~mm}$ centered near the top 2$5 \mathrm{~mm}$, near the middle, and near the bottom $2-5 \mathrm{~mm}$ of each column. (a) $4 \times 36 \mathrm{~mm}$ column containing $10 \%$ AG 4-X4 and 90\% UNOsphere DQ; (b) $4 \times 20 \mathrm{~mm}$ column containing $10 \%$ AG $4-\mathrm{X} 4$ and $90 \%$ SOURCE 30Q. 
Figure 2.4 shows the effect of using different proportions of AG 4-X4 and Q Sepharose FF for ethanolamine buffers containing $50 \mathrm{mM}$ chloride. As seen in this figure, smooth $\mathrm{pH}$ transitions are obtained in all three cases although longer transitions are achieved with higher percentages of AG 4-X4. For practical applications, a particular percentage of AG 4-X4 can be selected to yield a desired gradient. Although the mobile phase residence time, $L / u$, is only $1-4 \mathrm{~min}$, the experimental results are in close agreement with the analytical solution of the model equations indicating that neither mass transfer nor axial dispersion play a significant role for these conditions. Close agreement with the model also confirms that interactions of the mobile phase component with the strong base resin Q Sepharose FF have negligible effects so that the $\mathrm{pH}$ transitions are due exclusively to the AG 4-X4 resin.

Figure 2.5 shows the effects of buffer composition for mixtures of ethanolamine and Tris with $15 \mathrm{mM}$ chloride for a mixed-bed containing 10\% AG 4-X4 and 90\% Nuvia Q. Increasing the percentage of Tris in the buffer sharpens the induced $\mathrm{pH}$ gradient. This behavior is a result of the lower $p K_{a}$, and, hence, greater buffering capacity of Tris compared to ethanolamine, which causes the slow $\mathrm{pH}$ wave to travel faster through the column. As in the previous case, quantitative agreement with model predictions is excellent. 

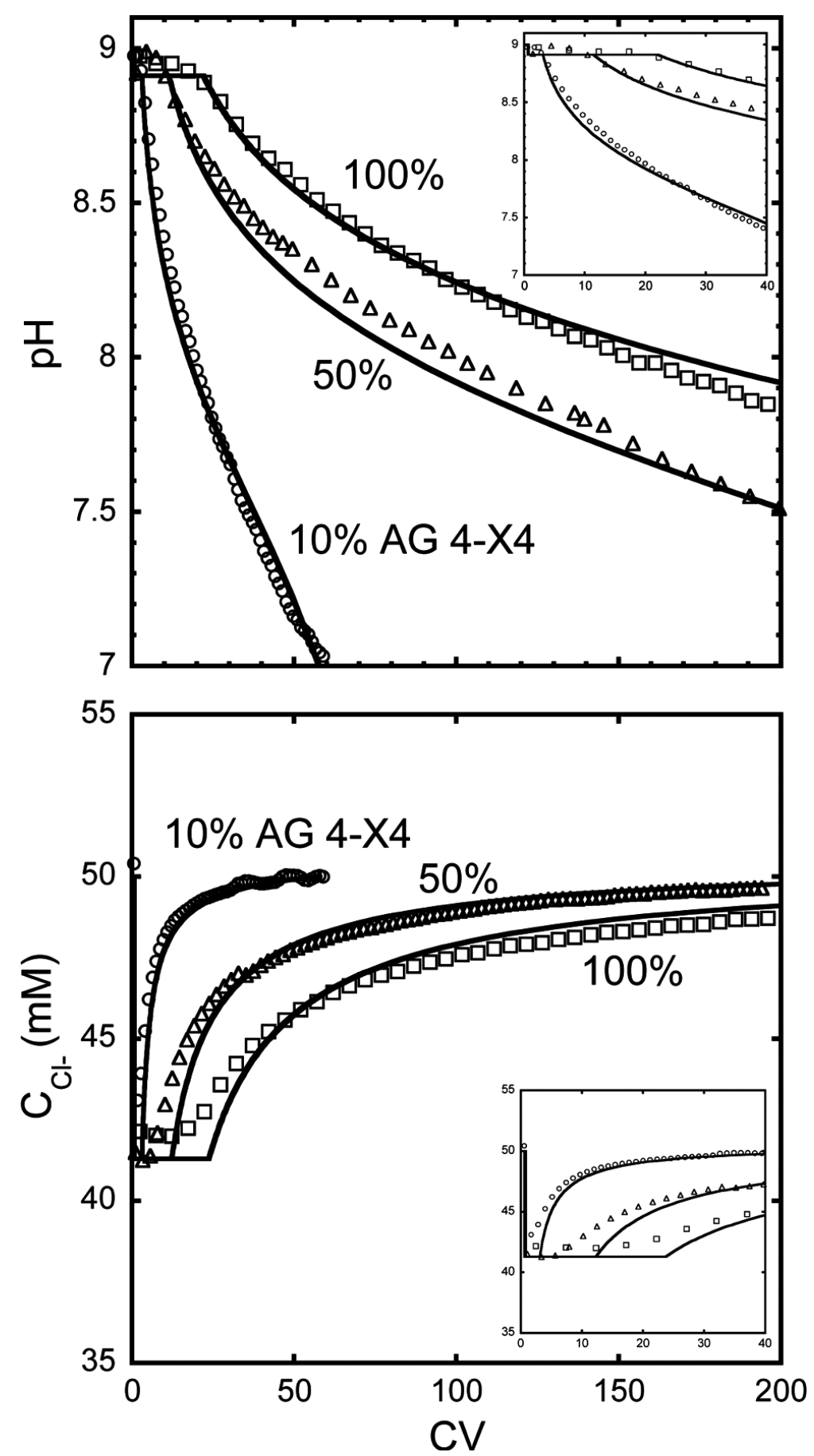

Figure 2.4 - Results obtained with a mixed-bed column of AG 4-X4 and Q Sepharose FF with varying volumetric percentages of $\mathrm{AG} 4-\mathrm{X} 4$ with a $\mathrm{pH}$ step from 9 to 7 using ethanolamine buffers containing $50 \mathrm{mM}$ chloride at $300 \mathrm{~cm} / \mathrm{hr}$ for the 100 and $50 \%$ columns, and $150 \mathrm{~cm} / \mathrm{hr}$ for the $10 \%$ column. Column length $=5 \mathrm{~cm}$ for the $100 \%$ and $50 \%$ AG $4-\mathrm{X} 4$ columns, and $20 \mathrm{~cm}$ for the $10 \%$ column. Symbols are experimental data and lines are model predictions. 

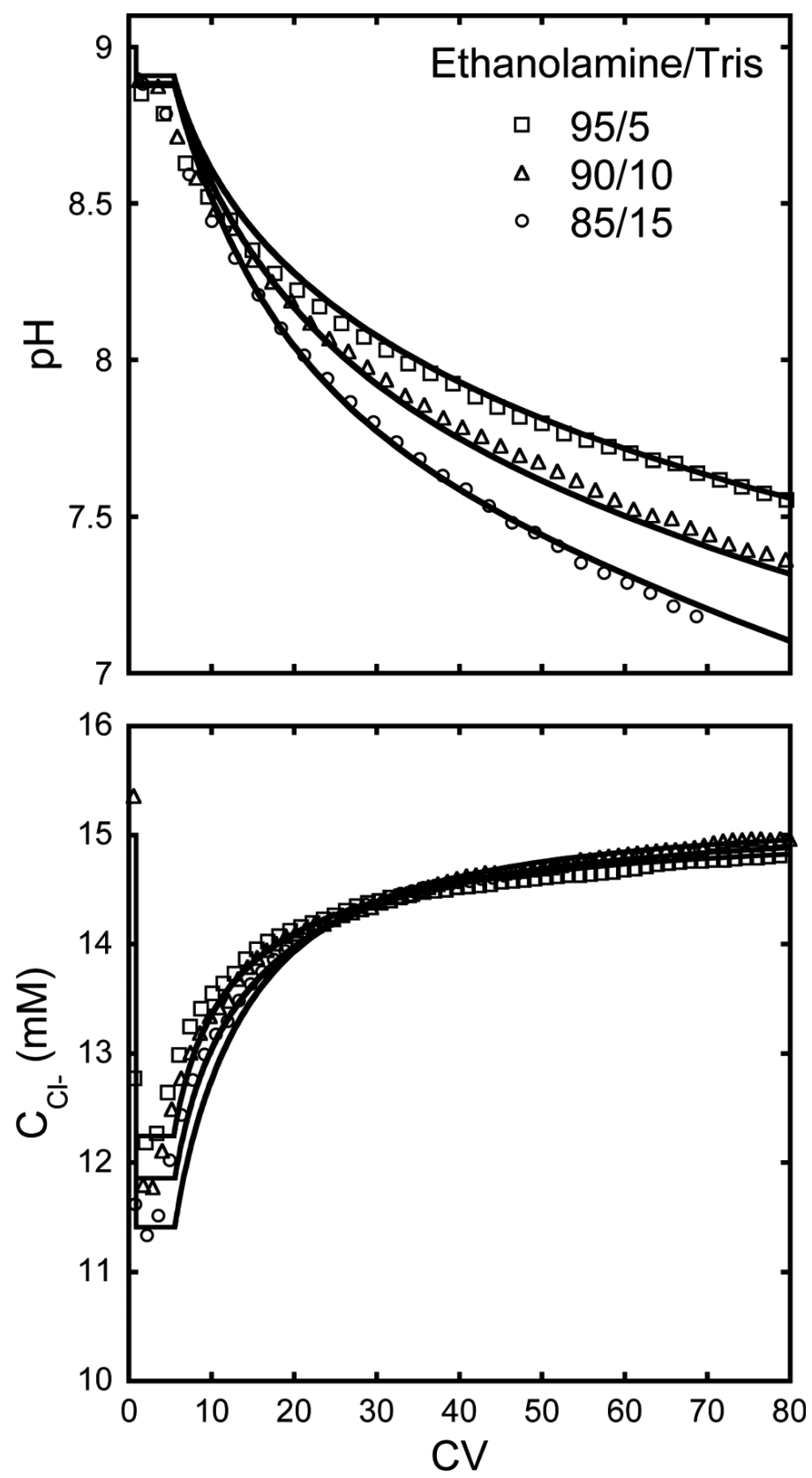

Figure 2.5 - Results obtained with a mixed-bed column containing 10\% AG 4-X4 and 90\% Nuvia Q with a pH step from 9 to 7 using ethanolamine/Tris buffer mixtures with varying composition each containing $15 \mathrm{mM}$ chloride at $150 \mathrm{~cm} / \mathrm{h}$. Column length=20 cm. Symbols are experimental data and lines are model predictions. 
Figure 2.6 shows the effect of chloride concentration for buffers containing $95 \%$ ethanolamine and 5\% Tris and a mixed-bed column containing 14\% AG 4-X4 and 86\% SOURCE 30Q. As seen in this figure, increasing the chloride concentration and, thus, the total buffer concentration, reduces the duration of the $\mathrm{pH}$ transition and results in a more linear $\mathrm{pH}$ gradient. The model is again in excellent agreement with the experimental result indicating that even though AG 4-X4 and SOURCE 30Q have very different mean particle sizes, particle size distributions, and particle shapes, the induced $\mathrm{pH}$ gradients conform closely to those expected for ideal conditions. The only substantial deviations are seen near the end of the $\mathrm{pH}$ transitions as the $\mathrm{pH}$ approaches the final value of 7 . Likely, this area is unimportant for protein separation as long as conditions are appropriately selected so that elution occurs in the middle of the gradient.

Figure 2.7 shows the $\mathrm{pH}$ profile obtained for a column containing $14 \%$ AG $4-\mathrm{X} 4$ and $86 \%$ SOURCE $30 \mathrm{Q}$ with a pH 9 to 7 step using buffers mixtures containing 93\% ethanolamine and 7\% BisTris and $15 \mathrm{mM}$ chloride. As seen in this figure, the $\mathrm{pH}$ transition is initially fairly gradual as in the previously shown results. However, as the $\mathrm{pH}$ falls below about 7.8, the slope of the $\mathrm{pH}$ profile increases dramatically, dropping quickly to the final $\mathrm{pH}$ of 7 . This behavior is due to the low $p K_{a}$ value of BisTris. When the $\mathrm{pH}$ is relatively high, BisTris $\left(p K_{a}=6.46\right.$ at $298 \mathrm{~K}$ ) has essentially no buffering capacity and is completely deprotonated. However, as the $\mathrm{pH}$ decreases, its presence as a buffer becomes significant, substantially speeding up and sharpening the $\mathrm{pH}$ wave. The model also predicts this behavior. 

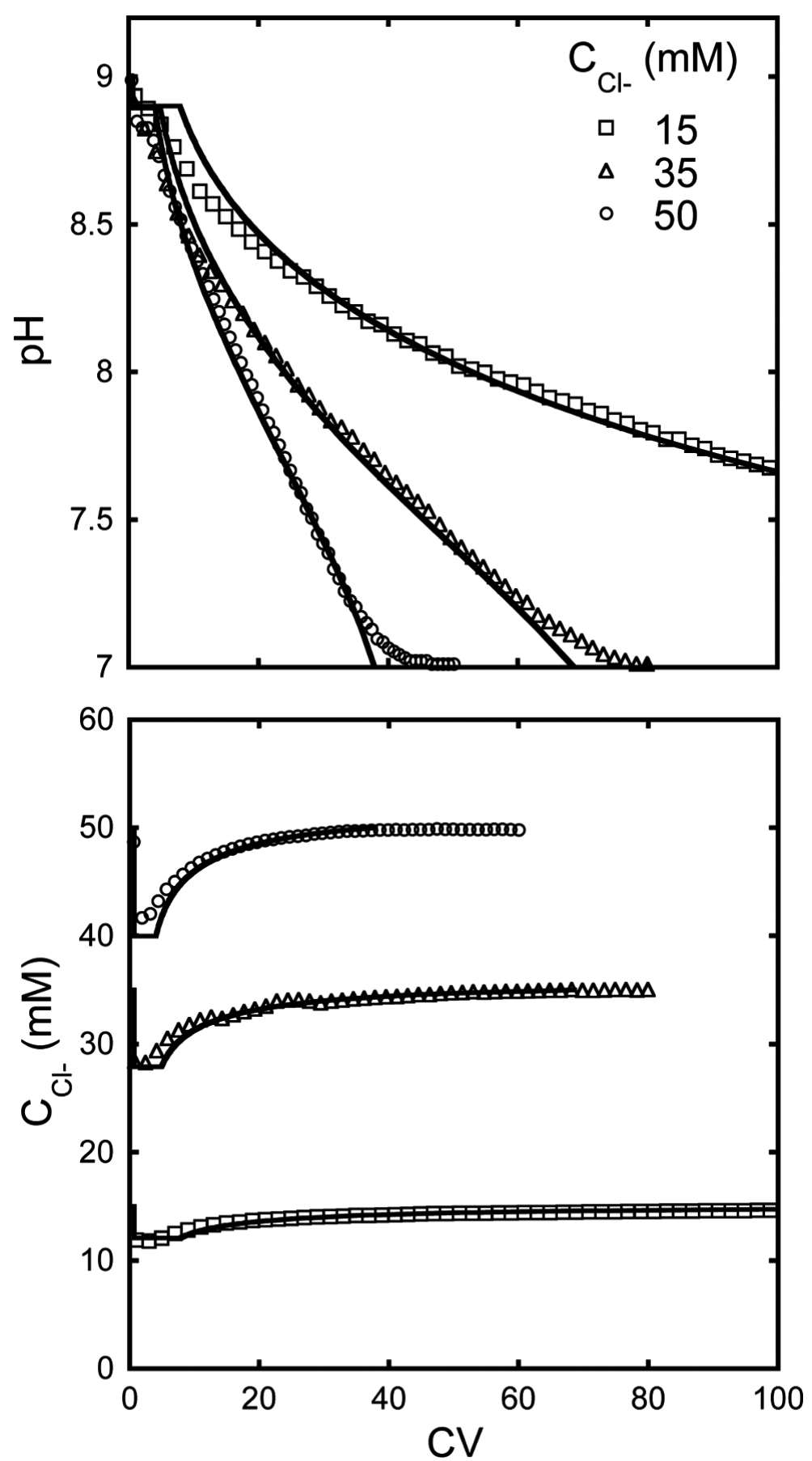

Figure 2.6 - Results obtained with a mixed-bed column containing 14\% AG 4-X4 and 86\% SOURCE 30 Q with a pH step from 9 to 7 using buffer mixtures containing 95\% ethanolamine and 5\% Tris with different chloride concentrations at $300 \mathrm{~cm} / \mathrm{h}$. Column length=20 cm. Symbols are experimental data and lines are model predictions. 


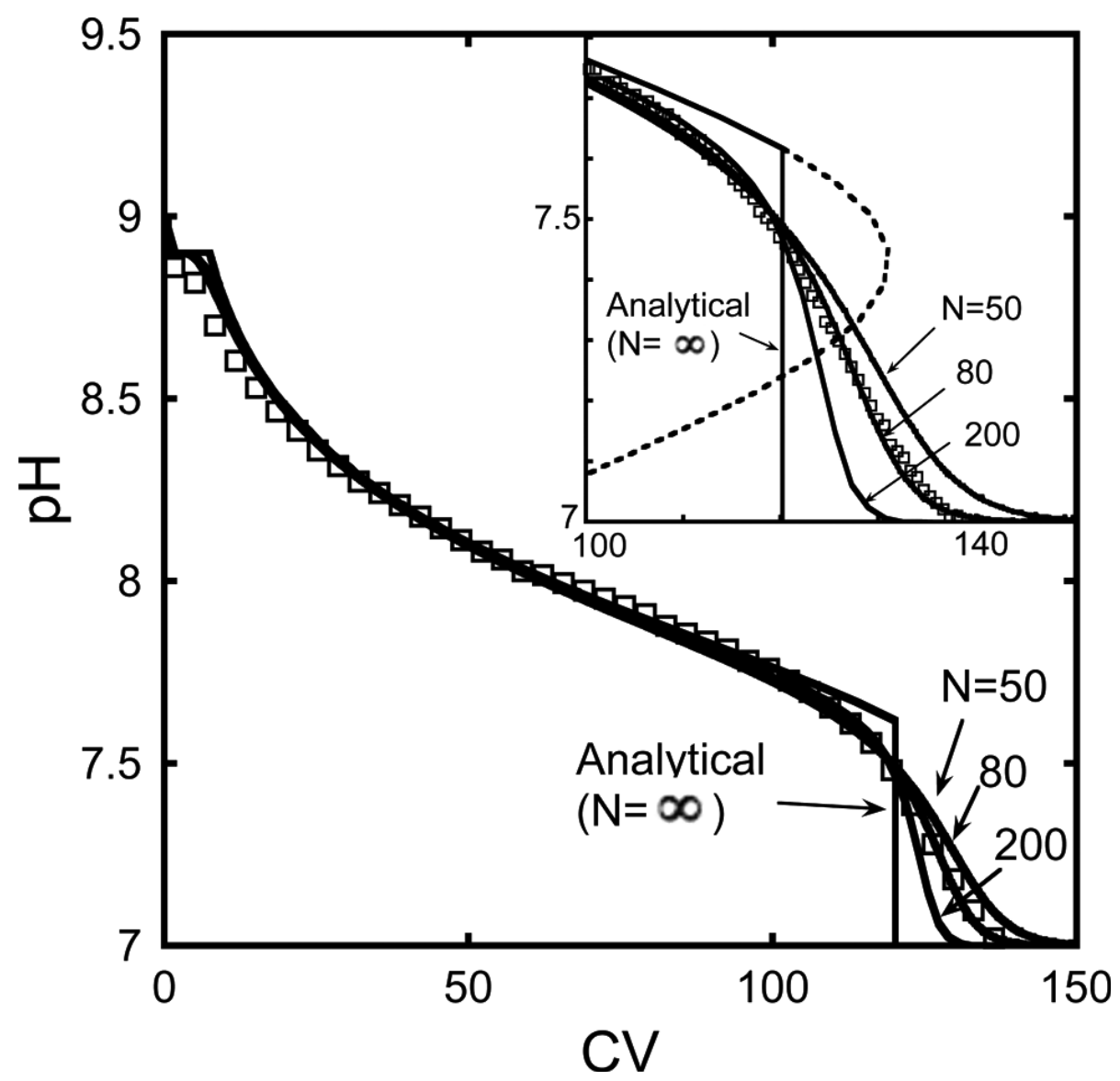

Figure 2.7 - pH profile obtained with a mixed-bed column containing 14\% AG 4-X4 and 86\% SOURCE $30 \mathrm{Q}$ with a $\mathrm{pH}$ step from 9 to 7 using buffer mixtures containing 93\% ethanolamine and 7\% BisTris with $15 \mathrm{mM}$ chloride concentrations at $300 \mathrm{~cm} / \mathrm{h}$. Column length=20 cm. Symbols are experimental data and solid lines are model predictions based on the analytical solution $(\mathrm{N}=\infty)$ and the numerical solution for 50 , 80 , and 200 discretization points. Inset shows the region between 100 and 150CV. The dashed line shows the simple wave profile calculated with eq. 16, which is unphysical as it predicts overlapping concentrations. 
The analytical solution predicts initially a smooth profile. As the $\mathrm{pH}$ decreases, however, the characteristic velocity, calculated according to Eq. (2.12), eventually reaches a minimum, which is indicated by the rightmost point of the dashed line in the inset of Figure 2.7. For these conditions, a shock wave, defined by a sharp transition between an intermediate chloride concentration and $\mathrm{pH}$, catches up with the simple wave giving a composite transition consisting of a simple wave followed by a shock wave. The intermediate chloride concentration at which this shock occurs, $C_{\mathrm{Cl}^{-}}^{\text {shock }}$ and the corresponding $\mathrm{pH}$ and shock velocity are readily found by equating simple wave and shock velocities (20), which yields:

$$
\left(\frac{d q_{C l^{-}}}{d C_{C l^{\prime}}}\right)_{C_{C l^{\prime}} \text { shock }}=\frac{q_{C l^{-}}\left(C_{C l^{\text {shock }}}^{\text {shock }}\right)-q_{C l^{-}}\left(C_{C l^{-}}^{\text {final }}\right)}{C_{C l^{-}}^{\text {shock }}-C_{C l^{-}}^{\text {final }}}
$$

For the conditions of Figure 2.7, Eq. 2.19 together with Eqs. 2.1-2.7 and 2.12 yields $C_{C l}^{\text {shock }}=14.68 \mathrm{mM}, p H^{\text {shock }}=7.617$, and $C V^{\text {shock }}=120.2$. The experimental results are consistent with the self-sharpening trend expected for such a shock transition. However, although the trends are consistent with the analytical solution, as seen in Figure 2.7, better quantitative agreement is seen with the numerical solution of the model equations using a finite number of discretization points. The results shown for $N=50,80$, and 200 are in nearly perfect agreement with the analytical solution at relatively high $\mathrm{pH}$, where the model predicts a simple wave and the effects of axial dispersion are negligible. However, in the shock transition zone, whose sharpness is affected by dispersion, the numerical results vary with $N$. For these conditions, the best fit of the experimental results is obtained with $N=80$, which provides good agreement with the experimental profile throughout the entire range of $\mathrm{pH}$ values. Although not shown for brevity, the 
chloride concentration profile, obtained from the effluent conductivity for this experiment, was also in similar agreement with this model prediction. Unfortunately, since the ion exchange equilibrium is not linear for our conditions, $N$ is not directly equivalent to the number of plates determined, for example, from an HETP test. Thus, a more complicated model, accounting explicitly for actual physical dispersion mechanisms is deemed necessary for a complete a priori prediction. Nevertheless it is apparent that, once $N$ is determined empirically for a given column, our simple model can be used to predict the effects of varying operating conditions. From a practical viewpoint, the behavior seen in Figure 2.7 could be used advantageously to create conditions where the initial shallow gradient separates a mixture of similar components, followed by a sharp drop in $\mathrm{pH}$ to strip late-eluting components from the column after the desired separation is complete. This would be analogous to a conventional strip step obtained by feeding multiple mobile phases at the column entrance, but with the added convenience that in this case the entire $\mathrm{pH}$ profile is the result of a single $\mathrm{pH}$ step at the column entrance.

A final consideration is the effect of temperature on the induced $\mathrm{pH}$ gradients. As discussed in the Methods section of this paper, the $p K_{a}$ values of the amine buffers used vary linearly with temperature with slopes between -0.020 and $-0.029{ }^{\circ} \mathrm{C}^{-1}$. Figure 2.8 shows the predicted induced $\mathrm{pH}$ gradients for the conditions of Figure 2.6 accounting for the effects of temperature on the buffers $p K_{a}$ values. As seen in this figure the effect of temperature on the induced $\mathrm{pH}$ gradient is significant suggesting that precise temperature control would be needed. This is however a general feature of anion exchange chromatography where amine buffers are typically used. 


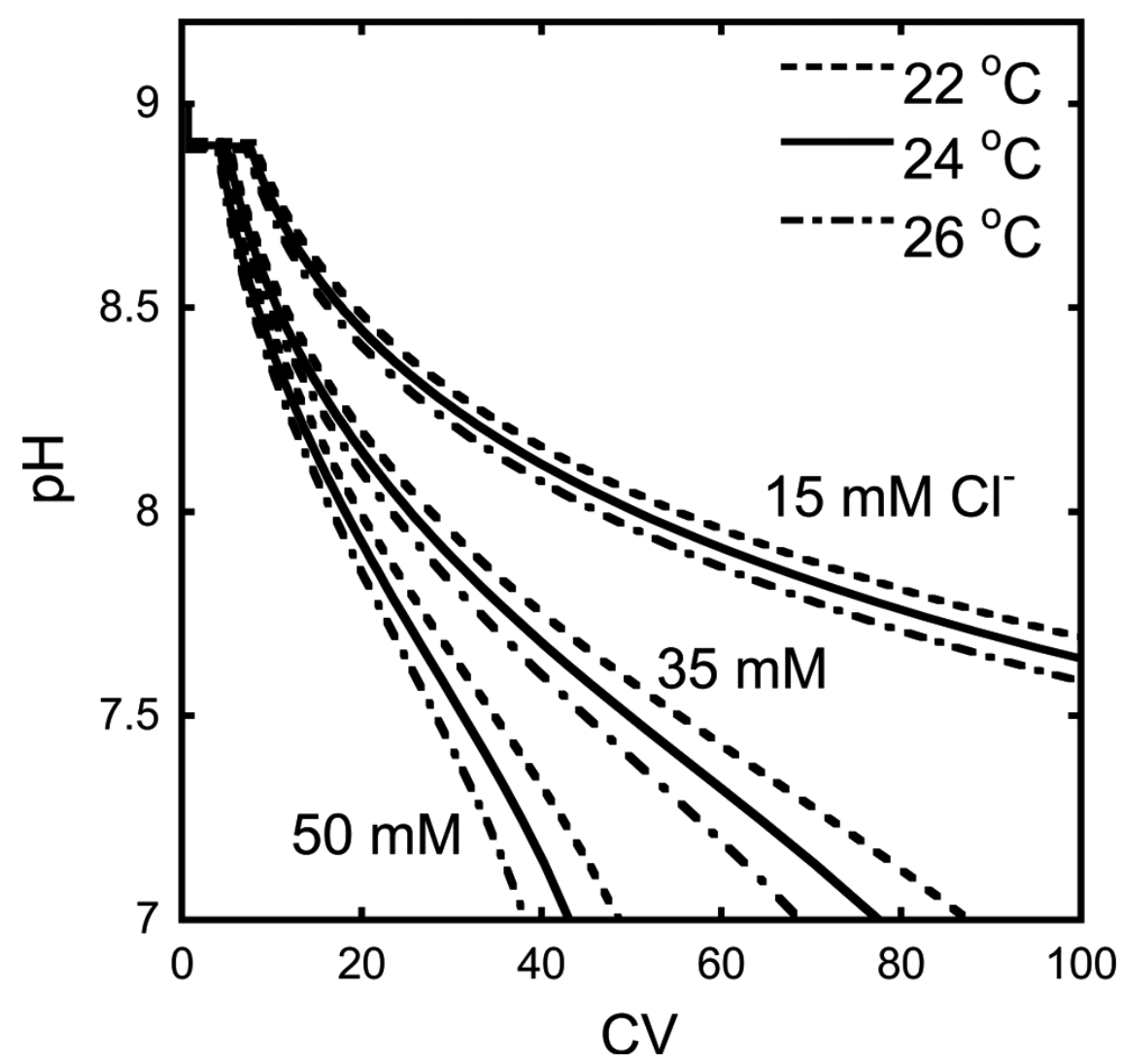

Figure 2.8 - Induced $\mathrm{pH}$ gradients for the conditions of Figure 6 predicted at 22, 24, and $26^{\circ} \mathrm{C}$ predicted by the model presented in this work accounting for the effects of temperature on the buffer pKa values based on the correlations in ref. (19). 


\subsubsection{Separation of $\mathrm{mAb}$ charge variants}

In this section we provide two application examples of the mixed-bed concept to protein separation in order to address two independent issues: (a) the ability to perform difficult protein separations, and (b) the absence of any effects of protein load on the $\mathrm{pH}$ gradient. Figure 2.9 demonstrates the separation of the deamidated mAb mixture described in the Materials section of this paper using a mixed-bed column containing 14\% AG 4-X4 and $86 \%$ SOURCE 30Q for the conditions of Figure $2.7(300 \mathrm{~cm} / \mathrm{h}, 20 \mathrm{~cm}$ column length) with a protein load of $2 \mathrm{mg}$ per $\mathrm{mL}$ of packed bed volume. For this purpose, the protein, dissolved in the initial $\mathrm{pH} 9$ buffer, was quickly applied to the column which was then washed with 5 column volumes of the initial buffer before changing over stepwise to the pH 7 elution buffer. Fractions were collected at the column outlet based on the UV trace at $280 \mathrm{~nm}$ as shown by the vertical bars in this figure. These fractions were concentrated using ultrafiltration, and subjected to IEF analysis using Coomassie blue stain. Ten $\mu \mathrm{g}$ of total protein were loaded in each lane, except for fraction 4 for which the load was between 2 and $3 \mu \mathrm{g}$. As seen in Figure 2.9, the deamidated mAb load contains three major and one minor band at $\mathrm{pI}$ values spanning from 8.2 , which is the $\mathrm{pI}$ of the native $\mathrm{mAb}$, to about 7.6. Although the UV trace shows multiple peaks, it is obvious that complete resolution was not attained. On the other hand, despite the relatively high mobile phase velocity $(300 \mathrm{~cm} / \mathrm{h})$, fractions with substantial homogeneity were obtained as indicated by the presence of only one major band for each of the fractions 1-3. Fraction 4 appears to be more heterogeneous, probably containing a broad range of more highly deamidated species with lower pIs and hence greater retentivity on anion exchangers. The rapid drop in $\mathrm{pH}$ for longer time obtained with the 

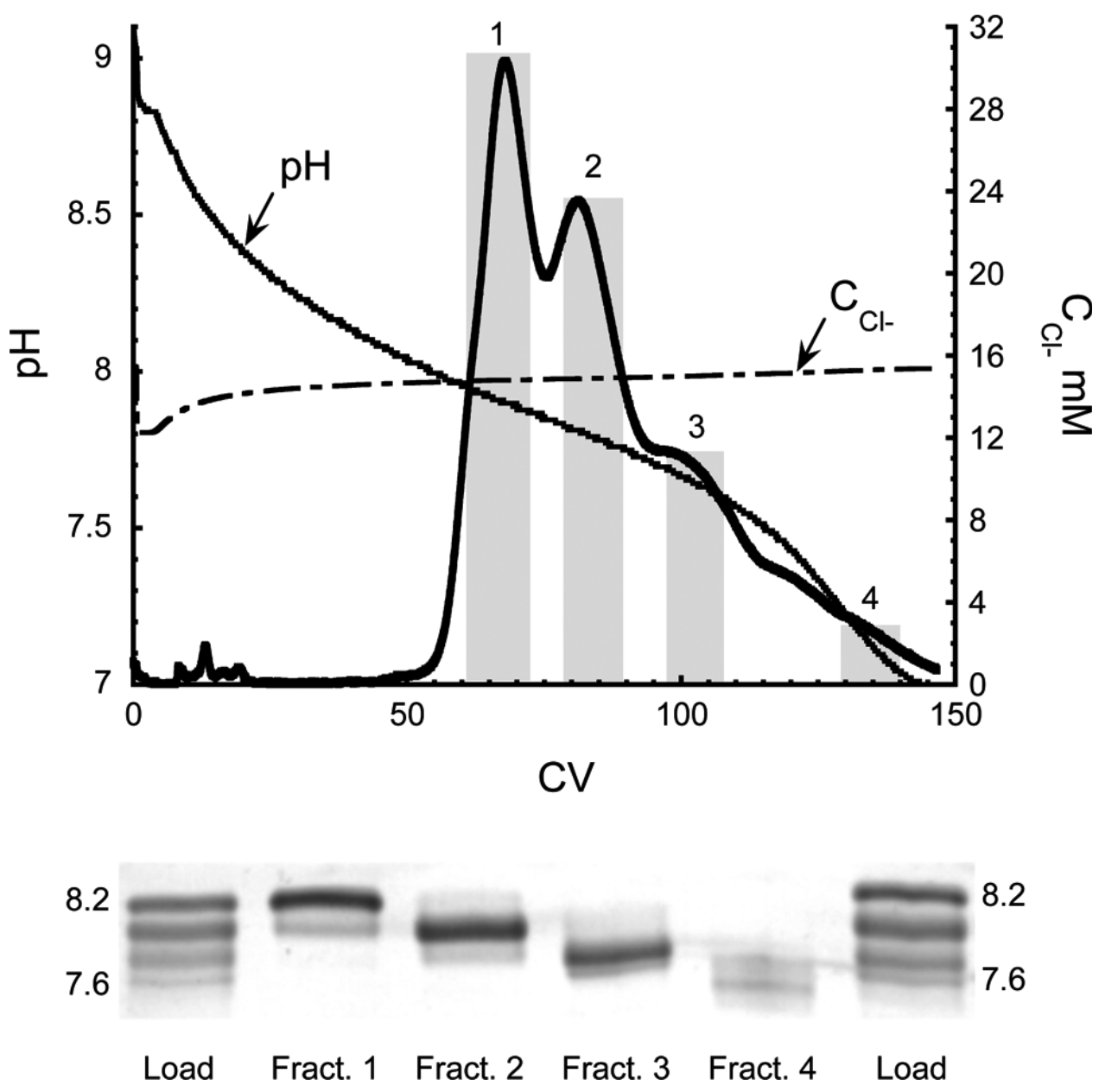

Figure 2.9 - Separation of deamidated mAb mixture with a mixed bed column containing 14\%AG 4-X4 and $86 \%$ SOURCE $30 \mathrm{Q}$ for the conditions of Figure 7 . The protein load was $2 \mathrm{mg} / \mathrm{mL}$ packed bed volume. Fractions were collected as indicated by the vertical grey bars. Solid and dashed lines show the $\mathrm{pH}$ and UV trace at $280 \mathrm{~nm}$ and the chloride concentration at the column outlet based on the conductivity trace. The figure at the bottom shows the IEF analysis results for the fractions along with $\mathrm{pI}$ values based on standard proteins. 
addition of 7\% BisTris to the buffer seems to do a good job stripping these variants in a relatively small volume. Based on the peak maxima and the $\mathrm{pH}$ trace, the elution $\mathrm{pH}$ values corresponding to peaks 1,2 , and 3 are approximately $7.9,7.8$, and 7.7, respectively. These values are somewhat lower than the corresponding estimated pI values determined by IEF $(8.2,8.0$, and 7.8 , respectively). This trend is consistent with the known behavior of chromatofocusing where proteins elute at $\mathrm{pH}$ lower than their $\mathrm{pI}$ on anion exchangers and at $\mathrm{pH}$ higher than their $\mathrm{pI}$ on cation exchangers $(9,11)$. It should be noted that in this proof-of-concept run no attempt was made to optimize the $\mathrm{pH}$ gradient to shorten its duration. Thus, elution occurred at relatively large $\mathrm{CV}$-values. The effect of the induced $\mathrm{pH}$ gradient duration on resolution will be considered in a future communication.

The second application example, shown in Figure 2.10, illustrates the effect of protein loading on the induced $\mathrm{pH}$ gradient formed with a mixed-bed column containing $10 \%$ AG 4-X4 and 90\% UNOsphere DQ. The non-deamidated mAb sample described in the Materials section was used for these experiments. Protein loads are given in this figure as $\mathrm{mg}$ of total protein per $\mathrm{mL}$ of packed bed volume. In each case, after loading the sample at $\mathrm{pH} 9$ and washing with the load buffer, elution was obtained with a $\mathrm{pH}$ step from 9 to 7 using buffer mixtures containing 97\% ethanolamine and 3\% Tris with $15 \mathrm{mM}$ chloride concentrations at $150 \mathrm{~cm} / \mathrm{hr}$. The results clearly confirm that the induced $\mathrm{pH}$ gradient was completely unaffected by the protein load and in good agreement with the prediction based on the analytical solution of the model equations, which is shown by the solid line. Thus, as predicted, $\mathrm{pH}$ gradient generation and protein binding were essentially decoupled through the use of the mixed-bed. Although IEF analyses were not conducted 


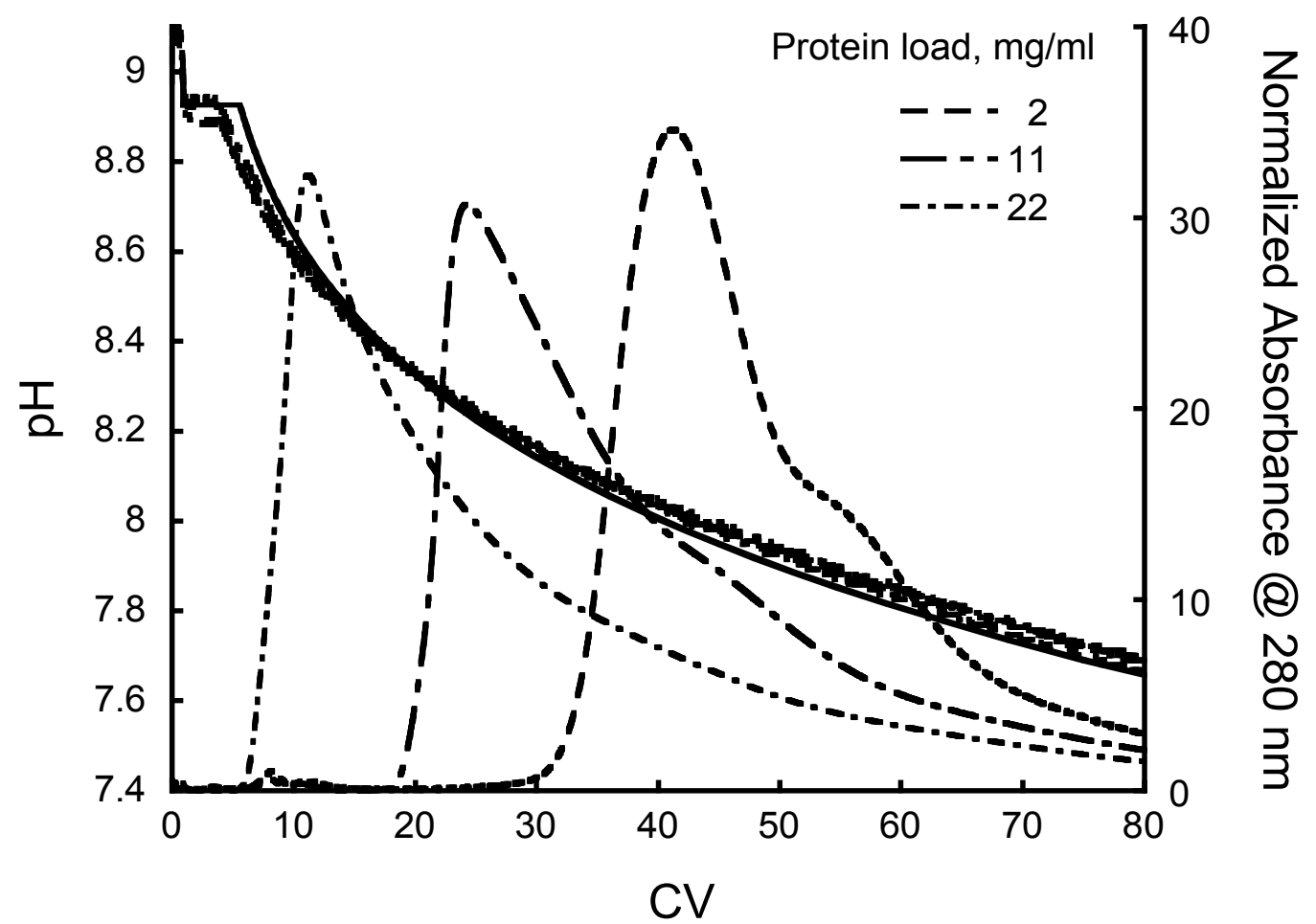

Figure 2.10 - $\mathrm{pH}$ gradients generated with a mixed-bed column containing 10\% AG 4-X4 and 90\% UNOsphere DQ at varying protein loads. The $\mathrm{pH}$ gradients were obtained with $\mathrm{pH}$ steps from 9 to $7 \mathrm{using}$ buffer mixtures containing 97\% ethanolamine and 3\% Tris with $15 \mathrm{mM}$ chloride concentrations. The protein elution profiles are normalized to peak area of the $2 \mathrm{mg} / \mathrm{mL}$ run to facilitate comparison. The solid line is the model prediction of $\mathrm{pH}$. Note that the experimental $\mathrm{pH}$ traces obtained at different protein loadings are virtually coincident. Mobile phase velocity $=150 \mathrm{~cm} / \mathrm{h}$; column length $=20 \mathrm{~cm}$. 
for these runs, the protein elution profiles shown in Figure 2.10 also show that separation of deamidated impurities was likely obtained at least at the lower protein loads. Increasing protein load obviously resulted in increasingly skewed peaks with earlier eluting maximum. Considering that the maximum mAb binding capacity of this resin is on the order of only $80 \mathrm{mg} / \mathrm{mL}$ (based on equilibrium isotherm measurements not shown here), the peak shapes obtained are likely a result of increasing non-linearity of the protein adsorption isotherm as the amount protein loaded approached the resin's binding capacity.

\subsection{Conclusions}

Induced $\mathrm{pH}$ gradients created by a step change in mobile phase $\mathrm{pH}$ using mixedbed columns of weak and strong anion exchange resins have been shown to be adjustable by varying concentration and type of buffers used, to be reproducible, and, in most cases, to be accurately predictable using a local equilibrium model. The duration of the induced $\mathrm{pH}$ gradients is controlled by the concentration and composition of the mobile-phase buffer and the weak base ligand content of the column. Increasing the buffer concentration or decreasing the weak ligand content by changing the ratio of weak and strong resin components results in gradients with a shorter duration. The $p K_{a}$ values of both the weak base resin and the non-interacting buffers determine the gradient shape. Mixtures of different buffering species can thus be used to obtain different $\mathrm{pH}$ gradient shapes including segmented $\mathrm{pH}$ gradients with different slopes in different regions.

The weak anion exchanger AG 4-X4 was used successfully in various mixtures with several different strong anion exchangers giving $\mathrm{pH}$ profiles that were independent of the particular strong anion exchanger used. Microscopic examination of embedded and 
stained columns show that this resin can be co-packed with several commercial strong anion exchangers resulting in a homogeneous distribution across column length and diameter. Although these experiments were limited to laboratory scale columns, it is likely that uniformly packed beds can also be obtained at the large scale provided that resins with reasonably well-matched particle sizes and density are used. As a practical application, the mixed-bed approach was demonstrated for the separation of the charge variants present in a deamidated $\mathrm{mAb}$ mixture. Although the separation was not optimized and was not complete, highly homogeneous fractions could be obtained with a $\mathrm{pH}$ gradient generated through a simple step change in buffer composition at the column entrance. Moreover, identical $\mathrm{pH}$ gradients could be obtained independent of protein load because $\mathrm{pH}$ gradient generation and protein binding occurred on separate phases in the mixed-bed.

As a practical tool for preparative separations, the mixed-bed approach has the advantage of simplicity and flexibility in that the same weak base resin can be used with multiple strong anion exchangers, each selected to optimize a particular separation. Compared to separations with $\mathrm{pH}$ gradients generated by applying a gradient at the entrance, separations with the mixed-bed columns presented in this work require only a step change in buffer. Thus, the gradient is not dialed in by programming a gradient pump, but is implemented through optimization of proper buffer compositions. This is also the case when our approach is compared with separations based on salt gradients. In order to obtain separations of protein charge variants with salt gradients at constant $\mathrm{pH}$, very shallow salt gradients would likely be needed, which could be difficult to generate reliably in a GMP setting. The gradients generated with our approach can be easily 
predicted with sufficient accuracy either using a simple equilibrium model (if only smooth $\mathrm{pH}$ transitions are expected) or using a numerical model that takes into account axial dispersion empirically (via a finite difference discretization of the equations) if shock waves are expected. Some disadvantages also exist. One is that a fraction of the column volume is not available for protein binding, but this can be minimized by using a weak ion exchanger with high ligand density. Another is associated with the potential complexity of mixing and co-packing different resins in the same column. Thus the advantages noted above have to be balanced against these potential disadvantages. In practice, the former are more likely to outweigh the latter when the separation is especially difficult and high resolution is required.

A final consideration is the predictability of protein elution and the effects of protein load on the separation. Since we have demonstrated that $\mathrm{pH}$ gradient generation and protein binding are effectively decoupled, it should be possible to predict these effects based on an experimental knowledge of protein chromatographic behavior on the strong resin component only, which will be presented in chapters 3 and 4 . 


\subsection{Symbols}

A Debye-Hückel constant

C mobile phase concentration $(\mathrm{mol} / \mathrm{L})$

$\mathrm{CV} \quad$ number of column volumes passed

$K_{a} \quad$ deprotonation equilibrium constant $(\mathrm{mol} / \mathrm{L})$

$K_{D} \quad$ distribution coefficient

$K_{w} \quad$ ionic product of water $(\mathrm{mol} / \mathrm{L})^{2}$

$L \quad$ column length $(\mathrm{cm})$

$N \quad$ number of axial discretization points in numerical solution

$q \quad$ adsorbed concentration based volume of resin solid ( $\mathrm{mol} / \mathrm{L}$ )

$q_{R}^{0} \quad$ concentration of weak base ligands in weak anion exchanger based on volume of resin solid (mol/L)

$t \quad$ time (s)

$u \quad$ mobile phase superficial velocity $(\mathrm{cm} / \mathrm{s})$

$v_{c} \quad$ characteristic velocity for simple waves $(\mathrm{cm} / \mathrm{s})$

$v_{s} \quad$ characteristic velocity for shock waves $(\mathrm{cm} / \mathrm{s})$

$V_{\text {col }} \quad$ column volume $(\mathrm{mL})$

$V_{R} \quad$ retention volume $(\mathrm{mL})$

$x \quad$ column axial coordianate $(\mathrm{cm})$

Greek symbols

$\varepsilon \quad$ extraparticle porosity

$\varepsilon_{p} \quad$ intraparticle porosity 
$\varepsilon_{t} \quad$ total column porosity

$\varphi_{w} \quad$ volume fraction of weak base resin in mixed-bed

$\gamma \quad$ thermodynamic activity coefficient 


\subsection{References}

1. Farnan, D.; Moreno, G. T. (2009) Multiproduct high-resolution monoclonal antibody charge variant separations by $\mathrm{pH}$ gradient ion-exchange chromatography. Anal. Chem., 81: 8846-8857.

2. Rea, J. C.; Moreno, G. T.; Lou, Y.; Farnan, D. (2011) Validation of a pH gradient-based ion-exchange chromatography method for high-resolution monoclonal antibody charge variant separations. J. Pharm. Biom. Anal., 54: 317323.

3. Ng, P. K.; He, J.; Snyder, M. A. (2009) Separation of protein mixtures using pHgradient cation-exchange chromatography. J. Chromatogr. A, 1216: 1372-1376.

4. Sluyterman, L.; Elgersma, O. (1978) Chromatofocusing: isoelectric focusing on ion-exchange columns I. general principles. J. Chromatogr., 150: 17-30.

5. Sluyterman, L.; Wijdenes, J. (1978) Chromatofocusing: isoelectric focusing on ion-exchange columns II. experimental verification. J. Chromatogr., 150: 31-44.

6. Liu, Y.; Anderson, D. J. (1997) Gradient chromatofocusing high-performance liquid chromatography. I. practical aspects. J. Chromatogr. A, 762: 207-217.

7. $\quad$ Bates, R. C.; Frey, D.D. (1998) Quasi-linear pH gradients for chromatofocusing using simple buffer mixtures: local equilibrium theory and experimental verification. J. Chromatogr. A. 814: 43-54.

8. Bates, R. C.; Kang, X.; Frey, D. D. (2000) High-performance chromatofocusing using linear and concave $\mathrm{pH}$ gradients formed with simple buffer mixtures. I. effect of buffer composition on the gradient shape. J. Chromatogr. A. 890: 25-36.

9. $\quad$ Kang, X.; Bates, R. C.; Frey, D. D. (2000) High-performance chromatofocusing using linear and concave $\mathrm{pH}$ gradients formed with simple buffer mixtures. II. separation of proteins. J. Chromatogr. A. 890: 37-43.

10. Pabst, T. M.; Carta, G.; Ramasubramanyan, N.; Hunter, A. K.; Mensah, P.; Gustafson, M. E. (2008) Separation of protein charge variants with induced $\mathrm{pH}$ gradients using anion exchange chromatographic columns. Biotechnol. Progr., 24: 1096-1106.

11. Pabst, T. M.; Antos, D.; Carta, G.; Ramasubramanyan, N.; Hunter, A. K. (2008) Protein separations with induced $\mathrm{pH}$ gradients using cation-exchange chromatographic columns containing weak acid groups. J. Chromatogr. A, 1181: 83-94. 
12. Pabst, T. M.; Carta, G.; Ramasubramanyan, N.; Hunter, A. (2008) Advances in chromatofocusing with unretained buffers challenging preparative protein separations. Paper presented at the $12^{\text {th }}$ International Symposium on Preparative and Industrial Chromatography and Allied Techniques - SPICA2008: Zurich, Switzerland.

13. Davies, C. W. (1962) Ion Association; Butterworths: London, U.K.

14. Helfferich, F. (1962) Ion Exchange; McGraw-Hill Book Company, Inc.: New York, United States

15. Pabst, T. M.; Carta, G. (2007) pH transitions in cation exchange chromatographic columns containing weak acid groups. J. Chromatogr. A, 1142: 19-31.

16. Bennett, B. J.; Helfferich, F. (1984) pH Waves in Anion Exchange Columns, in Ion Exchange Technology, Naden, D.; Streat, M. Eds. Chichester, U.K., 322-330.

17. Hagel, L.; Ostberg, M.; Andersson, T. (1996) Apparent pore size distributions of chromatography media. J. Chromatogr. A, 743: 33-42.

18. Corbett, R.; Carta, G.; Iskra, T.; Gallo, C.; Godavarti, R., Salm, J.R. (2013) Structure and protein adsorption mechanisms of clean and fouled tentacle-type anion exchangers used in a mAb polishing step. J. Chromatogr. A, 1278: 116125.

19. Beynon, R.; Easterby, J. (1996) Buffer Solutions; Bath Press: Bath, U.K.

20. Perez-Almodovar, E. X.; Tao, Y.; Carta, G. (2011) Protein adsorption and transport in cation exchangers with a rigid backbone matrix with and without polymeric surface extenders, Biotechnol. Progr., 27: 1264-1272.

21. Lenhoff, A. M. (2011) Protein adsorption and transport in polymer-functionalized ion-exchangers. J. Chromatogr. A, 1218: 8748-8759.

22. Carta, G.; Jungbauer, A. (2010) Protein Chromatography: Process Development and Scale-up; Wiley-VCH Verlag GmbH \& Co.: Darmstadt,Germany. 


\section{Predicting the resolution of $\mathrm{mAb}$ charge variants using mixed-beds of strong and weak anion exchange resins created with step-induced $\mathrm{pH}$ gradients at low protein loads}

\subsection{Introduction}

The separation of protein charge variants resulting from post translational modifications is industrially important in the production of many biopharmaceuticals since such charge variants can exhibit diminished pharmacological potency and/or stability compared to the native form (1). Ion exchange chromatography is commonly used for these separations as the strength of electrostatic interaction often varies for different variants. However, because of their similar molecular properties, these separations often require operation with either salt or $\mathrm{pH}$ gradients. In principle, $\mathrm{pH}$ gradients can be advantageous, since they can provide improved selectivity over salt gradients while allowing separation at low ionic strengths (2-4). In industrial practice, however, despite their advantages, $\mathrm{pH}$ gradients are seldom used, because of difficulties in reproducibly generating and controlling them at manufacturing scale.

Gradients in $\mathrm{pH}$ can be generated externally or can be induced within the column. Externally generated $\mathrm{pH}$ gradients are created by varying the $\mathrm{pH}$ of the mobile phase upstream of the column entrance. This is often achieved through the use of programmed in-line mixing to continuously vary the ratio of two buffer solutions. When applied to a strong ion exchanger, in the absence of interactions between buffer components and the stationary phase, the ensuing $\mathrm{pH}$ wave travels through the column at the velocity of the mobile phase. Induced $\mathrm{pH}$ gradients, on the other hand, can be generated within the column with a step change in $\mathrm{pH}$ applied at the column entrance either using retained 
buffering species, such as the ampholytes used in chromatofocusing $(5,6)$, or with unretained buffering species using a weak ion exchanger as the stationary phase. Under certain conditions, although a step change is applied at the column entrance, a smooth, reproducible $\mathrm{pH}$ gradient can be formed within the column. Since these gradients travel at a rate slower than the mobile phase velocity, individual species are focused at specific $\mathrm{pH}$ values along the traveling wave $(7,8)$.

Compared to operation with ampholytes, using a weak ion exchanger with unretained buffers is generally simpler and results in a process that is easier to predict. In this case, the $\mathrm{pH}$ gradients can be predicted solely based on the deprotonation constant and concentration of the weak base ligands and on the $p K_{a}$ values of the buffering species in the mobile phase (9-12). The former determine the $\mathrm{pH}$ range over which a smooth gradient can be induced and its overall duration, while the latter determine the shape of the $\mathrm{pH}$ gradient. Although several authors have already demonstrated empirically the resolution of protein mixtures using unretained buffers with either weak anion or weak cation exchangers (13-16), several drawbacks exist. The first is that, protein retention is generally difficult to predict because the charge of the weak ligands changes as the $\mathrm{pH}$ varies. The second is that, since the weak ion exchange ligands become uncharged at extreme $\mathrm{pH}$ values, unpredictable hydrophobic interactions can come into play altering selectivity and potentially affecting biomolecular properties. Finally, since the ligands responsible for the generation of the $\mathrm{pH}$ gradient are also responsible for protein binding, distortions in the $\mathrm{pH}$ profile can occur at the high protein loads that are typical of industrial chromatography. Even though in a polishing step, where the goal is to obtain resolution of a hard-to-remove impurity, the protein load averaged over the entire column 
volume is likely to be relatively low, the local adsorbed protein concentration can still be close to saturation thereby affecting the local $\mathrm{pH}$ profile if a single resin is used.

In our previous work in Chapter 2 (17), we have shown that some of these drawbacks can be overcome by using a mixed-bed column containing a small-pore weak ion exchanger packed together with a large-pore strong ion exchanger. In this approach, the small pores in the weak ion exchanger allow access only to small ions, thereby controlling $\mathrm{pH}$, but prevent proteins from entering the resin beads and thus interacting with the weak ligands. The large pores of the strong ion exchanger provide access to proteins allowing their separation through selective interaction with its strong ligands, without affecting the internally generated $\mathrm{pH}$ gradient. As shown in our prior work (17), because $\mathrm{pH}$ gradient generation and protein binding are effectively decoupled, the impact of protein load on the induced $\mathrm{pH}$ gradient is minimized and the $\mathrm{pH}$ gradient can be predicted accurately based on the behavior of the weak ion exchanger alone. Design flexibility is also improved as a single weak ion exchanger can be paired with different strong ion exchangers selected for different separation applications to optimize protein loading capacity, mass transfer, selectivity, and, ultimately, resolution. A particular advantage of the mixed-bed approach is that modeling and prediction of resolution are simplified. Weak and strong ion exchangers can be tested independently, the former for their ability to generate $\mathrm{pH}$ gradients and the latter for their ability to resolve protein mixtures at constant $\mathrm{pH}$. The prediction of resolution in a mixed-bed with varying $\mathrm{pH}$ is thus theoretically possible by combining the independent predictions of the effects of the two resins through a suitable model. 
This work has thus three major goals. The first is to develop a model to predict resolution obtained with $\mathrm{pH}$ gradients in mixed bed columns based on the independent determination of the ion-exchange properties of the weak base resin and of the chromatographic properties of the strong base resin. The second is to compare model predictions with experimental results obtained for the separation of the charge variants of a monoclonal antibody. The third is to demonstrate how the model can be used to select conditions that yield the desired resolution by "tuning" the parameters that determine the induced $\mathrm{pH}$ gradient.

\subsection{Theoretical development}

\subsubsection{Prediction of induced $\mathrm{pH}$ gradients in mixed-bed columns}

The model used to predict the induced $\mathrm{pH}$ gradients for a column containing a mixture of weak and strong anion exchangers was developed in our prior work (17). Thus, only a brief summary is provided here. With reference to a mobile phase containing one or more amine buffering species and chloride as the only counterion, the model assumes that: (a) the two ion exchangers are uniformly distributed throughout the column; (b) the buffering species do not interact with either the weak or the strong anion exchanger; (c) exchange of chloride and hydroxide ions occurs only on the weak anion exchange ligands while the strong anion exchange ligands remain in the chloride form; and (d) the mass transfer rate for ions is high so that local equilibrium is maintained between the stationary and mobile phases. The first assumption is corroborated by experiments reported in chapter 2, where embedding mixed-bed columns of the type used in this work in a resin, sectioning, and imaging the different particles showed that there 
was a random distribution across both column length and diameter. The second assumption is justified by the fact that the buffering species considered here are positively charged or neutral. The third assumption stems from the fact that the $p K_{a}$ of strong anion exchange ligands (e.g. quaternary ammonium ion) are very large $\left(p K_{a}>12\right)$ and that chloride ion is always in large excess compared to hydroxide at the $\mathrm{pH}$ values considered in this work. The last assumption stems from the relatively large diffusivity of the small ions (order of $10^{-5} \mathrm{~cm}^{2} / \mathrm{s}$ ). Based on these assumptions, the four components of the model are as follows:

a. Buffer species deprotonation equilibria

$$
C_{B_{i} H^{+}}=\frac{C_{B_{i}}^{0}}{1+\frac{K_{a, B_{i}}}{C_{H^{+}}}}
$$

b. Solution electroneutrality

$$
C_{H^{+}}+\sum_{i} C_{B_{i} H^{+}}=\frac{K_{W}}{C_{H^{+}}}+C_{C l^{-}}
$$

c. Chloride-hydroxide exchange equilibrium

$$
q_{w, C I^{-}}=\frac{1}{2}\left\{\frac{-C_{H^{+}} C_{C I^{-}}}{K_{R, w}}+\left[\left(\frac{C_{H^{+}} C_{C I^{\prime}}}{K_{R, w}}\right)^{2}+\frac{4 q_{R, w}^{0} C_{H^{+}} C_{C I^{\prime}}}{K_{R, w}}\right]^{\frac{1}{2}}\right\}
$$

\section{$\underline{\text { d. Material balances for the column }}$}

$$
\begin{gathered}
u \frac{\partial C_{B_{i}}}{\partial x}+\varepsilon_{t} \frac{\partial C_{B_{i}}}{\partial t}=0 \\
u \frac{\partial C_{C l^{-}}}{\partial x}+\varepsilon_{t} \frac{\partial C_{C l^{-}}}{\partial t}+(1-\varepsilon) \varphi_{w}\left(1-\varepsilon_{p, w}\right) \frac{\partial q_{w, C l^{-}}}{\partial t}=0
\end{gathered}
$$


In these equations, $C_{B_{i} H^{+}}$and $C_{B_{i}}^{0}$ are the protonated and total concentrations of amine $\mathrm{i}$, respectively, $K_{a, B_{i}}$ is the corresponding deprotonation equilibrium constant, $K_{W}$ is the ionic product of water, $q_{R, w}^{0}$ the concentration of weak base ligands in the weak anion exchanger, $K_{R, w}$ is the corresponding deprotonation constant, $u, x$, and $t$ are mobile phase superficial velocity, column length coordinate, and time, respectively, and $\varepsilon_{t}=\varepsilon+(1-\varepsilon)\left[\varphi_{w} \varepsilon_{p, w}+\left(1-\varphi_{w}\right) \varepsilon_{p, s}\right]$ is the total column porosity. The first term in this expression for $\varepsilon_{t}$ accounts for retention in the extraparticle void fraction, $\varepsilon$, while the second accounts for retention in the intraparticle pores, characterized by the porosities $\varepsilon_{p, w}$ and $\varepsilon_{p, s}$ of the weak and strong ion exchangers respectively, with $\varphi_{w}$ equal to the volume fraction of the weak anion exchanger in the mixed-bed. Note that $q$-values appearing in these equations are expressed per unit of solid resin volume of the weak base resin, thus excluding any contribution due to retention in the intraparticle void space.

As shown in ref. (17), two different methods can be used to solve these equations, the method of characteristics and a numerical algorithm. The former is semi-analytical and provides the limiting case when there is no axial dispersion. The latter accounts for non-idealities through the numerical dispersion introduced by a finite difference discretization scheme. Similar results were obtained with the two methods for conditions under which smooth $\mathrm{pH}$ gradients were obtained. The effect of dispersion was significant only for conditions where abrupt transitions (shock waves) were predicted in the $\mathrm{pH}$ gradients. The resin properties needed to make these calculations ( $\varepsilon_{p, w}=0.44, \varepsilon_{p, s}=0.63$, $q_{R, w}^{0}=3.45 \mathrm{~mol} / \mathrm{L}$ resin solid, and $\left.p K_{R, w}=-\log K_{R, w}=9.75\right)$ were obtained in our 
previous work (17). The amine buffer $p K_{a}$-values and their temperature dependences were obtained from Beynon and Easterby (18).

\subsubsection{Prediction of protein retention and band broadening in mixed-bed}

\section{columns}

Predicting protein retention in mixed-bed columns requires a description of protein adsorption equilibrium and kinetics in the strong ion exchanger component of the mixed-bed as a function of both $\mathrm{pH}$ and buffer composition. The approach used in our work to describe protein adsorption equilibrium is based on the stoichiometric displacement model, which regards protein binding as the result of the following ion exchange process (19-21):

$$
\mathrm{P}_{i}^{-z_{i}}+z_{i} \mathrm{RCl} \rightleftharpoons \mathrm{R}_{z_{i}} \mathrm{P}_{i}+z_{i} \mathrm{Cl}^{-}
$$

where $z_{i}$ is the protein effective binding charge, equal to the number of chloride counterions exchanged. Protein binding to the weak anion exchanger is neglected based on the assumption that its pores are sufficiently small to exclude protein molecules and that the external surface area of the particles is insignificant. Limiting our analysis to the linear isotherm case, which is obtained at low protein loads, protein binding to the strong anion exchanger is thus described by the following equation (18-20):

$$
q_{s, i}=\frac{K_{e, i}\left(q_{R, s}^{0}\right)^{z_{i}}}{\left(C_{C l^{-}}\right)^{z_{i}}} C_{i}
$$

where $K_{e, i}$ is the equilibrium constant for the protein-chloride exchange and $q_{R, s}^{0}$ is the concentration of charged ligands. While $q_{R, s}^{0}$ is theoretically constant for a strong ion exchanger, both $K_{e, i}$ and $z_{i}$ can vary with $\mathrm{pH}$ as the protonation of the charged residues 
on the protein varies. Additionally, these parameters can also depend on the type and concentration of the buffer $(19,22,23)$. Thus an empirical determination of their values is generally needed.

With regards to adsorption kinetics, diffusional mass transfer in the pores of the strong ion exchanger is expected to be dominant when the reduced velocity at which the process is operated exceeds about 100 (24). Although pore diffusion could be modeled rigorously by taking into account concentration gradients within the particles, a simpler formulation based on the linear driving force (LDF) model (25) has been adopted in this work. Accordingly, mass transfer of each protein in the strong anion exchanger is described by the following equation:

$$
\frac{\partial \bar{q}_{s, i}}{\partial t}=\frac{60 D_{e, i}}{d_{p}^{2}}\left(C_{i}-C_{i}^{*}\right)
$$

where $\bar{q}_{s, i}=\varepsilon_{p, s} K_{D, i} C_{i}+\left(1-\varepsilon_{p, s}\right) q_{s, i}$ is the average protein concentration in the particle, $D_{e, i}$ is the protein effective pore diffusivity, $d_{p}$ is the particle diameter, and $C_{i}^{*}$ is the protein concentration in equilibrium with $\bar{q}_{s, i} . K_{D, i}$ is the partition coefficient for unbound protein molecules between the mobile phase and the liquid contained within the pores. Based on Eq. (3.7), we have:

$$
C_{i}^{*}=\frac{\bar{q}_{s, i}}{\varepsilon_{p, s} K_{D, i}+\left(1-\varepsilon_{p, s}\right) K_{e, i}\left(q_{R, s}^{0}\right)^{z_{i}} /\left(C_{C l}\right)^{z_{i}}}
$$

The final component of the model is the following mass balance for each protein in the column:

$$
u \frac{\partial C_{i}}{\partial x}+\varepsilon \frac{\partial C_{i}}{\partial t}+(1-\varepsilon)\left(1-\varphi_{w}\right) \frac{\partial \bar{q}_{s, i}}{\partial t}=0
$$

Note that axial dispersion is neglected in this equation under the assumption that bandbroadening is controlled by the rate of mass transfer in the strong ion exchanger. Equations (3.7)-(3.10), written for each protein, are coupled to the equations describing 
ion interactions with the weak ion exchanger, Eqs. (3.1)-(3.5), and solved simultaneously to predict protein retention and band broadening in the mixed-bed column. A numerical solution was obtained by discretizing the spacial derivatives by backwards finite differences and solving the resulting system of ordinary differential equations by Gear's method using subroutine DVIPAG in the IMSL ${ }^{\circledR}$ Numerical Libraries (Rogue Wave Software, Boulder, CO, USA). The number of discretization points used for the calculations was 100 as in our previous work (17). This value was sufficiently large that numerical dispersion had no apparent effect on either the predicted $\mathrm{pH}$ gradient, which was controlled by the gradual wave behavior described by Eqs. (3.1)-(3.5), or on protein band broadening in the $\mathrm{pH}$ gradient runs, which was controlled by the mass transfer effects described by Eq. (3.8).

\subsection{Materials and methods}

\subsubsection{Materials}

The resins used in this work are AG 4-X4 from Bio-Rad Laboratories (Hercules, CA, USA) and SOURCE 30Q from GE Healthcare (Piscataway, NJ, USA). Their basic properties are summarized in Table 3.1. AG 4-X4 is a weak anion exchanger with trimethylamine functional groups, has a $1.4 \mathrm{kDa}$ size exclusion limit, and is comprised of irregular particles, $50-200 \mu \mathrm{m}$ in size. SOURCE $30 \mathrm{Q}$ is a strong anion exchanger based on a poly(styrene-divinyl benzene) matrix, and has large pores, a high size exclusion limit, and a narrow particle distribution with average diameter $28 \mu \mathrm{m}$ (17). 
Table 3.1 - Resin properties

\begin{tabular}{|l|c|c|}
\hline Resin & AG 4-X4 & SOURCE 30Q \\
\hline Functionality & $\begin{array}{c}\text { Tertiary } \\
\text { amine }\end{array}$ & $\begin{array}{c}\text { Quaternary } \\
\text { ammonium ion }\end{array}$ \\
\hline Mean particle diameter, $d_{p}(\mu \mathrm{m})[17]$ & $50-200^{(\mathrm{a})}$ & 28 \\
\hline Intraparticle porosity, $\varepsilon_{p}^{\left({ }^{(b)}\right.}[17]$ & 0.44 & 0.63 \\
\hline Size exclusion limit $(\mathrm{nm})^{(\mathrm{c})}[17]$ & $<2$ & $>40$ \\
\hline Weak base content in $\mathrm{mol} / \mathrm{L}$ resin solid $[17]$ & 3.45 & 0.427 \\
\hline Strong base content in mol/L resin solid & - & - \\
\hline
\end{tabular}

(d) Irregular shape - values given are the range of longest dimensions observed for hydrated particles

(e) Based on retention of glucose

(f) Hydrodynamic radius of dextran giving $K_{D}=0$

(g) Based on potentiometric titrations 
Chemicals used in buffer preparation were of ACS grade and were obtained from Thermo Fisher Scientific (Waltham, MA, USA). A monoclonal antibody (mAb) (IgG1, $M_{r} \sim 150 \mathrm{kDa}, \mathrm{pI} \sim 8.2$ ) was provided by MedImmune (Gaithersburg, MD, USA). The mAb sample was essentially $100 \%$ monomer based on size exclusion chromatography with a Superdex 200 column from GE Healthcare (Piscataway, NJ, USA). In separate experiments, the $\mathrm{mAb}$ was found to contain a major acidic variant with $\mathrm{pI} \sim 8.0$ accounting for about $20 \%$ of the total protein plus additional minor, more acidic variants with pI around 7.8 accounting for another $5 \%$ of the total. These variants could be distinguished by isoelectric focusing with precast IsoGel ${ }^{\circledR}$ Agarose IEF plates ( $\mathrm{pH}$ 7-11) from Lonza, Inc. (Allandale, NJ, USA) as described in ref. (17) and quantified by HPLC with a ProPac WCX-10 (Dionex, Sunnyvale, CA, USA) pellicular cation exchange column at pH 6.75 as described in ref. (26). While only minimal resolution was obtained by salt gradient anion exchange chromatography using SOURCE 30Q alone, as shown below, good resolution was obtained using a mixed-bed of AG 4-X4 and SOURCE 30Q with an induced $\mathrm{pH}$ gradient. In this case, two distinct peaks were observed, one containing the native $\mathrm{mAb}$ and the other the more strongly retained major acidic variant. Two separate samples with $90 \%$ purity of the native $\mathrm{mAb}$ and with $70 \%$ purity of the major acidic variant, respectively, were obtained by pooling fractions collected from several runs, concentrated to $1 \mathrm{~g} / \mathrm{L}$ by ultrafiltration with a $30 \mathrm{kDa}$ MWCO membrane, and refrigerated. These samples were used to independently characterize the chromatographic behavior of the native $\mathrm{mAb}$ and of the major acidic variant on SOURCE $30 \mathrm{Q}$. The purity of these samples was adequate to determine retention properties from 
gradient elution experiments, as it was possible to accurately determine the chloride concentration at elution from the peak maximum.

Buffers containing ethanolamine $\left(p K_{a}=9.50\right.$ at $\left.25{ }^{\circ} \mathrm{C}(18)\right)$ or Tris $\left(p K_{a}=8.06\right.$ at $25^{\circ} \mathrm{C}(18)$ ) and buffers containing mixtures of the two were prepared by adding the amine species in free-base form to $\mathrm{HCl}$ solutions of known concentration in the amounts needed to obtain the desired $\mathrm{pH}$. All experiments were conducted at room temperature, $24 \pm 2{ }^{\circ} \mathrm{C}$. Since temperature affects the $p K_{a}$ of the amine buffers used, the temperature was carefully monitored. The $\mathrm{pH}$ measurements were made with a Fisher Scientific Accumet combination electrode (Fisher Scientific, Pittsburgh, PA, USA).

\subsubsection{Methods}

\section{Resin charge density}

The weak base content of AG 4-X4 as given in Table 3.1 was determined in our prior work (17). The charge density of SOURCE 30Q, also reported in Table 3.1, was determined by packing a resin sample in a $5 \times 50 \mathrm{~mm}$ Tricorn column from GE Healthcare (Piscataway, NJ, USA), equilibrating it with a $15 \mathrm{mM}$ Tris- $\mathrm{HCl}$ solution at $\mathrm{pH} 8$, and applying a step-change to a $15 \mathrm{mM}$ Tris-benzoate solution also at $\mathrm{pH}$. An ÄKTA Explorer 10 unit (also from GE Healthcare) was used for these experiments at a flow rate of $1 \mathrm{~mL} / \mathrm{min}$. Benzoic acid, with a $p K_{a}$ of 4.2 (18), is negatively charged at $\mathrm{pH} 8$ and displaces the chloride ions initially present in the resin. A sharp breakthrough of benzoate ion is thus obtained, which can be monitored by UV at $280 \mathrm{~nm}$. Integration of the area above the resultant curve is then used to determine the resin charge density by material balance. The resulting value was $0.427 \mathrm{~mol} / \mathrm{L}$ of resin solid, which corresponds, approximately, to $100 \mu \mathrm{mol} / \mathrm{ml}$ of packed bed based on the extraparticle and intraparticle 
porosities of 0.35 and 0.63 , respectively. It should be noted that this value is to be regarded as an upper limit since we cannot completely exclude the possibility that nonelectrostatic interactions contributed, to some extent, to the retention of the benzoate front.

\section{Protein adsorption equilibrium and rate parameters}

The parameters describing protein retention on SOURCE 30Q were obtained from linear gradient elution (LGE) experiments at different $\mathrm{pH}$ values. These experiments were conducted with the SOURCE $30 \mathrm{Q}$ resin packed in a $5 \times 50 \mathrm{~mm}$ Tricorn column (GE Healthcare, Piscataway, NJ, USA) with $0.1 \mathrm{mg}$ injections of the mAb. After washing with $5 \mathrm{CV}$ of the running buffer $(10 \mathrm{mM}$ ethanolamine- $\mathrm{HCl})$ the column was eluted with linear gradients from $10 \mathrm{mM}$ ethanolamine- $\mathrm{HCl}$ to $150 \mathrm{mM}$ ethanolamine- $\mathrm{HCl}$ with varying slopes at different $\mathrm{pH}$ values. LGE experiments were also conducted with mobile phases containing Tris- $\mathrm{HCl}$ alone and $10 \mathrm{mM}$ ethanolamine- $\mathrm{HCl}$ with $\mathrm{NaCl}$. LGE results were analyzed by the method of Yamamoto and co-workers (27-29) as discussed below.

The mAb effective pore diffusivity in SOURCE 30Q was determined from a van Deemter curve obtained for non-binding conditions. For this purpose $20 \mu \mathrm{L}$ injections of the $\mathrm{mAb}$ dissolved in $10 \mathrm{mM}$ ethanolamine- $\mathrm{HCl}$ at $\mathrm{pH} 9$ containing $1 \mathrm{M} \mathrm{NaCl}$ were made to the SOURCE 30Q column described above and eluted isocratically at mobile phase superficial velocities from 75 to $1200 \mathrm{~cm} / \mathrm{h}$. The first and second central moments of the ensuing peaks were calculated numerically and the HETP calculated accordingly including corrections for the extra-column void volume and dispersion.

\section{Mixed-bed pH gradient separations}

Mixed-beds of AG 4-X4 and SOURCE 30Q were prepared by mixing the two resins in specified volumetric proportions and packing the mixture as described in ref. 
(17) in a 5x200 mm Tricorn column (GE Healthcare, Piscataway, NJ, USA) with a bed height of $20.0 \pm 0.2 \mathrm{~cm}$. After equilibration with the initial buffer $(\mathrm{pH}$ between 8.9 and 9.0), samples containing 1 to $11 \mathrm{mg}$ of the crude protein dissolved in the initial buffer were applied to the column, followed by a $5 \mathrm{CV}$ wash step with the same buffer. The mobile phase was then stepped to a $\mathrm{pH} 7$ solution with the same chloride concentration (12.5 to $50 \mathrm{mM})$ as the initial buffer. Elution was monitored using the UV, conductivity, and $\mathrm{pH}$ detectors of the ÄKTA Explorer 10 unit. Fractions of the column effluent were also collected and analyzed off-line for more precise determination of $\mathrm{pH}$. Protein concentrations were calculated from the UV detector data using the known extinction coefficient according to Lambert-Beer's law. The mobile phase velocity for these experiments was $300 \mathrm{~cm} / \mathrm{h}$.

\subsection{Results and discussion}

\subsubsection{Protein retention as a function of $\mathrm{pH}$ and mobile phase composition}

LGE experiments were conducted with the SOURCE 30Q column at $\mathrm{pH}$ values between 7.75 and 9.00 in $0.25 \mathrm{pH}$ increments. Figure 3.1 shows representative results for native $\mathrm{mAb}$ and the major acidic variant at $\mathrm{pH} 8.0$ with ethanolamine- $\mathrm{HCl}$ gradients (Figure 3.1a and 3.1b) and with $\mathrm{NaCl}$ gradients (Figure 3.1c), all with identical gradient slopes based on the chloride concentration. Figure 3.1a also gives two representative LGE results for the native $\mathrm{mAb}$ with a Tris- $\mathrm{HCl}$ gradient. In each case elution occurred at lower chloride concentration as the gradient length was increased. It is also apparent that the chloride concentration at elution was dependent on the buffer 

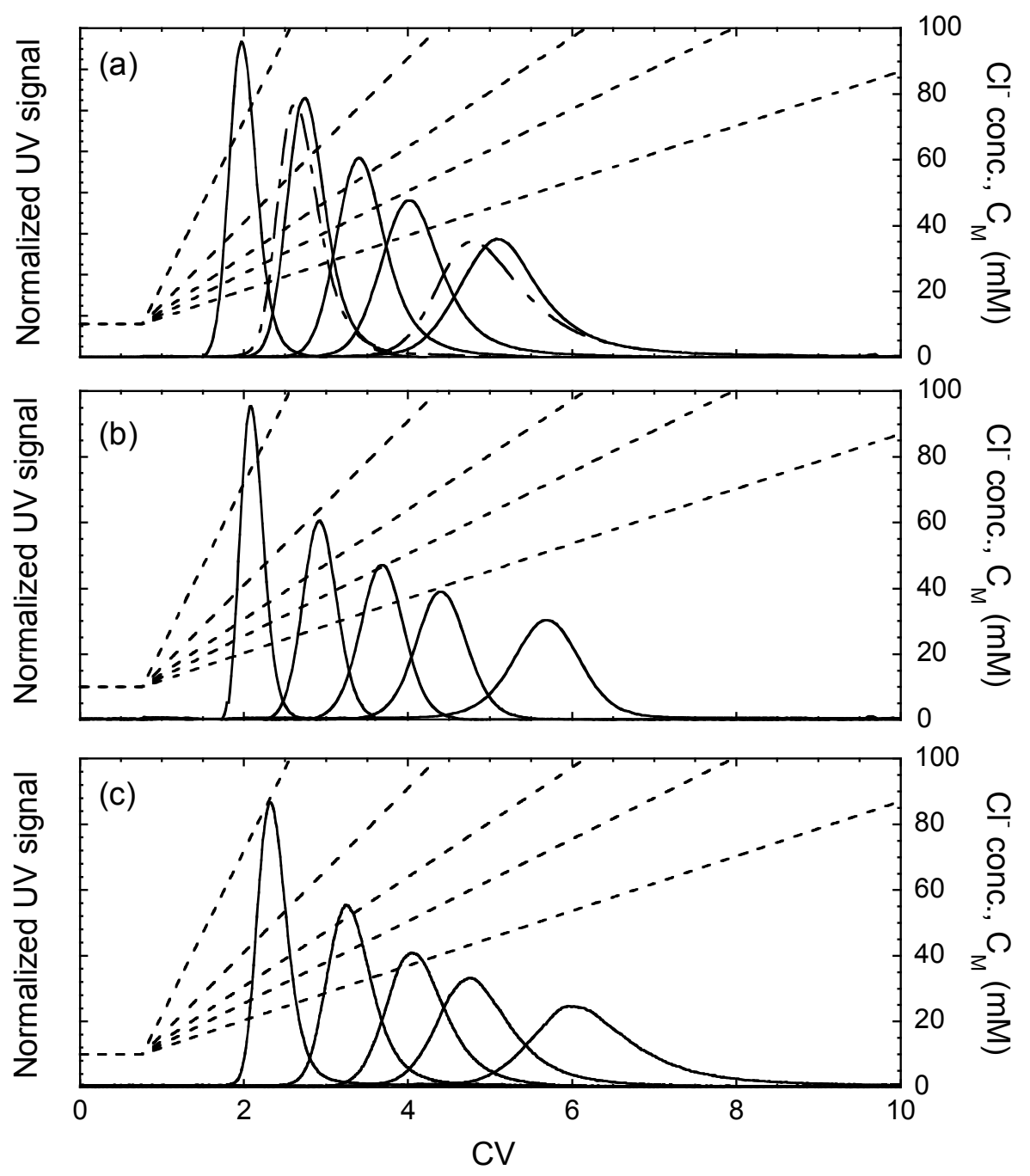

Figure 3.1 - LGE chromatograms for SOURCE 30Q column at $\mathrm{pH}$ 8.0. (a) native mAb with ethanolamine$\mathrm{HCl}$ gradients (solid lines) and with Tris- $\mathrm{HCl}$ gradients (dash-dotted lines); (b) major acidic variant with ethanolamine- $\mathrm{HCl}$ gradients; (c) native $\mathrm{mAb}$ with $\mathrm{NaCl}$ gradient in $10 \mathrm{mM}$ ethanolamine- $\mathrm{HCl}$. Normalized gradient slopes were $\gamma=3,4.5,6,9$, and $18 \mathrm{mM}$ chloride in all three cases with the gradient starting at 10 $\mathrm{mM}$ chloride. Column volume $=0.98 \mathrm{~mL}, L=5 \mathrm{~cm}, u=150 \mathrm{~cm} / \mathrm{h}$. 
species. While ethanolamine and Tris gave nearly identical results, $\mathrm{NaCl}$ gave very different retention with higher chloride concentration needed for elution compared to the amine buffers. The reason for the differences between $\mathrm{NaCl}$ and the amine- $\mathrm{HCl}$ eluents is not known, but it may be due to association of the amine species with the protein, which, in turn, could result in weaker binding. Since our $\mathrm{pH}$ gradient experiments involved only amine buffers, quantitative analyses were conducted only for the ethanolamine- $\mathrm{HCl}$ gradient data.

The relationship between the normalized gradient slope, $\gamma=\beta L / v$, and the mobile phase modifier (chloride ion in our case) at which each protein elutes from the column, $C_{C l, i}^{E}$, is given by $(24,27)$ :

$$
\gamma=\int_{C_{C l^{-}}^{I}}^{C_{C l^{-}, i}^{E}} \frac{d C_{C l^{-}}}{k_{i}^{\prime}-k_{C l^{-}}^{\prime}}
$$

where $\beta=\left(C_{c r}^{F}-C_{C r}^{I}\right) / t_{G}, L$ is the column length, $\varepsilon$ the extraparticle void fraction, $v$ the mobile phase interstitial velocity, $C_{C \zeta}^{I}$ and $C_{C \zeta}^{F}$ the initial and final chloride concentrations, respectively, $t_{G}$ the duration of the gradient, $k_{i}^{\prime}$ the protein retention factor as a function of $C_{C l^{-}}$, and $k_{C l^{-}}^{\prime}$ the chloride retention factor. Based on Eq. (3.7), $k_{i}^{\prime}$ can be written as follows:

$$
k_{i}^{\prime}=k_{i}^{\prime \infty}+A_{i}\left(C_{C^{-}}\right)^{-z_{i}}
$$

where $k_{i}^{\prime \infty}=\phi \varepsilon_{p, s} K_{D, i}, \phi=(1-\varepsilon) / \varepsilon$ and

$$
A_{i}=\phi\left(1-\varepsilon_{p, s}\right) K_{e, i}\left(q_{R, s}^{0}\right)^{z_{i}}
$$


In Eq. (3.13), the first term on the right hand side describes protein partitioning into the resin macropores while the second describes protein binding. Combining Eqs. (3.12) and (3.13) yields:

$$
\gamma=\int_{C_{C l^{-}}^{I}}^{C_{C T^{-}, i}^{E}} \frac{d C_{C C^{-}}}{A_{i}\left(C_{C l^{-}}\right)^{-z_{i}}+k_{i}^{\prime \infty}-k_{C l^{-}}^{\prime}}
$$

Thus, $z_{i}$ and $A_{i}$ can be obtained by conducting LGE experiments with different normalized gradient slopes, recording the chloride concentration at which the protein elutes, and comparing the results with Eq. (3.15). The retention factors $k_{i}^{\infty \infty}=0.803$ and $k_{C l^{-}}^{\prime}=1.11$ were obtained from pulse injection experiments with, respectively, the protein and chloride modifier under non-binding conditions. Integration of Eq. (3.15) was performed using the trapezoidal rule to determine the best-fit values of $z_{i}$ and $A_{i}$. For this purpose, different values of $z$ were tried in 0.01 increments and for each $z_{i}$ the value of $A_{i}$ that minimized the sum of error squares was determined using the Solver function in Excel. Figure 3.2 shows the results ( $\gamma$ vs. $C_{C l, i}^{E}$ on $\log -\log$ scales) comparing the experimental data for the native $\mathrm{mAb}$ (closed symbols) and major acidic variant (open symbols) with lines calculated from Eq. (3.15) with the best-fit values of $z_{i}$ and $A_{i}$. Note that these lines are not straight (as would be predicted from Eq. (3.15) for cases where $\left.k_{i}^{\prime 00}=k_{C l^{-}}^{\prime}(28-30)\right)$, although the deviation from linearity on these scales is relatively small. As seen in the figure, their slope decreases as the $\mathrm{pH}$ decreases indicating that the effective binding charges decrease for both species as the $\mathrm{pH}$ is lowered.

The retention factor calculated using the best-fit $z_{i}$ and $A_{i}$ values for the native $\mathrm{mAb}$ (solid lines) and major acidic variant (dashed lines) are shown in Figure 3.3. For both species, retention increases with $\mathrm{pH}$ as the protein negative charge increases. 
However, even at or below the protein $\mathrm{pI}(\sim 8.2)$, there is still significant retention. For these conditions, the net protein charge is low or even positive suggesting that proteinsurface interactions are likely the result of clustered negatively charged residues that interact favorably with the quaternary ammonium ion ligands in the SOURCE 30Q resin. Another possibility is that non-electrostatic interactions (e.g. hydrophobic) contribute to protein binding. However, this possibility seems unlikely for our conditions, as batch isotherm experiments (discussed in chapter 4) indicated little or no $\mathrm{mAb}$ binding at $\mathrm{pH}$ values near or below the $\mathrm{pI}$ when the chloride concentration was higher than $50 \mathrm{mM}$. At all $\mathrm{pH}$ values investigated the major acidic variant was more strongly retained than the native $\mathrm{mAb}$, consistent with its lower $\mathrm{pI}$ compared to the native $\mathrm{mAb}$ and, hence, greater negative charge at a given $\mathrm{pH}$. The spread between curves for the two species also 


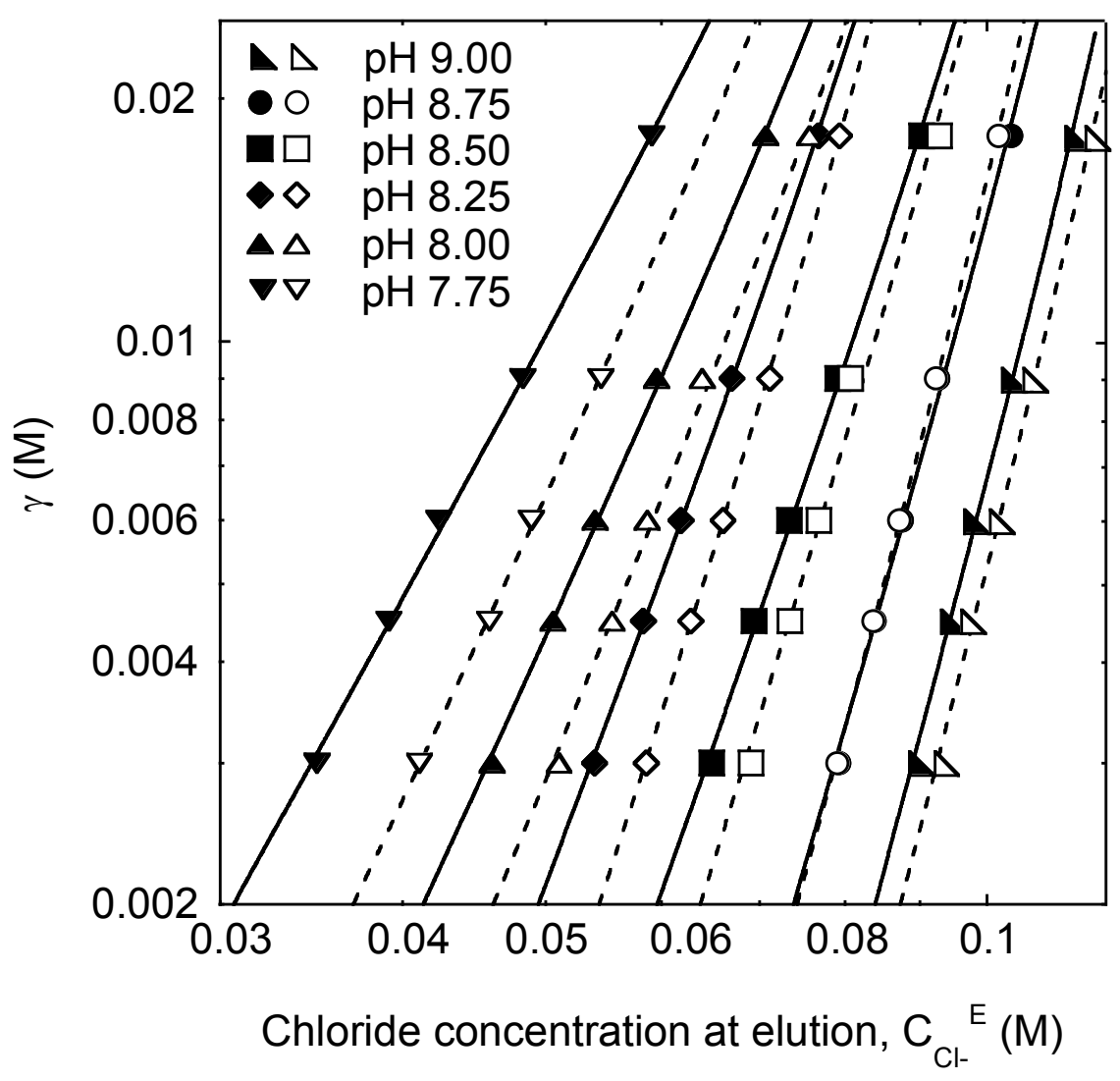

Figure 3.2 - Log-log plot of the normalized gradient slope vs. the chloride concentration at elution for LGE experiments with a SOURCE $30 \mathrm{Q}$ column with gradients in ethanolamine- $\mathrm{HCl}$ at different $\mathrm{pH}$ values. Closed symbols and solid lines are for the native mAb. Open symbols and dashed lines are for the major acidic variant. 


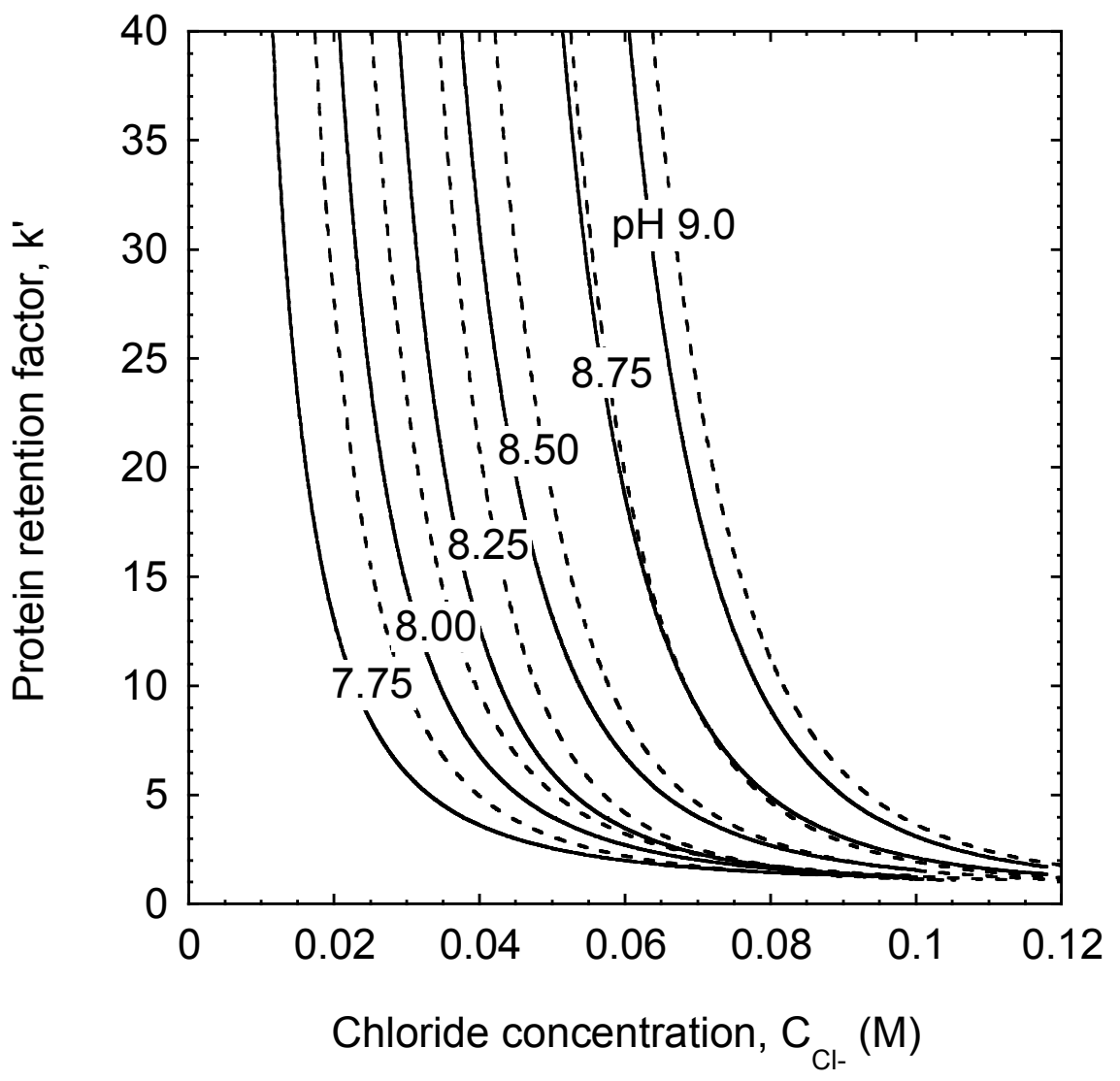

Figure 3.3 - Retention factors for native mAb (solid lines) and major acidic variant (dashed lines) on SOURCE 30Q plotted as a function of chloride concentration in ethanolamine- $\mathrm{HCl}$ buffers at different $\mathrm{pH}$ values. 
decreases as the $\mathrm{pH}$ increases up to $\mathrm{pH} 8.75$ increasing only slightly as the $\mathrm{pH}$ is increased further to 9. Better selectivity is obviously obtained when the protein is near or below the isolectric points, when binding occurs only at very low chloride concentrations.

Finally, Figure 3.4 shows the $z_{i}$ and $A_{i}$ values as a function of $\mathrm{pH}$. As seen in this figure, over the $\mathrm{pH}$ range investigated, $z_{i}$ increases linearly with $\mathrm{pH}$ for both native $\mathrm{mAb}$ and major acidic variant and is consistently higher by about 0.5 units for the latter. The regressed lines are $z=2.826 \times(\mathrm{pH})-19.77$ and $z=2.608 \times(\mathrm{pH})-17.47$, for the native $\mathrm{mAb}$ and variant, respectively. $A$ has the opposite trend, decreasing sharply with increasing $\mathrm{pH}$. Since $A$ is theoretically related to $z$ through Eq. (3.14), $K_{e}$ and $q_{R, s}^{0}$ can be determined by fitting this equation to the $A$-data using the regressed linear relationship describing $z$ as a function of $\mathrm{pH}$. Values of $K_{e}=0.226$ and 0.168 are obtained in this manner for the native $\mathrm{mAb}$ and major acidic variant, respectively, with $q_{R, s}^{0}=0.160 \mathrm{~mol} / \mathrm{L}$ resin solid. The latter value is much smaller than the independently determined resin charge density (Table 3.1), suggesting that due to steric interactions, only a fraction of the ligands present in SOURCE 30Q can actually interact with the mAb. 


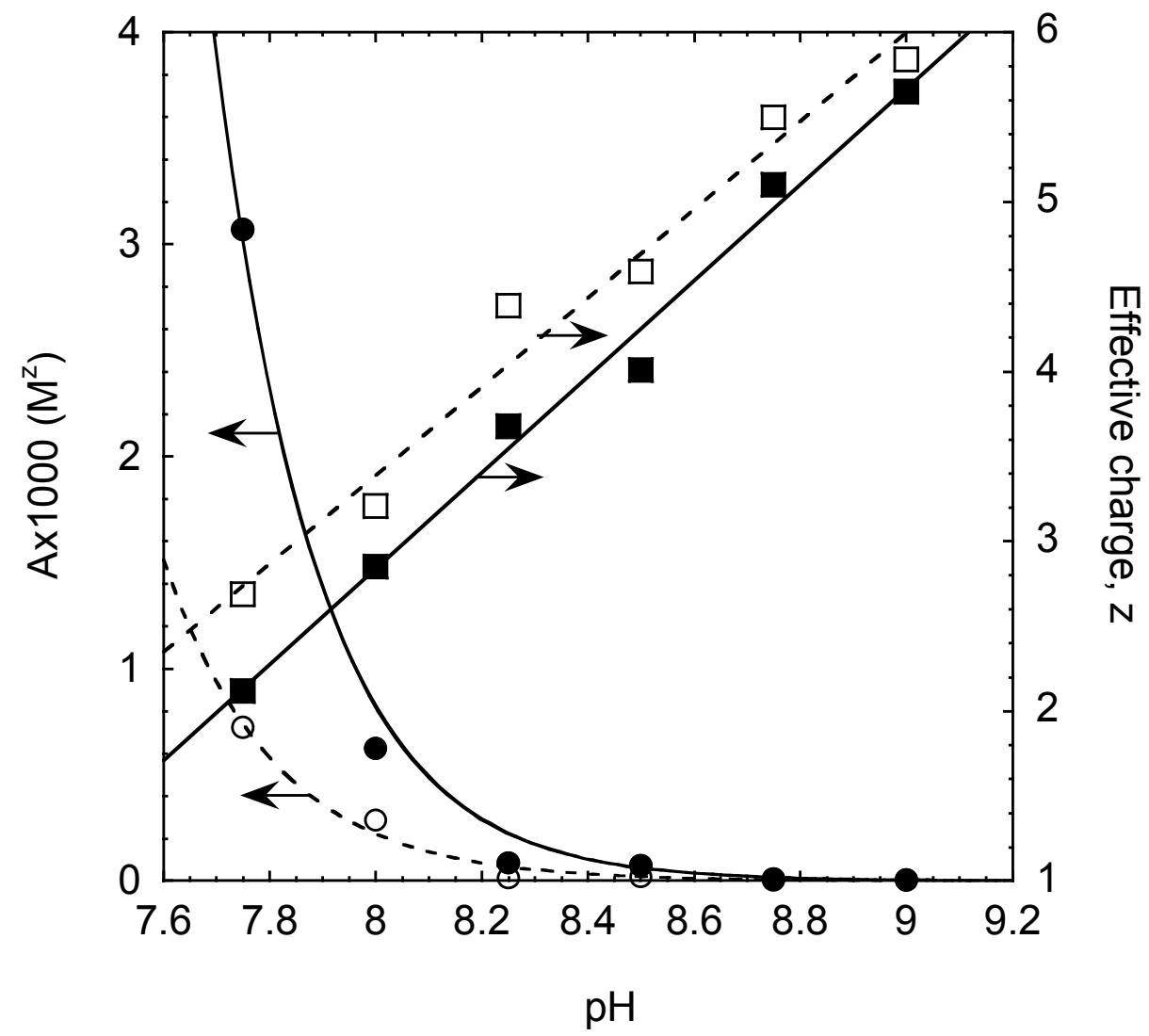

Figure 3.4 - Effective binding charge, $z$, and $A$-values as a function of $\mathrm{pH}$ for native $\mathrm{mAb}$ (solid symbols and lines) and major acidic variant (open symbols and dashed lines) on SOURCE 30Q in ethanolamine$\mathrm{HCl}$ solutions. Lines are calculated as described in the text. 


\subsubsection{Mass transfer properties}

The mass transfer properties of the $\mathrm{mAb}$ in the SOURCE 30Q resin were determined from pulse-response experiments under non-binding conditions as described in Section 3.2.2. Since there is no significant difference in molecular size and no resolution between species under these conditions, the crude mAb mixture was used for these experiments. The results are shown in Figure 3.5a. The peak broadens and becomes more skewed as the mobile phase velocity increases indicating that kinetic effects are dominant. The first moment calculated from these peaks is $0.65 \pm 0.04 \mathrm{CV}$. Since $\varepsilon=0.36$ for this column, this value yields $k^{\prime}=k^{\prime \infty}=\varepsilon_{p, s} K_{D}=0.803$ or $K_{D}=0.71$, indicating that the $\mathrm{mAb}$ molecules can access a large fraction of the total intraparticle porosity $\left(\varepsilon_{p, s}=0.63\right)$.

Figure $3.5 \mathrm{~b}$ shows the corresponding reduced HETP $\left(h=\mathrm{HETP} / d_{p}\right)$ as a function of reduced velocity, $v^{\prime}=v d_{p} / D_{0}$, where $d_{p}$ is the particle diameter and $D_{0}$ the free solution diffusivity of the mAb $\left(D_{0}=5.0 \times 10^{-7} \mathrm{~cm}^{2} / \mathrm{s}(31)\right)$. The effective pore diffusivity is obtained from the slope of this plot as (30):

$$
\frac{D_{e}}{D_{0}}=\frac{1}{30 \phi}\left(\frac{k^{\prime}}{1+k^{\prime}}\right)^{2}\left(\frac{d h}{d v^{\prime}}\right)^{-1}
$$

The regressed value obtained from this equation is $D_{e}=(7.2 \pm 0.5) \times 10^{-8} \mathrm{~cm}^{2} / \mathrm{s}$. The corresponding ratio $D_{e} / D_{0}=0.14$ is typical for macroporous resins such as SOURCE 30Q (24). Protein mass transfer for the weak anion exchanger is neglected as the protein is completely excluded from its pores and the external particle surface area is very small. 

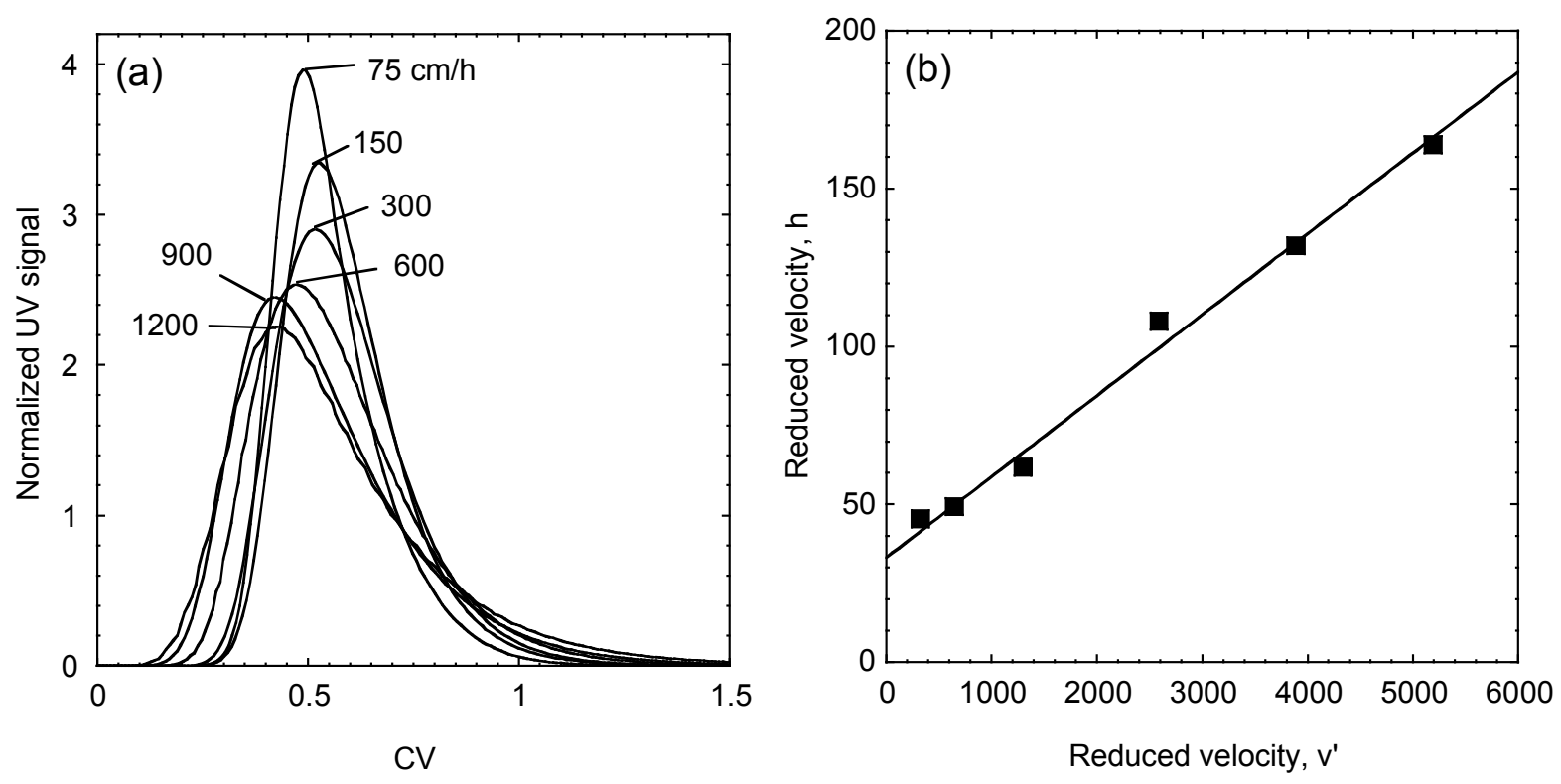

Figure 3.5 - mAb isocratic elution peaks obtained for the SOURCE 30Q column at different mobile phase velocities under non-binding conditions (a) and corresponding van Deemter plot (b). 


\subsubsection{Separations with induced $\mathrm{pH}$ gradients}

Two different AG 4-X4/SOURCE 30Q mixed-bed columns both with a length of approximately $20 \mathrm{~cm}$ but containing 10 and 14\% AG 4-X4, respectively, were used for these experiments. In both cases, buffers containing 95\% ethanolamine and 5\% Tris with different chloride concentrations, prepared as discussed in Section 3.2.1, were used with a $\mathrm{pH}$ step from $9.0 \pm 0.1$ to 7.0. These buffers were shown in our previous work (17) to yield smooth $\mathrm{pH}$ gradients with reasonable durations. Note that in this range the $\mathrm{pH}$ gradient results are not very sensitive to the initial $\mathrm{pH}$.

Figure 3.6 shows the experimental results for the $14 \%$ AG $4-\mathrm{X} 4$ column with buffers containing different chloride concentrations. In each case, following the $\mathrm{pH}$ step change at $0 \mathrm{CV}$, the $\mathrm{pH}$ decreases smoothly. As shown in our prior work (17), the conductivity of the column effluent remains fairly constant throughout each of these runs (data not shown here). With $50 \mathrm{mM}$ chloride (Figure 3.6a), the induced $\mathrm{pH}$ gradient is almost linear and has a shorter duration. However, there is no visible resolution of the charge variants. The induced $\mathrm{pH}$ gradient duration becomes longer as the chloride concentration is reduced (Figure $3.6 \mathrm{~b}$ and $\mathrm{c}$ ), and some resolution of the major acidic variant becomes evident. Finally, with $15 \mathrm{mM}$ chloride (Figure 3.6d), the induced $\mathrm{pH}$ gradient is very shallow leading to two distinct elution peaks. IEF analyses of fractions collected for the $15 \mathrm{mM}$ chloride run near the maxima of the two protein peaks, conducted as described in ref. (17), are shown in Figure 3.7. These results confirm that substantial resolution of late eluting charge variants was obtained for these conditions. The first peak contains pure native $\mathrm{mAb}$ ( $\mathrm{pI} \sim 8.2$ ), the second the major acidic variant 

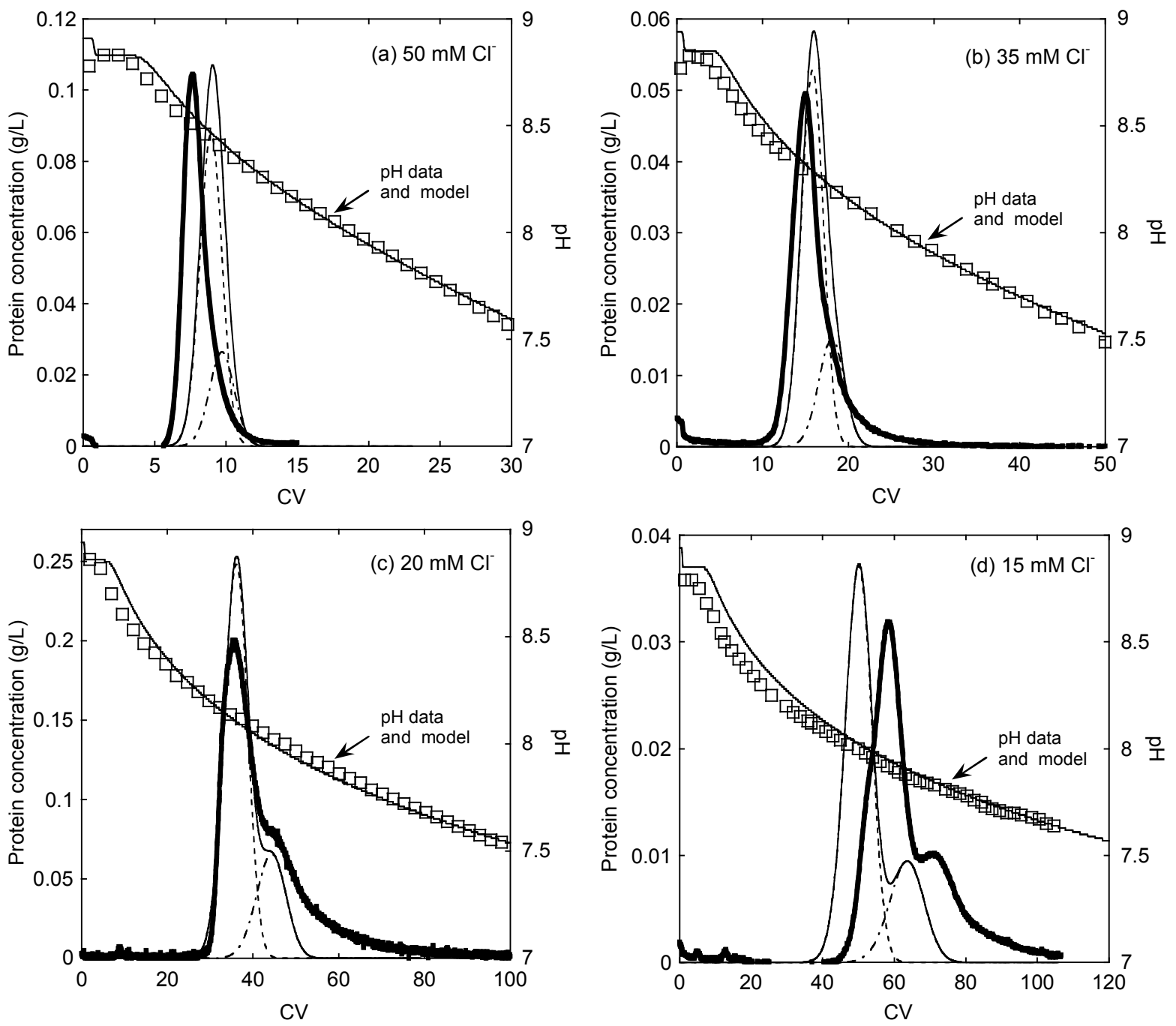

Figure 3.6 - Separation of $\mathrm{mAb}$ charge variants with a mixed-bed column containing 14\% AG 4-X4 using pH 9 to 7 steps with (a) 50, (b) 35, (c) 20, and (d) $15 \mathrm{mM}$ chloride concentration. Protein sample loads were $1 \mathrm{mg}$ for a and $\mathrm{b}, 11 \mathrm{mg}$ for $\mathrm{c}$, and $2 \mathrm{mg}$ for $\mathrm{d}$. Thick solid lines and squares are experimental data. Thin lines are model predictions for total $\mathrm{mAb} \longrightarrow$, native $\mathrm{mAb}$-----, and major acidic variant . . . . . Column volume $=3.97 \mathrm{~mL}, L=20.2 \mathrm{~cm}, u=300 \mathrm{~cm} / \mathrm{h}$ 


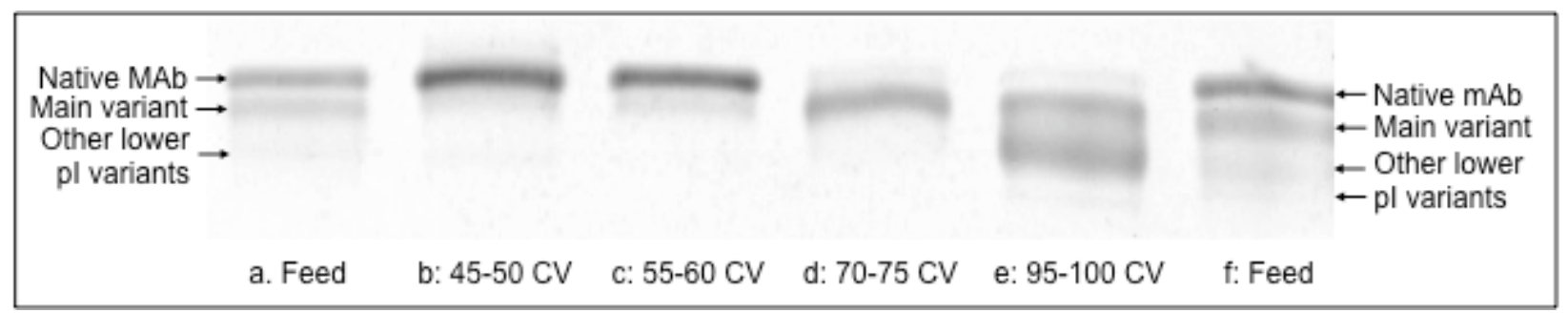

Figure 3.7 - IEF analyses of fractions collected from the run in Figure $6 \mathrm{~d}$ at the $\mathrm{CV}$-values indicated for each lane. Lanes $b$ through $f$ used higher protein loads to improve visualization of the minor, lower $\mathrm{pI}$ variants. 
( $\mathrm{pI} 8.0$ ), and the tailing portion a mixture of a few lower pI species. For all four runs, model predictions based on parameters determined independently (Figure 3.6) are in reasonable agreement with the experimental profiles, although there are some deviations between predicted and experimental retention volumes. These deviations are likely due in large part to small differences between predicted and experimental $\mathrm{pH}$ values. Since $\mathrm{pH}$ has a very strong effect on protein retention, small differences in $\mathrm{pH}$ can result in fairly large differences in retention volumes. Additionally, there could be inaccuracies in the model parameters that lead to slightly over-predicting retention when elution occurs at relatively high $\mathrm{pH}$ values (e.g. Figure 3.6a) and to slightly under-predict it when elution occurs at lower $\mathrm{pH}$ values. In practice, the model parameters could be adjust empirically to fit the experimental behavior better than the predictions shown here, which are based entirely on independent experimental measurements. Figure 3.8 shows the $\mathrm{pH}$ at which elution occurs as a function of chloride concentration, based on the data in Figure 3.6 (and those from additional runs not shown in Figure 3.6). The apparent variability in elution $\mathrm{pH}$ occurs in large part because of inaccuracies in $\mathrm{pH}$, whose repeatability was generally $\pm 0.05 \mathrm{pH}$ units. As seen in this figure, resolution occurs over a small range of $\mathrm{pH}$ values, thus requiring very shallow $\mathrm{pH}$ gradients. At higher chloride concentrations, the induced $\mathrm{pH}$ gradient becomes steeper and the $\mathrm{pH}$ at which elution occurs also increases, while the difference in elution $\mathrm{pH}$ between native $\mathrm{mAb}$ and major acidic variant narrows. This behavior, which is predicted well by the model, is different from that obtained for salt gradients at constant $\mathrm{pH}$. In our case, elution occurs earlier in the gradient (i.e. at higher $\mathrm{pH}$ ) with steeper $\mathrm{pH}$ gradients, while with salt gradient elution, 


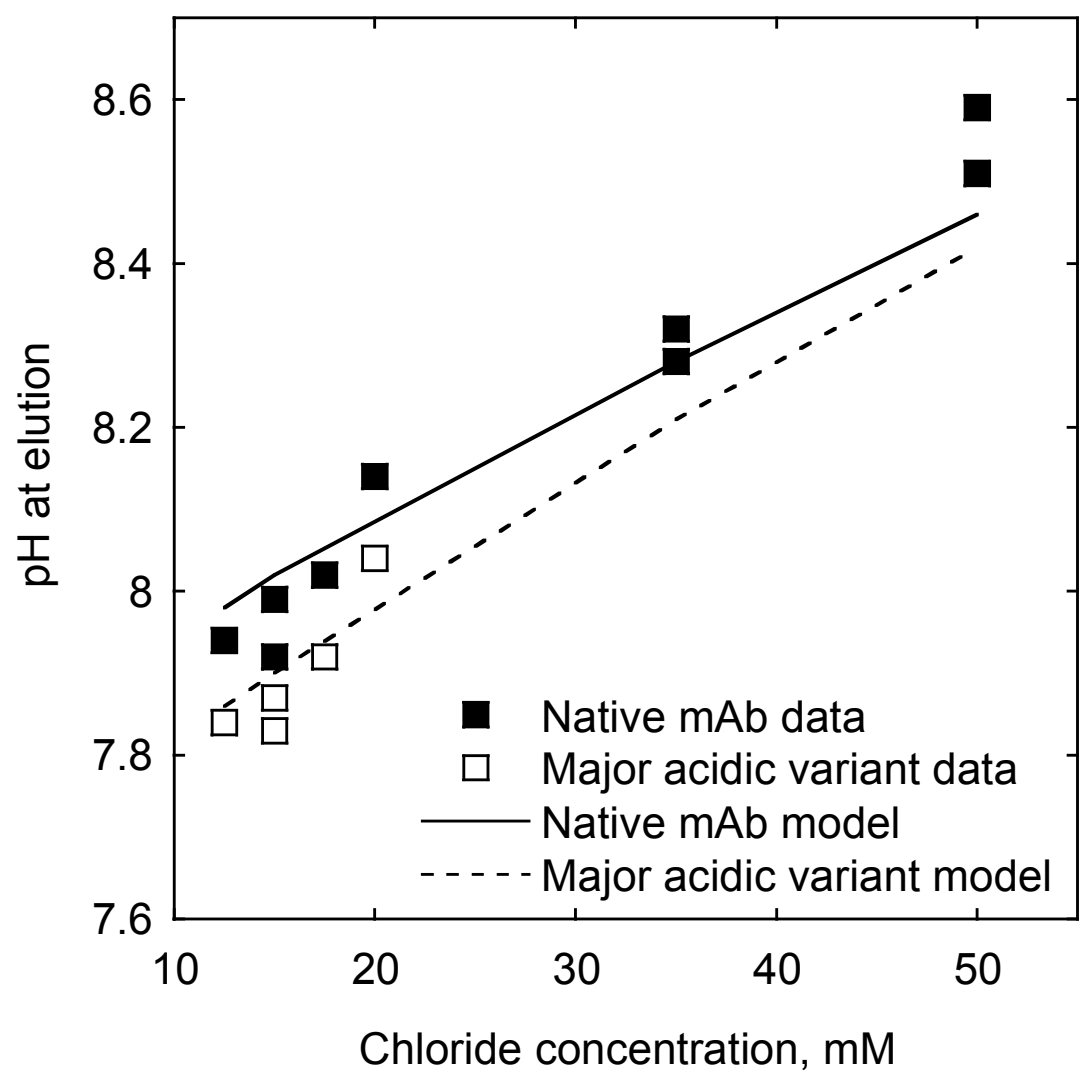

Figure 3.8 - Comparison of experimental and predicted elution $\mathrm{pH}$ as a function of buffer chloride concentration for the conditions of Figure 6. Elution $\mathrm{pH}$ for the major acidic variant could not be determined experimentally at chloride concentrations higher than $20 \mathrm{mM}$. 
elution occurs later in the gradient (i.e. at higher salt concentrations) with steeper salt gradients.

Figure 3.9 shows the results for the $10 \%$ AG $4-\mathrm{X} 4$ column with buffers containing $15 \mathrm{mM}$ chloride. The eluted peak profile shows again two distinct peaks followed by a tailing portion. As in the previous case, model predictions based on parameters determined independently are in agreement with the experimental profiles, demonstrating the ability of the model to predict both the induced $\mathrm{pH}$ gradient and the protein retention and peak widths over relatively broad ranges of conditions. The current model accounts only for the native $\mathrm{mAb}$ and the major acidic variant which elutes closest to the native $\mathrm{mAb}$, and disregards more acidic minor variants. Thus, as before, it does not predict the behavior of those lower $\mathrm{pI}$ variants that elute much later resulting in extensive tailing. In practice, however, this may not be important, as the main practical problem would be to separate the most closely eluting species. 


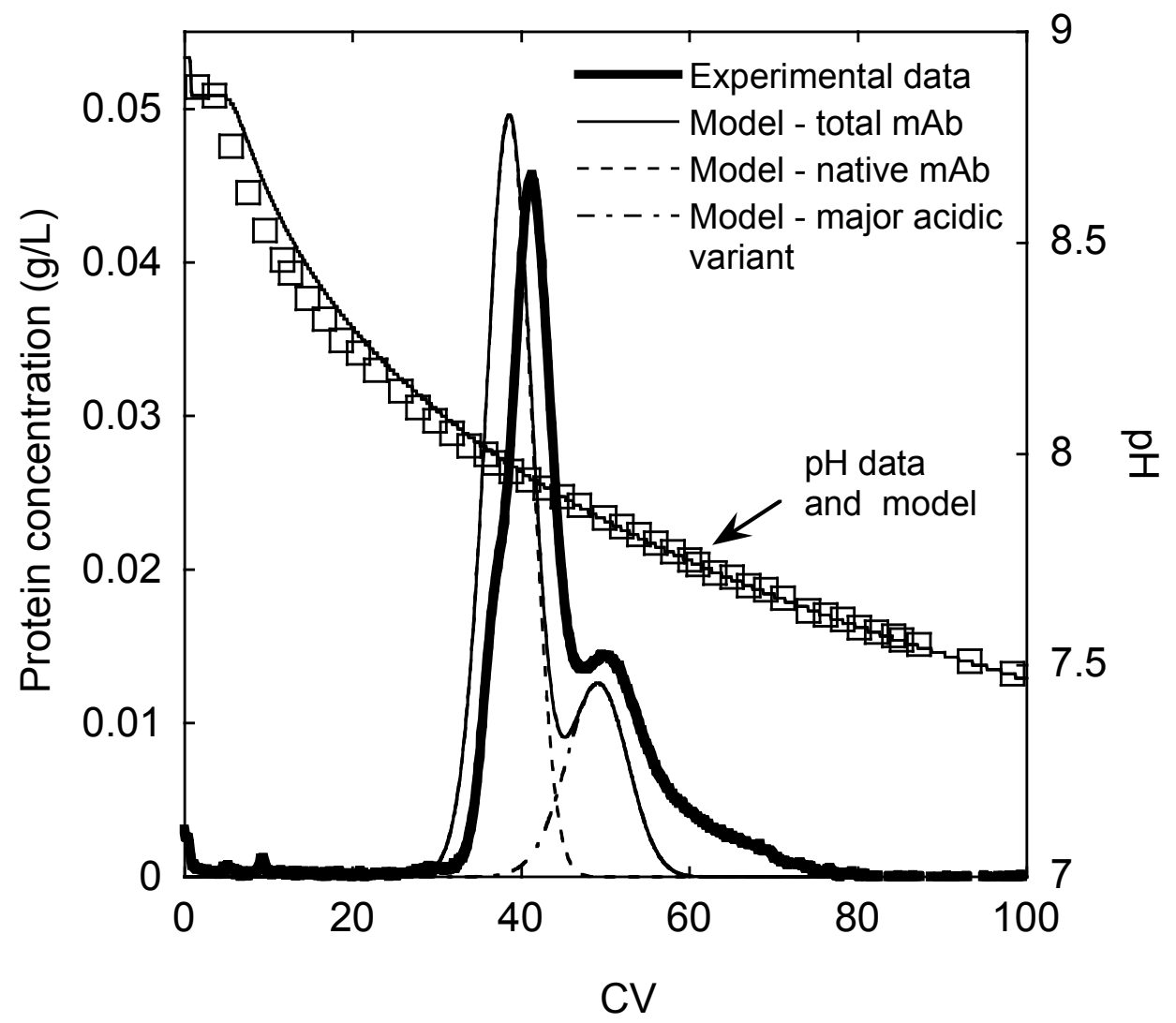

Figure 3.9 - Separation of $\mathrm{mAb}$ charge variants with a mixed-bed column containing $10 \%$ AG $4-\mathrm{X} 4$ using a $\mathrm{pH} 9$ to 7 step with $15 \mathrm{mM}$ chloride concentration. The protein load was $2 \mathrm{mg}$. Thick solid lines and squares are experimental data. Thin lines are model predictions for total $\mathrm{mAb}$, native $\mathrm{mAb}$, and major acidic variant. Column volume $=3.91 \mathrm{~mL}, L=19.9 \mathrm{~cm}, u=300 \mathrm{~cm} / \mathrm{h}$ 


\subsection{Conclusions}

A model has been developed to predict protein retention and resolution of charge variants in a mixed-bed column with induced $\mathrm{pH}$ gradients generated using a $\mathrm{pH}$ step change at the column entrance. The column comprises weak base resin with small pores inaccessible to proteins and a strong base resin into which protein can diffuse and adsorb. The former generates smooth $\mathrm{pH}$ gradients through interactions of the buffer component with the weak base ligands, while the latter performs the separation as a result of specific electrostatic interactions between the protein molecules and its strong-base ligands. The model merges two components - one that predicts the $\mathrm{pH}$ gradient based on a description of ion-exchange equilibrium in the weak base resin, and one that describes protein adsorption on the strong base resin as a function of $\mathrm{pH}$ and counterion concentration. Band broadening is negligible for the small ions that are responsible for generating the $\mathrm{pH}$ gradient, but is described for the protein on the strong base resin using a linear driving force approximation. A procedure is outlined to independently determine the model parameters for the separate components of the mixed-bed system, and then use these parameters to predict the behavior of the mixed system. As shown in our prior work (17), the parameters needed to describe the generation of $\mathrm{pH}$ gradients are obtained from a potentiometric titration of the weak anion exchanger. Those needed to describe protein adsorption equilibrium and kinetics for the strong anion exchanger are obtained from linear gradient elution experiments at constant $\mathrm{pH}$ and from pulse injections under nonbinding conditions. The ability of the model to predict resolution in mixed-bed columns is demonstrated for the separation of a native $\mathrm{mAb}$ from an acidic variant with slightly lower $\mathrm{pI}$ using the resin $\mathrm{AG} 4-\mathrm{X} 4$ as the weak anion exchanger and SOURCE 30Q as the 
strong one. The stoichiometric displacement model was found to provide a good description of the relationship between protein retention and chloride ion concentration, while an empirical linear relationship was found to describe the effect of $\mathrm{pH}$ on the protein effective binding charge. Diffusional transport of the mAb in the pores of the strong base resin was found to be rate limiting. Using the parameters as determined independently for the two resins, the model was found to fairly accurately predict protein elution $\mathrm{pH}$, retention, and resolution in mixed-bed columns containing differing percentages of weak base resin, operated at differing mobile phase compositions.

From a practical viewpoint, it is clear that the difficult separation of mAb charge variants (and likely other proteins) can be conveniently conducted in a predictable manner with $\mathrm{pH}$ gradients generated in mixed-bed columns in response to a $\mathrm{pH}$ step. The mixed-bed approach allows one to characterize each resin component separately. The model presented in this work allows one to predict their combined behavior providing the means for rational selection and model-driven optimization of combinations of mobile phase composition and mixed-bed composition to yield the desired separation performance. Since column length and flow rate appear explicitly in the model, their effects can also be estimated from model calculations. The model does have some weaknesses, especially with regards to predicting the $\mathrm{pH}$ profiles at the higher $\mathrm{pH}$ values. In general, the model over-predicted $\mathrm{pH}$ in the initial part of the gradient. The reasons for this behavior are not known, but we observed that the prediction could not be improved by simply changing the current model parameters, indicating that a different description of the chloride/hydroxide exchange on the weak base resin at the higher $\mathrm{pH}$ values may be needed to improve accuracy. It should also be noted that predicting protein retention in 
our experiments is inherently difficult as protein interactions with the stationary phase are extremely sensitive to $\mathrm{pH}$ near the protein $\mathrm{pI}$, which is likely to have caused some of the observed discrepancies in elution $\mathrm{pH}$. Another consideration is the effect of protein loading on resolutions. We have already demonstrated (17), that protein loading does not affect the $\mathrm{pH}$ gradient in our mixed-bed system. However, overloaded conditions are likely to reduce resolution as a result of non-linear and competitive binding. These effects will be examined in a future communication. A final consideration is whether it is possible to obtain a uniform distribution of the two resins in large-scale columns. As discussed in chapter 2, this possibility has to be addressed experimentally. Although in our columns the different resin sizes and densities did not cause problems, packing largescale columns uniformly may require using resins with similar size and density. 


\subsection{Symbols}

$A_{i} \quad$ adsorption equilibrium parameter for protein i defined by Eq. (14) (mol/L) ${ }^{\mathrm{z}}$

$C_{i} \quad$ mobile phase concentration of species $\mathrm{i}(\mathrm{mol} / \mathrm{L})$

$C_{i}^{0} \quad$ total concentration of amine $B_{i}(\mathrm{~mol} / \mathrm{L})$

$C_{i}^{*} \quad$ mobile phase concentration of species $\mathrm{i}$ in equilibrium with its concentration in the particle $(\mathrm{mol} / \mathrm{L})$

$C_{\mathrm{Cl}^{-}}^{F} \quad$ final chloride concentration $(\mathrm{mol} / \mathrm{L})$

$C_{\mathrm{Cl}^{-}}^{I} \quad$ initial chloride concentration $(\mathrm{mol} / \mathrm{L})$

$C_{\mathrm{Cl}^{-}, i}^{E}$ chloride concentration at which protein i elutes $(\mathrm{mol} / \mathrm{L})$

CV number of column volumes passed

$d_{p} \quad$ particle diameter $(\mathrm{cm})$

$D_{e, i} \quad$ effective diffusivity of protein $\mathrm{i}\left(\mathrm{cm}^{2} / \mathrm{s}\right)$

$D_{0} \quad$ free solution diffusivity of protein $\left(\mathrm{cm}^{2} / \mathrm{s}\right)$

$h$ reduced height equivalent to a theoretical plate $=\mathrm{HETP} / d_{p}$

$k_{i}^{\prime} \quad$ retention factor of protein i

$k_{i}^{\prime \infty} \quad$ retention factor of protein i for non-binding conditions

$K_{a, i} \quad$ deprotonation equilibrium constant of amine $B_{i}(\mathrm{~mol} / \mathrm{L})$

$K_{D, i} \quad$ distribution coefficient for protein i between mobile phase and pore liquid

$K_{e, i} \quad$ equilibrium constant in stoichiometric displacement model, Eq. (7)

$K_{R, w} \quad$ deprotonation constant of weak base ligands (mol/L)

$K_{W} \quad$ ionic product of water $(\mathrm{mol} / \mathrm{L})^{2}$ 
$L \quad$ column length $(\mathrm{cm})$

$q_{s, i} \quad$ adsorbed concentration of protein i on strong base resin (mol/L of resin solid)

$q_{w, i}$ adsorbed concentration of ion i on weak base resin (mol/L of resin solid)

$q_{R, w}^{0} \quad$ concentration of weak base ligands in weak anion exchanger ( $\mathrm{mol} / \mathrm{L}$ of resin solid)

$q_{R, S}^{0} \quad$ concentration of strong base ligands in strong anion exchanger $(\mathrm{mol} / \mathrm{L}$ of resin solid)

$\bar{q}_{s, i} \quad$ concentration of protein i on the strong base resin averaged over the particle volume $(\mathrm{mol} / \mathrm{L})$

$t \quad$ time (s)

$u \quad$ mobile phase superficial velocity $(\mathrm{cm} / \mathrm{s})$

$v \quad$ mobile phase interstitial velocity $(\mathrm{cm} / \mathrm{s})$

$v^{\prime} \quad$ reduced velocity $=v d_{p} / D_{0}$

$x \quad$ column axial coordinate $(\mathrm{cm})$

$z_{i} \quad$ effective binding charge of protein $\mathrm{i}$

Greek symbols

$\beta \quad$ linear gradient slope ( $\mathrm{mol} / \mathrm{L} \mathrm{s})$

$\varepsilon \quad$ extraparticle porosity of mixed-bed column

$\varepsilon_{p, s} \quad$ intraparticle porosity of strong base resin

$\varepsilon_{p, w} \quad$ intraparticle porosity of weak base resin

$\varepsilon_{t} \quad$ total porosity of mixed-bed column

$\varphi_{w} \quad$ volume fraction of weak base resin in the mixed-bed column 
$\gamma \quad$ normalized linear gradient slope $=\beta L / v(\mathrm{~mol} / \mathrm{L})$

$\phi \quad$ ratio of stationary phase and mobile phase in mixed-bed column $=(1-\varepsilon) / \varepsilon$ 


\subsection{References}

1. Harris, R.J.; Kabakoff, B.; Macchi, F.D.; Shen, F.J.; Kwong, M.; Andya, J.D.; Shire, S.J.; Bjork, N.; Totpal, K.; Chen, A.B. (2001) Identification of multiple sources of charge heterogeneity in a recombinant antibody. J. Chromatogr. B. 752: $233-245$.

2. Farnan, D.; Moreno, G. T. (2009) Multiproduct high-resolution monoclonal antibody charge variant separations by $\mathrm{pH}$ gradient ion-exchange chromatography. Anal. Chem., 81: 8846-8857.

3. Rea, J. C.; Moreno, G. T.; Lou, Y.; Farnan, D. (2011) Validation of a pH gradient-based ion-exchange chromatography method for high-resolution monoclonal antibody charge variant separations. J. Pharm. Biom. Anal., 54: $317-$ 323.

4. Ng, P. K.; He, J.; Snyder, M. A. (2009) Separation of protein mixtures using pHgradient cation-exchange chromatography. J. Chromatogr. A, 1216: 1372-1376.

5. Sluyterman, L.; Elgersma, O. (1978) Chromatofocusing: isoelectric focusing on ion exchange columns I. General principles. J. Chromatogr., 150: 17-30.

6. Sluyterman, L.; Wijdenes, J. (1978) Chromatofocusing: isoelectric focusing on ion exchange columns II. Experimental verification. J. Chromatogr., 150: 31-44.

7. $\quad$ Bates, R. C.; Frey, D.D. (1998) Quasi-linear pH gradients for chromatofocusing using simple buffer mixtures: local equilibrium theory and experimental verification. J. Chromatogr. A. 814: 43-54.

8. Bates, R. C.; Kang, X.; Frey, D. D. (2000) High-performance chromatofocusing using linear and concave $\mathrm{pH}$ gradients formed with simple buffer mixtures. I. effect of buffer composition on the gradient shape. J. Chromatogr. A. 890: 25-36.

9. Perez, J.S.; Frey, D.D. (2005) Behavior of the inadvertent $\mathrm{pH}$ transient formed by a salt gradient in the ion-exchange chromatography of proteins. Biotechnol. Progr. 21: 902-910.

10. Pabst, T.M.; Carta, G. (2007) pH transitions in cation exchange chromatographic columns containing weak acid groups. J. Chromatogr. A 1142: 19-31.

11. Kang, K.; Frey, D.D. (2004) Chromatofocusing of peptides and proteins using linear $\mathrm{pH}$ gradients formed on strong ion-exchange adsorbents. Biotechnol. Bioeng. 87 (2004) 376-387. 
12. GE Healthcare Bio-Sciences, Ion Exchange Chromatography and Chromatofocusing: Principles and Methods, Piscataway, NJ, 2010.

13. Kang, X.; Bates, R. C.; Frey, D. D. (2000) High-performance chromatofocusing using linear and concave $\mathrm{pH}$ gradients formed with simple buffer mixtures. II. separation of proteins. J. Chromatogr. A. 890: 37-43.

14. Pabst, T. M.; Antos, D.; Carta, G.; Ramasubramanyan, N.; Hunter, A. K. (2008) Protein separations with induced $\mathrm{pH}$ gradients using cation-exchange chromatographic columns containing weak acid groups. J. Chromatogr. A, 1181: 83-94.

15. Pabst, T. M.; Carta, G.; Ramasubramanyan, N.; Hunter, A. K.; Mensah, P.; Gustafson, M. E. (2008) Separation of protein charge variants with induced $\mathrm{pH}$ gradients using anion exchange chromatographic columns. Biotechnol. Progr., 24: 1096-1106.

16. Kang, A.K.; Kutzko, J.P.; Hayes, M.L.; Frey, D.D. (2013) Monoclonal antibody heterogeneity analysis and deamidation monitoring with high-performance cationexchange chromatofocusing using simple, two component buffer systems. $J$. Chromatogr. A 1283: 89-97.

17. Vetter, T.A.; Ferreira, G.; Robbins, D.; Carta, G. (2014) Mixed-beds of strong and weak anion exchange resins for protein separations with step-induced $\mathrm{pH}$ gradients. Sep. Sci. Technol., 49: 477-489.

18. Beynon, R.; Easterby, J. (1996) Buffer Solutions; Bath Press: Bath, U.K.

19. Kopaciewicz, W.; Rounds, M.; Fausnaugh, J.; Regnier, F.E. (1983) Retention model for high-performance ion-exchange chromatography. J. Chromatogr. 266: $3-21$.

20. Yamamoto, S.; Nakanishi, K.; Mastuno, R. (1988) Ion Exchange Chromatography of Proteins. New York: Dekker.

21. Brooks, C.A.; Cramer, S.M. (1992) Steric mass-action ion-exchange displacement profiles and induced salt gradients. AIChE J. 38: 1969-1978.

22. Malmquist, G.; Lundell, N. (1992) Characterization of the influence of displacing salts on retention in gradient elution ion-exchange chromatography of proteins and peptides. J. Chromatogr. 627: 107-124.

23. Bosma, J.C.; Wesselingh, J.A. (1998) $\mathrm{pH}$ dependence of ion-exchange equilibrium of proteins. AIChE J. 44: 2399-2409. 
24. Carta, G.; Jungbauer, A. (2010) Protein Chromatography - Process Development and Scale-up, Wiley-VCH, Weinheim, Germany.

25. LeVan, M.D.; Carta, G. (2007) Adsorption and Ion Exchange, in Perry's Chemical Engineers' Handbook - Eighth Edition, D.W. Green (ed.), Section 16, McGrawHill, New York.

26. Tao, Y.; Carta, G.; Ferreira, F.; Robbins, D. (2011) Adsorption of deamidated antibody variants on macroporous and dextran-grafted cation exchangers: I. Adsorption equilibrium. J. Chromatogr. A 1218: 1519-1529.

27. Yamamoto, S.; Nakanishi,K.; Matsuno, R.; Kamikubo, T. (1983) Ion-exchange chromatography of proteins - prediction of elution curves and operatingconditions. 1. Theoretical considerations. Biotechnol. Bioeng. 25: 1465-1483.

28. Yamamoto, S. (1995) Plate height determination for gradient elution chromatography of proteins. Biotechnol. Bioeng. 48: 444-451.

29. Ishihara, T.; Kadoya, T.; Yamamoto, S. (2007) Application of a chromatography model with linear gradient elution experimental data to the rapid scale-up in ionexchange process chromatography of proteins. J. Chromatogr. A 1162: 34-40.

30. Carta, G. Ubiera, A.R.; Pabst, T.M. (2005) Protein mass transfer kinetics in ion exchange media: measurements and interpretations. Chem. Eng. Technol. 28: 1252-1264

31. Perez Almodovar, E.X.; Glatz, B.; Carta, G. (2012) Counterion effects on protein adsorption equilibrium and kinetics in polymer-grafted cation exchangers. $J$. Chromatogr. A 1253: 83-93. 


\section{Resolution of protein charge variants in mixed-bed chromatography columns with step-induced $\mathrm{pH}$ gradients at high protein loads}

\subsection{Introduction}

Protein charge variants that occur as the result of post-translational modifications are a common source of product-related impurities in the industrial-scale production of biopharmaceuticals (1). Charge variants may have altered structure, stability, and/or reduced activity, making their removal important for the production of safe and effective drug products. Because the molecular properties of the variants are quite similar to those of the native species, they may be difficult to resolve effectively in chromatographybased separations without shallow salt or $\mathrm{pH}$ gradients, which can present manufacturing challenges.

In general the industrial separation of charge variants is difficult because there is a tradeoff between peak resolution and productivity. While analytical methods based, for example, on high performance liquid chromatography (HPLC) with pellicular particles, or on isoelectric focusing (IEF) can resolve many charge variants, these methods require low protein loads and/or elevated operating pressures that are not suitable for large scale operations. Chromatographic separations based on low-pressure ion exchange materials with salt gradients are more practical for these operations and have shown some success. Because of the larger particle size of these materials, shallow gradients and low flow rates are often required to provide good resolution.

Gradients in $\mathrm{pH}$ have also been shown to be effective for the separation of protein charge variants, often exhibiting improved resolution compared to salt gradients. Both 
salt and $\mathrm{pH}$ gradients are usually generated by mixing appropriate buffers in time-varying proportions at the column entrance $(2,3,4)$. Alternatively, $\mathrm{pH}$ gradients can also be generated or induced within the column as a result of interactions of buffer components with the stationary phase $(5,6)$. In this case, the $\mathrm{pH}$ gradient is generated with a step change in $\mathrm{pH}$ at the column entrance and propagates through the column at a rate smaller than the mobile phase velocity. Because the protein charge varies with $\mathrm{pH}$, the separated protein species can be focused along the traveling $\mathrm{pH}$ wave at $\mathrm{pH}$ values where the protein chromatographic velocity equals the local velocity of the $\mathrm{pH}$ wave. The ensuing focusing effect results in sharper peaks and, thus, improved resolution $(7,8)$. Traveling $\mathrm{pH}$ waves of this type can be generated either using buffer species, called ampholytes, that are bound to a strong ion exchange resin and serve as immobilized buffers (9), or using non-interacting buffer species in conjunction with a weak ion exchange resin $(10,11,12)$. In the latter case, the weak ion exchanger provides both buffering capacity needed to create the $\mathrm{pH}$ gradient and binding sites to retain the protein species. Although both of these approaches have been shown to be effective, several drawbacks exist for each. One drawback is that predicting the separation is difficult because the charges of both the ampholytes (or the weak ion exchange resin) and the protein vary along the $\mathrm{pH}$ gradient. Moreover, when using a weak ion exchanger with unretained buffers, the resin charge can become very small at $\mathrm{pH}$ extremes along the gradient giving rise to unpredictable and undesirable hydrophobic interactions. Finally, since $\mathrm{pH}$ generation and protein retention are based on the same resin functional groups, the protein and buffer counterions compete for binding on the same sites mutually affecting each other and causing distortions of the $\mathrm{pH}$ wave at high protein loadings. 
In Chapters 2 and $3(13,14)$ we have shown that some of the limitations of using a weak ion exchanger with unretained buffers for induced $\mathrm{pH}$ gradient separations can be overcome with a mixed-bed system comprising a strong ion exchanger with suitably large pores packed together in the same column with a weak ion exchanger with pores sufficiently small to prevent interaction with proteins while still permitting fast exchange of counterions. In such a system, the weak ion exchanger generates the $\mathrm{pH}$ gradient as a result of its buffering capacity while the strong ion exchanger provides sites for protein retention. Since the two functions of $\mathrm{pH}$ generation and protein retention are effectively decoupled with this approach, there is virtually no interference between the two functions improving the flexibility and predictability of the process by allowing each material to be modeled and optimized individually. Chapter 2 (13) demonstrated the mixed-bed approach using columns containing the weak anion exchanger, AG 4-X4 (Bio-Rad Laboratories, Hercules, CA, USA) in combination with various commercially available strong anion exchangers. Because of the high density of weak base groups in AG 4-X4, only a small percentage ( $10-15 \%$ by volume) of this resin in the mixed-bed was sufficient to create stable and relatively linear $\mathrm{pH}$ gradients induced by a $\mathrm{pH}$ step at the column entrance using unretained amine buffers. A model was developed to successfully predict the induced $\mathrm{pH}$ gradients based solely on the potentiometric titration curve of the AG 4$\mathrm{X} 4$ resin. As a result, $\mathrm{pH}$ gradients could be predicted with the same model parameters for any of the strong anion exchangers tested. The resolution of protein charge variants was also demonstrated in this work for the mixed-bed system based on IEF analyses of the eluted fractions. As a result of the very small size exclusion limit of AG 4-X4, which 
rendered the weak base ligands essentially inaccessible by the protein, the induced $\mathrm{pH}$ gradients were shown to be effectively insensitive to the amount of protein loaded.

Chapter 3 (14) further developed a model to predict the protein elution behavior in the mixed-bed system. This model combined the ion-exchange equilibrium model for the weak base resin with a description of protein retention on the strong base resin component of the mixed-bed using parameters determined independently for each resin. The model could successfully predict resolution of protein charge variants but was limited to analytical protein loads, generally less than $0.5 \mathrm{mg} / \mathrm{ml}$ of column volume, where retention was adequately described by a linear isotherm relationship and competition among adsorbed protein species could be neglected.

The objective of this chapter is twofold. The first objective is to empirically determine the effects of protein load on resolution. A monoclonal antibody (mAb) containing a discrete distribution of charge variants was used as a test system using our previously developed mixed-bed column. Resolution was determined as a function of protein load using HPLC, for loads ranging from analytical injections to values comparable in magnitude to the protein equilibrium binding capacity of the strong base resin component of the mixed-bed. The second objective is to develop a model to predict retention and resolution at high protein loads, where protein binding cannot be described by a linear isotherm and competition between charge variants for the strong base resin functional groups cannot be neglected.

\subsection{Theoretical development}

For our mixed-bed approach, $\mathrm{pH}$ gradient generation and protein binding occur on the two separate resin components, so mutually independent models can be used to 
describe each phenomenon. These two models are then coupled through the relationship between protein binding and the local values of $\mathrm{pH}$ and counterion concentration at each point and time in the mixed-bed.

\subsubsection{Prediction of induced $\mathrm{pH}$ gradients}

The model used to describe counterion interactions on the weak base resin component of the mixed-bed is the same as that described in Chapter 2 (13) and is based on the following four assumptions: (a) both resins are evenly distributed throughout the column; (b) the buffering species do not interact with either resin; (c) counterion exchange occurs only on the weak base resin; and (d) local equilibrium exists for the counterion exchange on the weak base resin. These four assumptions, validated in Chapter 2 (13) lead to the following equations for amine buffer species with chloride as the counterion:

a. Buffer species deprotonation equilibria

b. Solution electroneutrality

$$
C_{B_{i} H^{+}}=\frac{C_{B_{i}}^{0}}{1+\frac{K_{a, B_{i}}}{C_{H^{+}}}}
$$

$$
C_{H^{+}}+\sum_{i} C_{B_{i} H^{+}}=\frac{K_{W}}{C_{H^{+}}}+C_{C l^{-}}
$$

c. Chloride-hydroxide exchange equilibrium

$$
q_{C l^{-}, w}=\frac{1}{2}\left\{\frac{-C_{H^{+}} C_{C l^{-}}}{K_{R, w}}+\left[\left(\frac{C_{H^{+}} C_{C l^{-}}}{K_{R, w}}\right)^{2}+\frac{4 q_{R . w}^{0} C_{H^{+}} C_{C l^{-}}}{K_{R, w}}\right]^{\frac{1}{2}}\right\}
$$


d. Material balances for the column

$$
\begin{gathered}
u \frac{\partial C_{B_{i}}}{\partial x}+\varepsilon_{t} \frac{\partial C_{B_{i}}}{\partial t}=0 \\
u \frac{\partial C_{C l}}{\partial x}+\varepsilon_{t} \frac{\partial C_{C l^{-}}}{\partial t}+(1-\varepsilon) \varphi_{w}\left(1-\varepsilon_{p, w}\right) \frac{\partial q_{C l^{\prime}, w}}{\partial t}=0
\end{gathered}
$$

In these equations, $C_{B_{i}}^{0}$ and $C_{B_{i} H^{+}}$are, respectively, the total and protonated concentrations of amine buffer species $B_{i}, K_{a, B_{i}}$ is the corresponding deprotonation equilibrium constant, $K_{W}$ is the ionic product of water, $q_{R, w}^{0}$ and $K_{R, w}$ are, respectively, the concentration of weak base ligands in the weak anion exchanger and the corresponding deprotonation constant, and $u, x$, and $t$ are, respectively, the mobile phase superficial velocity, the column length coordinate, and time, respectively. The quantity $\varepsilon_{t}=\varepsilon+(1-\varepsilon)\left[\varphi_{w} \varepsilon_{p, w}+\left(1-\varphi_{w}\right) \varepsilon_{p, s}\right]$ is the total column porosity where $\varepsilon$ is the extraparticle porosity of the mixed-bed, $\varepsilon_{p, w}$ and $\varepsilon_{p, s}$ are the intraparticle porosities of the weak and strong base resin, respectively, and $\varphi_{w}$ is the volume fraction of the weak base resin in the mixed-bed. The $q$-values in these equations are resin-phase concentrations expressed in terms of solid resin volume, thereby excluding the retention within the intraparticle void space. As shown in Chapters 2 and $3(13,14)$, these equations can be solved either analytically, using the method of characteristics, or numerically, discretizing Eqs. (4.4) and (4.5) by finite differences. The numerical solution approach was used in this work. The resin properties for this model ( $\varepsilon_{p, w}=0.44, \varepsilon_{p, s}=0.63, q_{R, w}^{0}=$ $3.45 \mathrm{mmol} / \mathrm{ml}$ resin solid, and $\left.p K_{R, w}=9.75\right)$ were determined experimentally as 
discussed in Chapter 2 and $3(13,14)$ while the $p K_{a}$-values for the amine buffers were those obtained from Beynon and Easterby (15).

\subsubsection{Prediction of protein binding and elution}

Protein binding to the strong base resin component of the mixed-bed is a function of both the local $\mathrm{pH}$ and the counterion concentration. Both vary along the $\mathrm{pH}$ wave induced by the weak base resin. In our prior work in Chapter 3, which was limited to low-load conditions and, hence, linear isotherms, protein binding was described using the stoichiometric displacement model $(15,17)$, which is based on the assumption that a protein, $\mathrm{P}_{i}$, with effective binding charge $z_{i}$ displaces $z_{i}$ counterions when binding to the strong base resin according to the following relationship:

$$
\mathrm{P}_{i}^{z_{i}-}+z_{i} \mathrm{RCl}=\mathrm{R}_{z_{i}} \mathrm{P}_{i}+z_{i} \mathrm{Cl}^{z_{i}}
$$

The following expression was derived for low loadings of each protein i:

$$
q_{s, i}=\frac{K_{e, i}\left(q_{R, s}^{0}\right)^{z_{i}}}{\left(C_{C l^{-}}\right)^{z_{i}}} C_{i}
$$

where $q_{s, i}$ and $C_{i}$ are the bound and solution protein concentrations, respectively, $q_{R, s}^{0}$ is the resin charge density, and $K_{e, i}$ is the equilibrium constant for the exchange reaction shown in Eq. (4.6). In Chapter 3 (14), the values of $q_{R, s}^{0}, z_{i}$ and $K_{e, i}$ were determined for a native $\mathrm{mAb}$ and for a major charge variant based on elution experiments conducted with salt gradients at different $\mathrm{pH}$ values using a column packed with the strong base resin. Over a relatively broad $\mathrm{pH}$ range ( $\mathrm{pH} 7$ to 9$), z_{i}$ was found to be a linear function of $\mathrm{pH}$ for each of the two species, while $q_{R, s}^{0}$ and the values of $K_{e, i}$ for each species could be treated as $\mathrm{pH}$-independent constants. 
The steric mass action law model (SMA) of Brooks and Cramer (18) is used in this work to extend the description of protein binding equilibrium to high protein loads. Accordingly, protein binding in a multicomponent system comprising $n$ species is given by the following equation (19):

$$
q_{s, i}=\frac{K_{e, i}\left[q_{R, s}^{0}-\sum_{j=1}^{n}\left(z_{i}+\sigma_{i}\right) q_{s, i}\right]^{z_{i}}}{\left(C_{C l^{\prime}}\right)^{z_{i}}} C_{i}
$$

where $\sigma_{i}$ is the so-called hindrance parameter, which is introduced to describe the number of functional groups on the resin surface that are shielded by a bound protein molecule. Since the emphasis of this work is on protein charge variants that have the same size and only small differences in charge, the same value of $\sigma$, independent of $\mathrm{pH}$, can be expected for each species.

The final component of the model for protein binding to the strong base resin describes the rate of mass transfer. Because of the low diffusivities, pore diffusion is expected to be the main resistance and, thus, the dominant contribution to band broadening. Following our work in Chapter 3 (14), the rate of protein adsorption and desorption is described by the following linear driving force (LDF) model (20):

$$
\frac{\partial \bar{q}_{s, i}}{\partial t}=\frac{15 D_{e, i}}{r_{p}^{2}}\left(C_{i}-C_{i}^{*}\right)
$$

where $\bar{q}_{s, i} \sim\left(1-\varepsilon_{p, s}\right) q_{s, i}$ is the protein concentration in the strong base resin averaged over the particle volume, $D_{e, i}$ is the effective pore diffusivity, and $r_{p}$ is the resin particle radius. $C_{i}^{*}$ is the protein solution concentration in equilibrium with $q_{s, i}$ and is obtained from Eq. (4.8). Since the emphasis of this work is on overloaded conditions, where the 
$q_{s, i}$-values are large, protein retention in the solution phase within the particle pores is neglected.

In order to predict the elution profile for overloaded conditions in the mixed-bed column, the following material balance is written for each protein species:

$$
u \frac{\partial C_{i}}{\partial x}+\varepsilon \frac{\partial C_{i}}{\partial t}+(1-\varepsilon)\left(1-\varphi_{w}\right) \frac{\partial \bar{q}_{s, i}}{\partial t}=0
$$

and solved together with Eqs. (4.8) and (4.9) using the values of $\mathrm{pH}$ and $\mathrm{C}_{\mathrm{Cl}^{-}}$predicted by the $\mathrm{pH}$ gradient model, Eqs. (4.1)-(4.5). In this work, the combined equations were solved numerically by backwards finite differences solving the resulting system of ordinary differential equations by Gear's method using subroutine DVIPAG in the

IMSL $^{\circledR}$ Numerical Libraries (Rogue Wave Software, Boulder, CO, USA) as described in Chapter 3 (14). The effects of numerical dispersion, which are inherent with this solution method, were minimized by using 100 discretization points. As shown in Chapters 2 and $3(13,14)$, this number resulted in insignificant additional band broadening beyond that caused by intraparticle mass transfer.

\subsection{Experimental}

\subsubsection{Materials}

The resins used in this work, AG 4-X4 from Bio-Rad Laboratories (Hercules, CA, USA), and SOURCE 30Q from GE Healthcare (Piscataway, NJ, USA), are the same as those used in Chapter 3 (14). The relevant resin properties are summarized in Table 4.1. AG 4$\mathrm{X} 4$ is a weak anion exchanger with trimethylamine functional groups on irregularly shaped particles 50-200 $\mu \mathrm{m}$ in size, and features a $1.4 \mathrm{kDa}$ size exclusion limit. 
SOURCE 30 Q is a strong anion exchanger with quaternary amine functional groups on poly(styrene-divinyl benzene) spherical particles with an average diameter of $28 \mu \mathrm{m}$, and large pores that provide a high size exclusion limit.

All buffer chemicals were of ACS reagent grade and were obtained from Thermo Fisher Scientific (Waltham, MA, USA). For this work, the test protein was a monoclonal antibody $(\mathrm{mAb})\left(\operatorname{IgG} 1, M_{r} \sim 150 \mathrm{kDa}, \mathrm{pI} \sim 8.2\right)$ provided by MedImmune (Gaithersburg, MD, USA). Size exclusion chromatography with a Superdex 200 column from GE Healthcare (Piscataway, NJ, USA) indicates that the mAb sample was essentially $100 \%$ monomer. However, isoelectric focusing with precast IsoGel® Agarose IEF plates $(\mathrm{pH} 7$ 11) from Lonza, Inc. (Allandale, NJ, USA) show the presence of a main charge variant with $\mathrm{pI} \sim 8.0$ plus additional minor charge variants with lower $\mathrm{pI}(14)$. HPLC analyses were conducted on a Model e2695 system from Waters Corporation (Milford, MA, USA) using a ProPac WCX-10 pellicular CEX column obtained from Dionex (Sunnyvale, CA, USA) with a $26 \mathrm{CV}$ gradient from 0 to $40 \mathrm{mM} \mathrm{NaCl}$ in $20 \mathrm{mM}$ sodium phosphate buffer at $\mathrm{pH}$ 6.75. Figure 4.1 shows a typical HPLC analysis result for the mAb feedstock. Based on the areas of the three main peaks, the crude mAb contains about $70 \%$ of the native species (assumed to be the largest of the three peaks) as well as two main variants, V1 and V2, corresponding to about 23 and 7\% of the total protein. As discussed in our prior work $(13,14)$, the variants are likely a result of deamidation of the native protein. Accordingly, the protein net charge becomes more negative for the variants, resulting in weaker retention and, thus, earlier elution on the analytical CEX column. 
Table 4.1 - Summary of relevant resin properties

\begin{tabular}{|l|c|c|}
\hline Resin & AG 4-X4 & SOURCE 30Q \\
\hline Functionality & $\begin{array}{c}\text { Tertiary } \\
\text { amine }\end{array}$ & $\begin{array}{c}\text { Quaternary } \\
\text { ammonium } \\
\text { ion }\end{array}$ \\
\hline Mean particle diameter $(\mu \mathrm{m})(14)$ & $50-200^{(\mathrm{a})}$ & 28 \\
\hline Intraparticle porosity ${ }^{(\mathrm{b})}(14)$ & 0.44 & 0.63 \\
\hline Size exclusion limit $(\mathrm{nm})^{(\mathrm{c})}(14)$ & $<2$ & $>40$ \\
\hline Weak base content in $\mathrm{mmol} / \mathrm{ml} \mathrm{resin} \mathrm{solid}^{(\mathrm{d})}(14)$ & 3.45 & - \\
\hline
\end{tabular}

(a) Irregular shape - values are the range of longest dimensions observed for hydrated particles

(b) Based on retention of glucose

(c) Hydrodynamic radius of dextran that is fully excluded

(d) Based on potentiometric titrations 


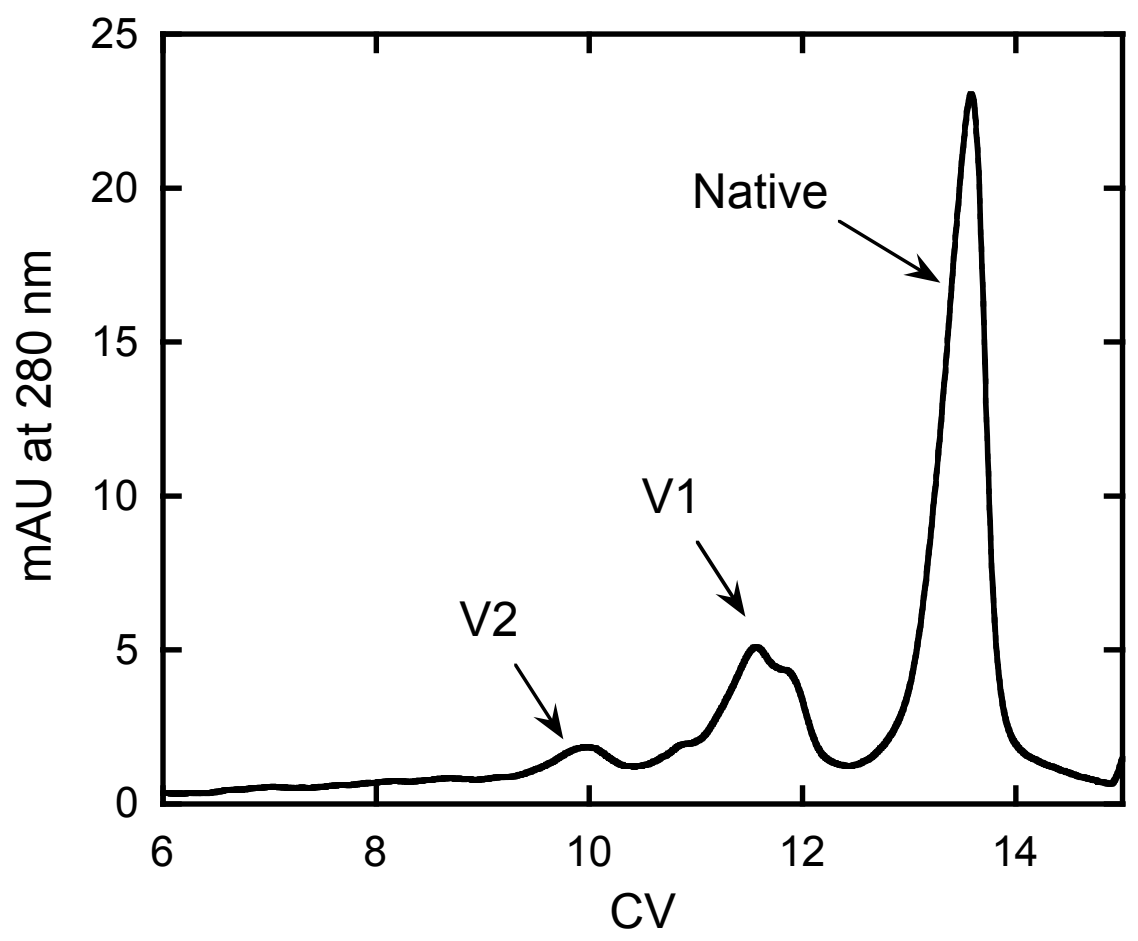

Figure 4.1 - HPLC analysis of mAb feedstock with a ProPac WCX-10 pellicular CEX column. Three main peaks are identified as the native mAb (70\%), variants V1 (23\%), and V2 (7\%) of the total area. 
The buffers in this study contained a 95/5 ratio of ethanolamine $\left(p K_{a}=9.50\right.$ at 25 $\left.{ }^{\circ} \mathrm{C}\right)$ and Tris $\left(p K_{a}=8.06\right.$ at $\left.25^{\circ} \mathrm{C}\right)$ that were prepared by titrating $\mathrm{HCl}$ solutions of known concentration to the desired $\mathrm{pH}$ values with the amine species in free-base form. As shown in Chapters 2 and $3(13,14)$, this ratio was able to produce a $\mathrm{pH}$ gradient of reasonable duration with sufficient buffering capacity at both ends of the gradient. Since temperature affects the $p K_{a}$ values of the amine buffers used, the temperature was carefully monitored, with all experiments conducted at room temperature, $24 \pm 2{ }^{\circ} \mathrm{C}$. A glass combination electrode (S20 SevenEasy pH, Mettler Toledo, Columbus, OH, USA) was used to measure the $\mathrm{pH}$ with a precision of $\pm 0.01 \mathrm{pH}$ units.

\subsubsection{Methods}

\section{Adsorption Isotherms}

Batch isotherm experiments were conducted for the mAb on SOURCE 30Q at $\mathrm{pH}$ 9.0, 8.5, 8.0, and 7.5 using buffers with 15,30 , and $50 \mathrm{mM}$ ethanolamine. The resin was first equilibrated with each buffer and then centrifuged for 12 minutes at $5000 \mathrm{rpm}$ in 1.5 $\mathrm{ml}$ filter vials to remove liquid from the resin particles. Separate 1.5-ml mAb samples with protein concentrations between 0.1 and $3.0 \mathrm{mg} / \mathrm{ml}$ were buffer-exchanged using 30,000 MWCO ultrafiltration centrifuge vials and added to $1.7-\mathrm{ml}$ vials together with 10 to $75 \mathrm{mg}$ of resin and mixed continuously on a rotating wheel at $30-60 \mathrm{rpm}$ for 20 hours. After equilibration, the vials were centrifuged for two minutes at $5000 \mathrm{rpm}$ to settle out the resin. The supernatant mAb concentration was then determined from the UV absorbance at $280 \mathrm{~nm}$ using a $5 \mathrm{~mm}$ quartz cuvette, with dilutions made to keep the absorbance less than or equal to 1 to ensure linearity of response. The total protein bound to the resin for each condition was then calculated by mass balance. 


\section{Mixed-bed pH gradient based separations}

Mixed-beds of AG 4-X4 and SOURCE 30Q were prepared by mixing the two resins in the desired volumetric proportion and packing the mixed slurry in a $5 \mathrm{~mm}$ diameter x $200 \mathrm{~mm}$ long Tricorn column (GE Healthcare, Piscataway, NJ, USA) as described in Chapters 2 and $3(13,14)$. The column used for the experiments in this work contained 14 volume $\%$ AG 4-X4 and had a bed height of $20.2 \mathrm{~cm}$. The experiments were conducted using an ÄKTA Explorer 10 from GE Healthcare (Piscataway, NJ, USA) according to the following procedure. The mixed-bed was first equilibrated with about 30 column volumes $(C V)$ of the high $\mathrm{pH}$ buffer, which contained $15 \mathrm{mM} \mathrm{Cl}^{-}$and a $95 / 5$ mixture of ethanolamine and Tris at $\mathrm{pH}$ 9.0. The crude $\mathrm{mAb}$, dissolved in the initial buffer at a concentration of $8.6 \mathrm{mg} / \mathrm{ml}$ was then loaded to the column in volume sufficient to achieve protein loads between 0.45 and $21.5 \mathrm{mg} / \mathrm{ml}$ of total column volume. After a 5 $C V$ wash with the load buffer, the mobile phase was stepped to a $\mathrm{pH} 7$ buffer also containing $15 \mathrm{mM} \mathrm{Cl}^{-}$and a 95/5 mixture of ethanolamine and Tris. The flow rate was kept at $1 \mathrm{ml} / \mathrm{min}$ for all steps, corresponding to a superficial velocity of $300 \mathrm{~cm} / \mathrm{h}$. Elution was monitored with the UV, conductivity, and $\mathrm{pH}$ detectors of the ÄKTA Explorer 10 unit. The UV detector signal was converted to protein concentration using the mAb extinction coefficient, $1.49 \mathrm{AU} /(\mathrm{mg} / \mathrm{ml})$, according to Lambert-Beer's law. In addition, fraction collected at various time intervals were buffer exchanged to $\mathrm{pH} 6.75$ phosphate and analyzed by HPLC with a ProPac WCX pellicular CEX column as described in Section 4.3.1 to determine their composition. Note that, obviously, the order of elution in the ProPac CEX column, where the charge variants elute earlier than the main native 
species, is opposite to the order of elution along the $\mathrm{pH}$ gradient in the mixed-bed AEX column, where the charge variants elute later.

\subsection{Results and discussion}

\subsubsection{Adsorption isotherms}

Figure 4.2 shows the batch isotherms for adsorption of the crude mAb mixture on SOURCE 30Q at different $\mathrm{pH}$ values and chloride concentrations in $95 / 5$ ethanolamine/Tris mixed buffers. As expected, the highest protein binding occurs at the highest $\mathrm{pH}$, where the protein has the highest negative charge, and at the lowest chloride concentration, where competition by the chloride counterions is lowest. Note that significant binding occurs even at or below the mAb pI, indicating that protein binding is likely a result of clustered negatively charged residues on specific portions of the protein surface.

The parameters used to describe the adsorption isotherm data in terms of the SMA model were determined as follows. The mAb binding behavior at low loadings on SOURCE 30Q was determined in Chapter 3 (14) for purified samples of the native species (N) and of the main variant (V1) using linear salt gradient elution chromatography at different $\mathrm{pH}$ values. These determinations yielded the following values for the resin charge density, $q_{R, s}^{0}$, the equilibrium constants, $K_{e, N}$ and $K_{e, V 1}$, and for the protein effective charge values, $z_{N}$ and $z_{V 1}$, valid at $\mathrm{pH}$ values between 7.5 and 9: 


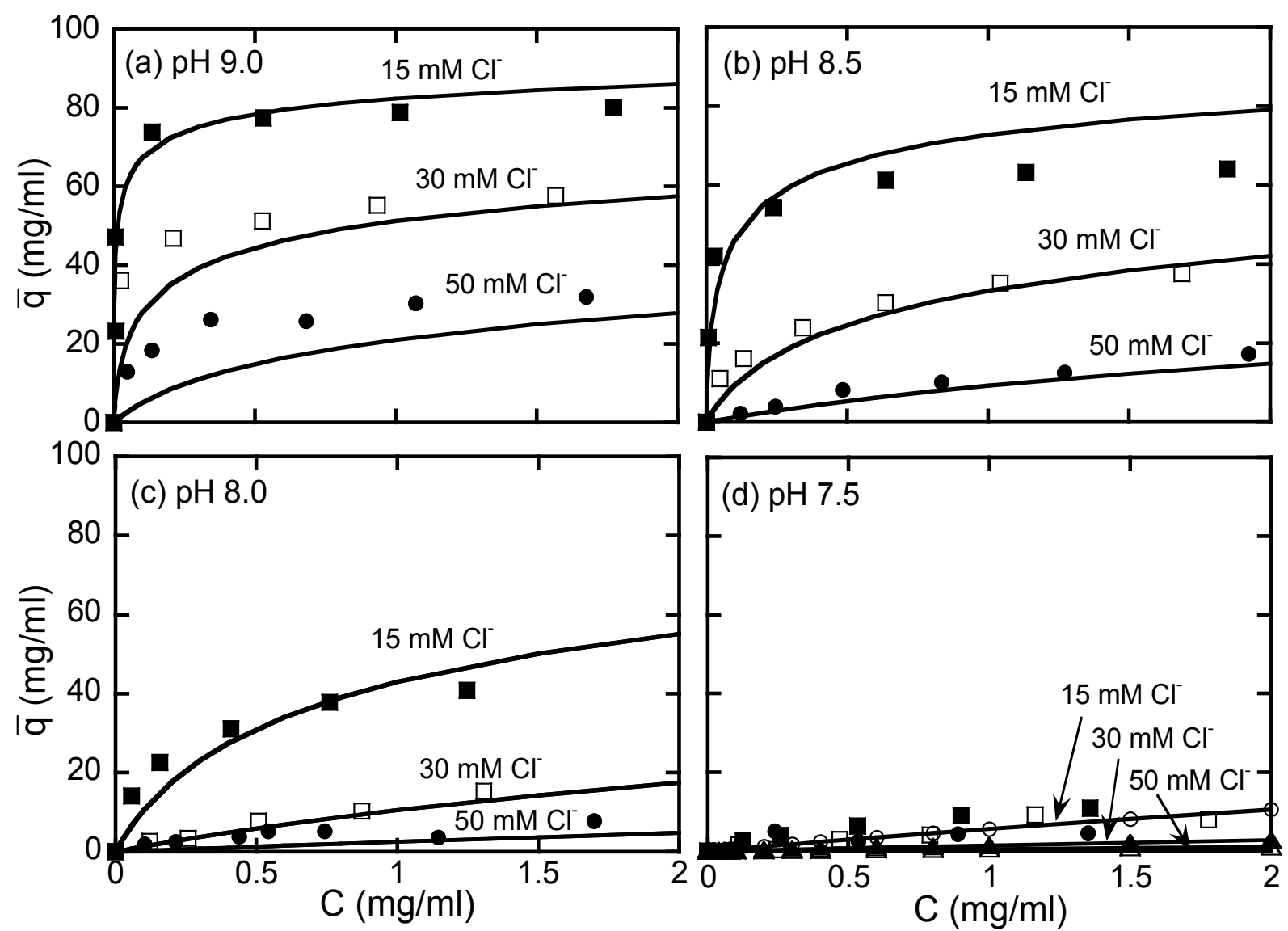

Figure 4.2 - Adsorption isotherms for the crude mAb feedstock on SOURCE 30Q at pH 9.0 (a), 8.5 (b), 8.0 (c), and 7.5 (d) in 95/5 ethanolamine/Tris buffers containing different chloride concentrations. The total bound protein concentration shown on the y-axis, $\bar{q}$, is expressed in $\mathrm{mg}$ per $\mathrm{ml}$ of resin particle volume. Lines are based on the three-component SMA model Eq. (8) with parameters described in the text. 


$$
\begin{aligned}
& q_{R, s}^{0}=0.160 \mathrm{mmol} / \mathrm{ml} \text { resin solid } \\
& K_{e, N}=0.226 \\
& K_{e, V 1}=0.168 \\
& z_{N}=2.826 \times p H-19.77 \\
& z_{V 1}=2.608 \times p H-17.47
\end{aligned}
$$

The same parameters were used in this work to describe the isotherm data. However, for improved accuracy, based on the HPLC analysis in Figure 4.1 and on the $\mathrm{pH}$ gradient elution behavior discussed below, at least a second variant must be included in the description of the mAb binding behavior. Since no data for the behavior of this second, minor variant are available, we simply assumed that:

$$
\begin{aligned}
& K_{e, V 2}=K_{e, V 1} \times \frac{K_{e, V 1}}{K_{e, N}}=0.125 \\
& z_{V 2}=z_{V 1}+\left(z_{V 1}-z_{N}\right)=2.390 \times p H-15.17
\end{aligned}
$$

This assumption is consistent with the origin of the charge variants present in the $\mathrm{mAb}$ sample, which, as discussed above, are likely related to deamidation. With increasing deamidation, variants with slightly more negative net charge are produced resulting in stronger retention and tailing elution profiles in the mixed-bed AEX column. With this assumption, the only remaining parameters in the SMA expression for a three-component system, Eq. (4.8), are the $\sigma$-values. Since the variants have the same size and similar charge, we assumed the same $\sigma$ for all three species and determined best-fit value of $\sigma=75$ by regressing the isotherm data. Since the selectivity is expected to be small and the change in solution concentration upon adsorption was generally less than $30 \%$, we assumed that the percentage of each species in the equilibrated bulk solution was the same as that present in the mAb feedstock. As seen in Figure 4.2, the three-component 
SMA model provides a reasonably accurate description of protein binding as a function of $\mathrm{pH}$, protein concentration, and chloride concentration.

\subsubsection{Mixed-bed pH gradient based separations}

Figures 4.3-4.6 show the results of mixed-bed $\mathrm{pH}$ gradient based chromatographic separations at increasing protein loadings from 0.45 to $21.5 \mathrm{mg} / \mathrm{ml}$. It should be noted that, based on the isotherm data and accounting for the extraparticle porosity and the fraction of SOURCE $30 \mathrm{Q}$ in the column, the maximum mixed-bed column mAb binding capacity is on the order of $40 \mathrm{mg} / \mathrm{ml}$ of mixed-bed volume at $\mathrm{pH} 9$ and $15 \mathrm{mM} \mathrm{Cl}^{-}$. Thus the protein loads used in induced $\mathrm{pH}$ gradient runs span the range from an analytical injection at $0.45 \mathrm{mg} / \mathrm{ml}$ to conditions where about half of the column protein binding capacity is used.

The data at the lowest protein load $(0.45 \mathrm{mg} / \mathrm{ml}$, Fig. 4.3$)$ are the same as those reported in Fig. 3.6c in Chapter 3 (14). The lines show the predictions based on the full non-linear isotherm model using the effective pore diffusivity $D_{e}=7.2 \times 10^{-8} \mathrm{~cm}^{2} / \mathrm{s}$, determined in Chapter 3 (14) for all three protein species. All other model parameters were as described above. Because of the small protein load used in this case, the model lines are indistinguishable from those obtained from our previous linear-isotherm model (14) indicating that the full model extrapolates to the correct dilute limit. Although model predictions somewhat underestimate the elution $\mathrm{pH}$, the predicted peak shape is in good agreement with the experimental data. It should be noted that predicting retention in these systems is inherently difficult, since protein binding is very sensitive to both $\mathrm{pH}$ and counterion concentration, so that even small errors in predicting the latter values can translate to large errors in predicted protein retention. 


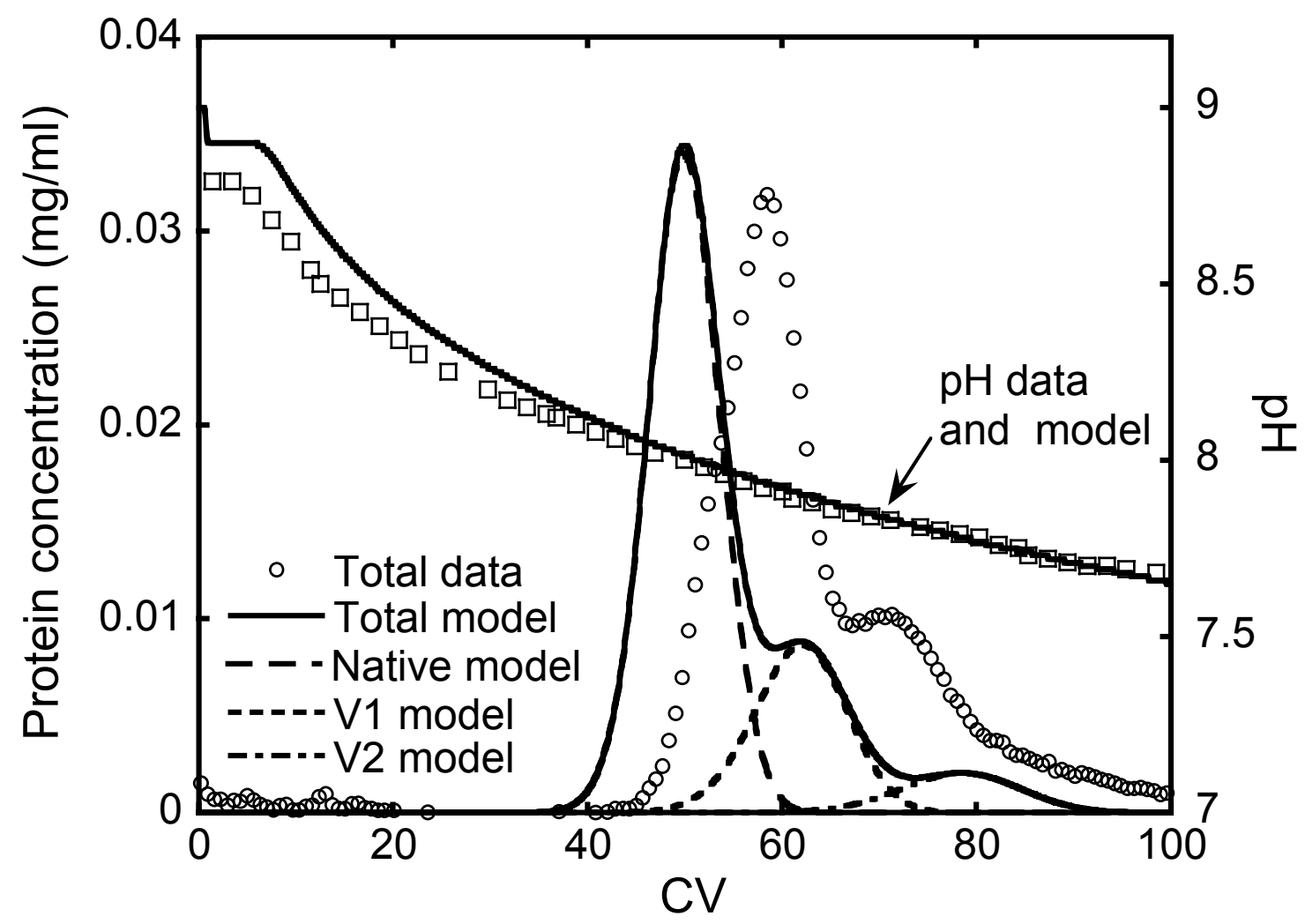

Figure 4.3 - Separation of $\mathrm{mAb}$ charge variants using the mixed-bed column with a $0.45 \mathrm{mg} / \mathrm{ml}$ total protein load. Dots are experimental data and lines are model predictions. 


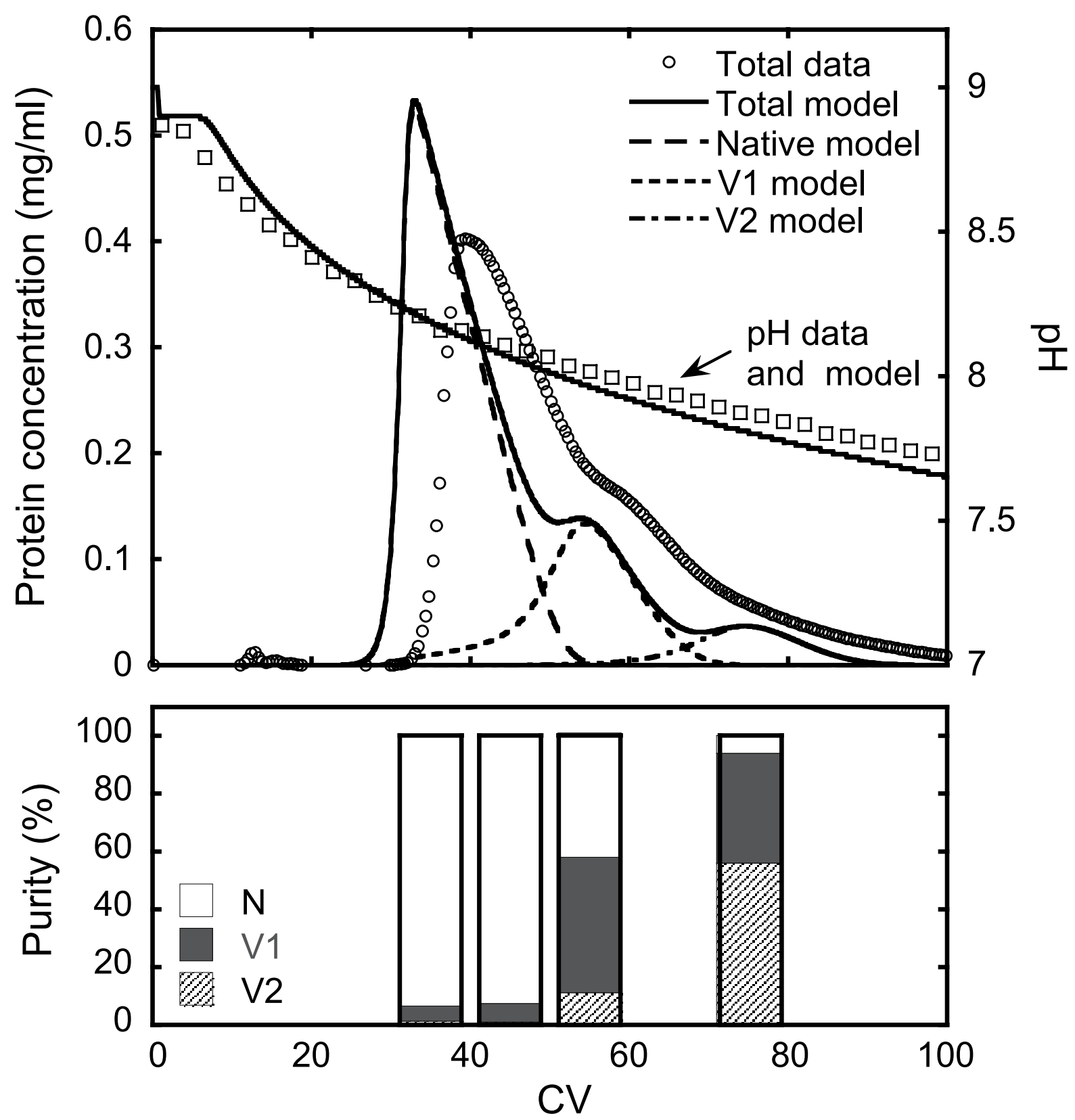

Figure 4.4 - Separation of mAb charge variants using the mixed-bed column with an $8.6 \mathrm{mg} / \mathrm{ml}$ total protein load. Dots are experimental data and lines are model predictions. Purity values determined by HPLC are shown for fractions collected at various times along the $\mathrm{pH}$ gradient. 

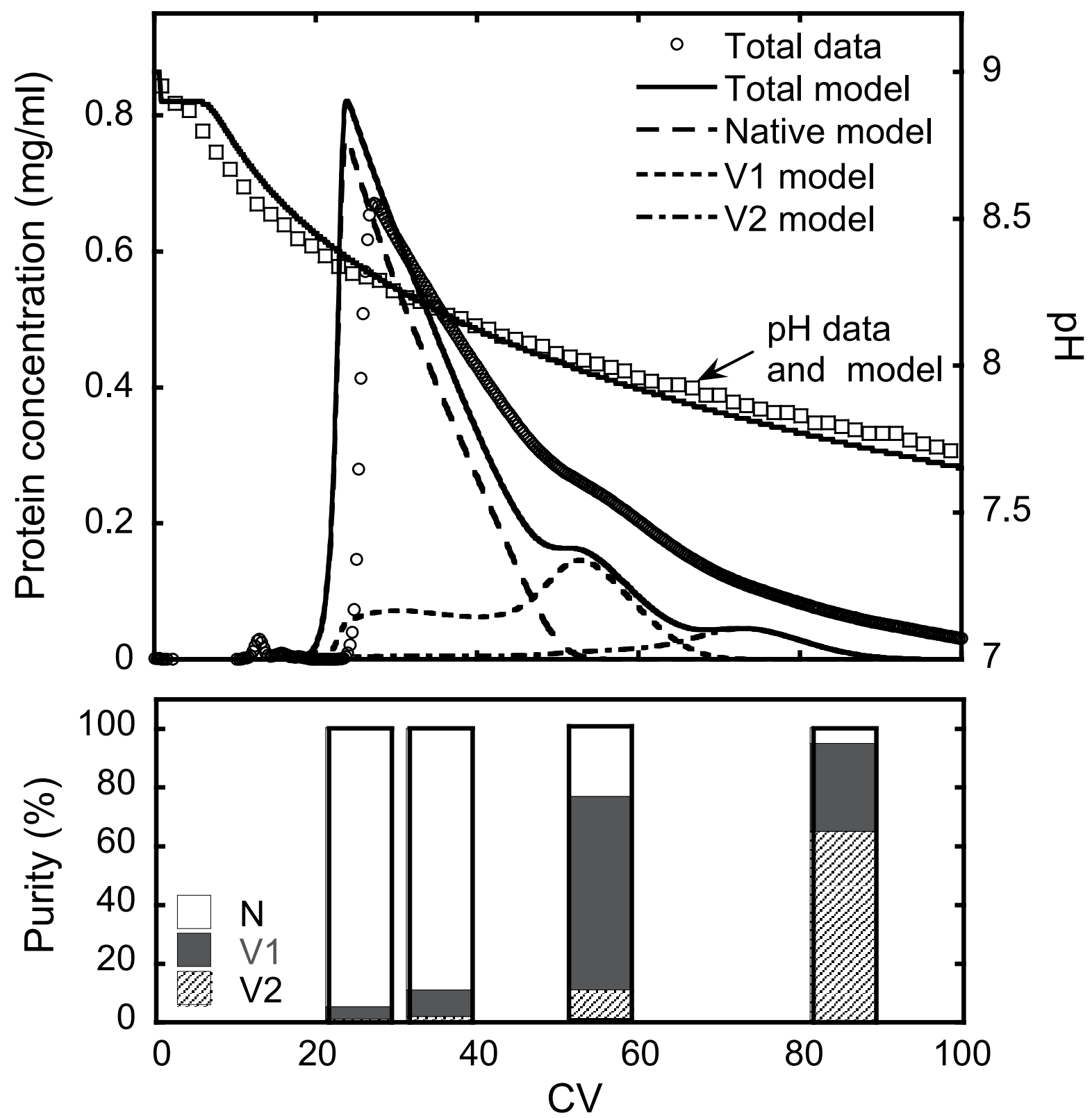

Figure 4.5 - Separation of mAb charge variants using the mixed-bed column with a $15 \mathrm{mg} / \mathrm{ml}$ total protein load. Dots are experimental data and lines are model predictions. Purity values determined by HPLC are shown for fractions collected at various times along the $\mathrm{pH}$ gradient. 

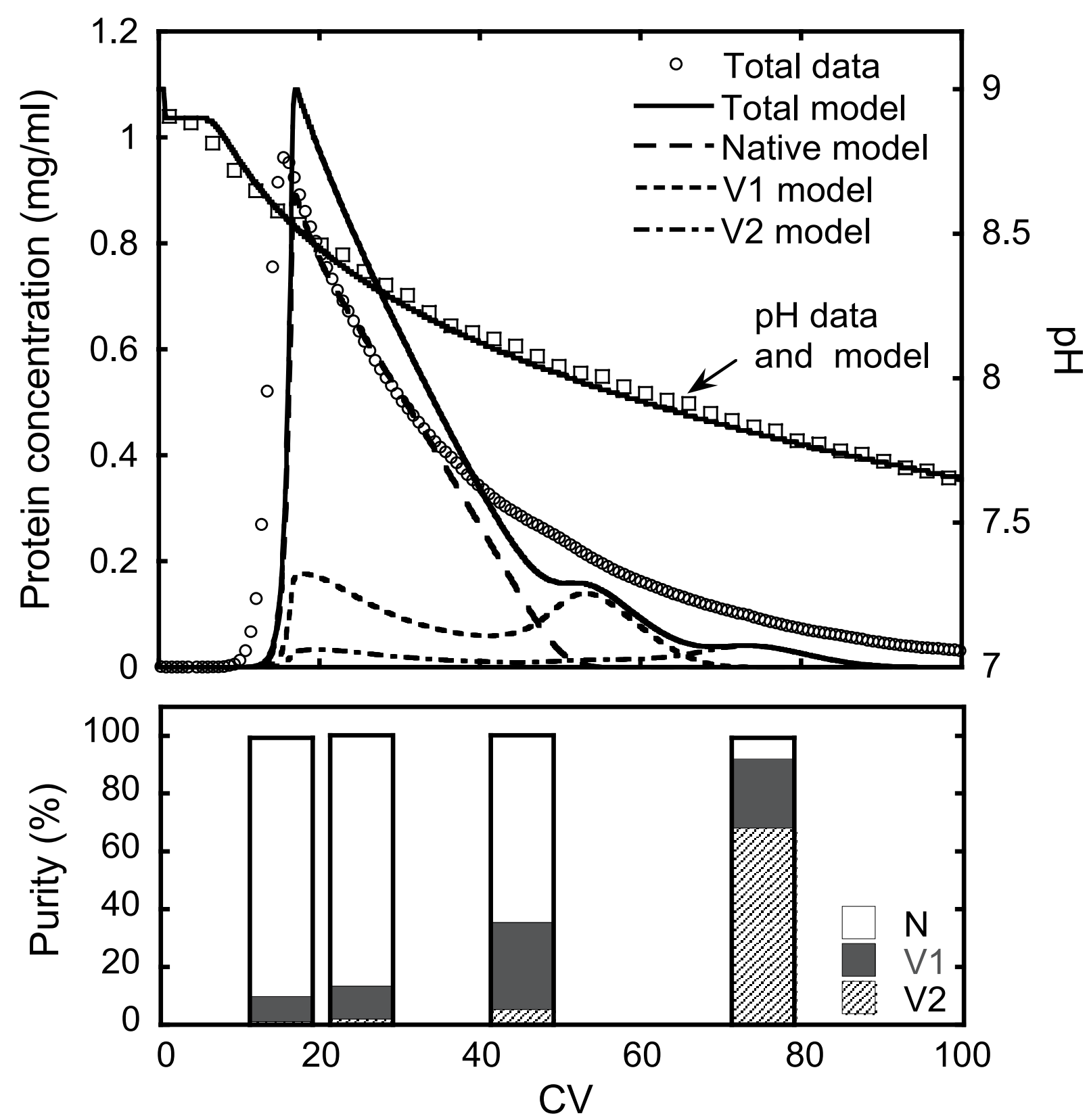

Figure 4.6 - Separation of $\mathrm{mAb}$ charge variants using the mixed-bed column with a $21.5 \mathrm{mg} / \mathrm{ml}$ total protein load. Dots are experimental data and lines are model predictions. Purity values determined by HPLC are shown for fractions collected at various times along the $\mathrm{pH}$ gradient. 
Figure 4.4 shows the results for an $8.6-\mathrm{mg} / \mathrm{ml}$ protein load along with the purity of selected fractions determined by HPLC. For these conditions, the eluted peak becomes more skewed and elutes earlier in the gradient as a result of the overloaded conditions. As seen in the figure, fractions with high purity in the native species and fractions enriched in the two variants were collected at various points along the $\mathrm{pH}$ gradient. Model predictions using the same parameters as those used in Figure 4.3 are consistent with the experimental results. Although the elution $\mathrm{pH}$ is somewhat underestimated, the peak shape is predicted well. Figures 4.5 and 4.6 at further increased protein loads of 15 and $21.5 \mathrm{mg} / \mathrm{ml}$, respectively, show the same general trends. As the protein load is increased, the peak elutes earlier and becomes even more skewed, resulting in less effective separation, consistent with model predictions. Even at the highest load, however, fractions with high purity in the native form are still obtained along with fractions that are highly enriched in the variants.

As seen in Figs. 4.3-4.6, variation in the protein load has no significant effect on the induced $\mathrm{pH}$ gradient. In fact, for all four cases the experimental $\mathrm{pH}$ profiles are consistent with the same model prediction confirming that decoupling of $\mathrm{pH}$ gradient generation and protein binding has been effectively achieved.

\subsection{Conclusions}

The operability of a mixed-bed column for the chromatographic separations of protein charge variants with induced $\mathrm{pH}$ gradients is demonstrated over a broad range of protein loads, from analytical injections to loads at high as $50 \%$ of the column equilibrium protein binding capacity. The mixed-bed system, comprising a mixture of a small-pore weak base resin and a large-pore strong base resin, combines the simplicity 
and reliability of a $\mathrm{pH}$ step elution process with the high resolution capability of a $\mathrm{pH}$ gradient operation. Decoupling of the $\mathrm{pH}$ gradient generating functions of the small-pore weak base resin and the protein binding function of the strong base resin, results in induced $\mathrm{pH}$ gradients that are unaffected by the protein load. Moreover, decoupling the two functions allows for the independent characterization and modeling of the phenomena occurring in each resin. For the resolution of the charge variants present in a model mAb, separation of these closely related species is attained in a laboratory scale column. Consistent with model predictions based on parameters determined separately for each resin component, resolution decreases as the protein load increases as a result of competitive binding and non-linear isotherm behavior. Even at the highest load used, however, fractions with high purity in the native mAb and fractions highly enriched in the variants are obtained along the induced $\mathrm{pH}$ gradient. Model predictions based on an extension of our previously developed linear model by incorporating the SMA model to describe competitive binding for overloaded conditions, are found to be in substantial agreement with the experimental trends providing a tool to assess the ability of different strong base resins to achieve resolution in the mixed-bed system based on independently determined retention, equilibrium, and rate parameters. 


\subsection{Symbols}

$C_{i} \quad$ mobile phase concentration $(\mathrm{mmol} / \mathrm{ml})$

$C_{i}^{*} \quad$ mobile phase concentration in equilibrium with the protein concentration in the particle $(\mathrm{mmol} / \mathrm{ml})$

$\mathrm{CV}$ number of column volumes passed

$D_{e, i} \quad$ effective diffusivity $\left(\mathrm{cm}^{2} / \mathrm{s}\right)$

$K_{a, B_{i}} \quad$ deprotonation equilibrium constant for amine buffer $B_{i}(\mathrm{mmol} / \mathrm{ml})$

$K_{e, i} \quad$ equilibrium constant in stoichiometric displacement model, Eq. (6)

$K_{R, w} \quad$ deprotonation constant for weak base ligands ( $\left.\mathrm{mmol} / \mathrm{ml}\right)$

$K_{W} \quad$ ionic product of water $(\mathrm{mmol} / \mathrm{ml})^{2}$

$q_{i} \quad$ adsorbed concentration ( $\mathrm{mmol} / \mathrm{ml}$ of resin solid)

$q_{R, w}^{0} \quad$ concentration of weak base ligands in weak base exchanger ( $\mathrm{mmol} / \mathrm{ml}$ of resin solid)

$q_{R, s}^{0} \quad$ concentration of strong base ligands in strong base exchanger $(\mathrm{mmol} / \mathrm{ml}$ of resin solid)

$\bar{q}_{s} \quad$ particle-average concentration $(\mathrm{mmol} / \mathrm{ml})$

$r_{p} \quad$ particle radius $(\mathrm{cm})$

$t \quad$ time (s)

$u \quad$ mobile phase superficial velocity $(\mathrm{cm} / \mathrm{s})$

$v$ mobile phase interstitial velocity $(\mathrm{cm} / \mathrm{s})$

$x \quad$ column axial coordinate $(\mathrm{cm})$

$z_{i} \quad$ protein effective binding charge 


\section{Greek symbols}

$\varepsilon \quad$ extraparticle bed porosity (void fraction)

$\varepsilon_{p, s} \quad$ intraparticle porosity of strong base resin

$\varepsilon_{p, w} \quad$ intraparticle porosity of weak base resin

$\varepsilon_{t} \quad$ total column porosity

$\varphi_{w} \quad$ volume fraction of weak base resin in the mixed-bed column

$\sigma_{i} \quad$ hindrance parameter in SMA model, Eq. (8) 


\subsection{References}

1. Harris, R. J.; Kabakoff, B.; Macchi, F.D.; Shen, F.J.; Kwong, M.; Andya, J.D., Shire, S.J.; Bjork, N.; Totpal, K.; Chen, B. (2001) Identification of multiple sources of charge heterogeneity in a recombinant antibody. J. Chromatogr. B. 752: $233-245$.

2. Farnan D.; Moreno, G.T. (2009) Multiproduct high-resolution monoclonal antibody charge variant separations by $\mathrm{pH}$ gradient ion-exchange chromatography. Anal. Chem. 81: 8846-8857.

3. Rea, J.C.; Moreno, G.T; Lou, Y.; Farnan, D. (2011) Validation of a pH gradientbased ion-exchange chromatography method for high-resolution monoclonal antibody charge variant separations. J. Pharm. Biomed. Anal. 54: 317-323.

4. Ng, P.K.; He, J.; Snyder, M.A. (2009) Separation of protein mixtures using pHgradient cation-exchange chromatography. J. Chromatogr. A. 1216: 1372-1376.

5. Sluyterman, L.; Elgersma, O. (1978) Chromatofocusing: Isoelectric Focusing on Ion-Exchange Columns I. General Principles. J. Chromatogr. 150: 17-30.

6. Sluyterman, L.; Wijdenes, J. (1978) Chromatofocusing: Isoelectric Focusing on Ion-Exchange Columns II. Experimental Verfication. J. Chromatogr. 150: 31-44.

7. Bates, R.C.; Frey, D.D. (1998) Quasi-linear pH gradients for chromatofocusing using simple buffer mixtures: local equilibrium theory and experimental verification. J. Chromatogr. A. 814: 43-54.

8. Kang, X.; Bates, R.C.; Frey, D.D. (2000) High-performance chromatofocusing using linear and concave $\mathrm{pH}$ gradients formed with simple buffer mixtures II. Separation of proteins. J. Chromatogr. A. 890: 37-43.

9. GE Healthcare Bio-Sciences, Ion Exchange Chromatography and Chromatofocusing: Principles and Methods, Piscataway, NJ, 2010.

10. Kang, X.; Frey, D.D. (2003) High-performance cation-exchange chromatofocusing of proteins. J. Chromatogr. A. 991: 117-128.

11. Pabst, T.M.; Antos, D.; Carta, G.; Ramasubramanyan, N.; Hunter, A.K. (2008) Protein separations with induced $\mathrm{pH}$ gradients using cation-exchange chromatographic columns containing weak acid groups. J. Chromatogr. A. 1181: 83-94. 
12. Pabst, T.M.; Carta, G.; Ramasubramanyan, N.; Hunter, A.K.; Mensah, P.; Gustafson, M.E. (2008) Separation of protein charge variants with induced $\mathrm{pH}$ gradients using anion exchange chromatographic columns. Biotechnol. Progr. 24: 1096-1106.

13. Vetter, T.A.; Carta, G.; Ferreira, G.; Robbins, D. (2014) Mixed-beds of strong and weak anion exchange resins for protein separations with step-induced $\mathrm{pH}$ gradients. Sep. Sci. Technol. 49: 477-489.

14. Vetter, T.A.; Carta, G.; Ferreira, G.; Robbins, D. (2014) Predicting Retention and Resolution of Protein Charge Variants in Mixed-beds of Strong and Weak Anion Exchange Resins with Step-induced pH Gradients," Sep. Sci. Technol., in press, DOI: $10.1080 / 01496395.2014 .907810$.

15. Beynon, R.; Easterby, J. (1996) Buffer Solutions. Bath Press: Bath, U.K.

16. Kopaciewicz, W.; Rounds, M.; Fausnaugh, J.; F.E. (1983) Retention model for high-performance ion-exchange chromatography. J. Chromatogr. 266: 3-21.

17. SYamamoto, S.; Nakanishi, K.; Mastuno, R. (1988) Ion Exchange Chromatography of Proteins. New York: Dekker, 1988.

18. Brooks, C.A.; Cramer, S.M. (1992) Steric mass-action ion-exchange displacement profiles and induced salt gradients. AIChE J. 38: 1969-1978.

19. Gallant, S.R.; Kundu, A.; Cramer, S.M. (1995) Modeling non-linear elution of proteins in ion-exchange chromatography. J. Chromatogr. A. 702: 125-142

20. Levan, M.D.; Carta, G. (2007) Adsorption and Ion Exchange. In Perry's Chemical Engineering Handbook, Eighth Edition, D.W. Green (ed.), Section 16, McGraw-Hill, New York. 


\section{Conclusions and recommendations}

\subsection{Conclusions}

The work presented here has shown the utility of the mixed-bed approach for generating induced $\mathrm{pH}$ gradients to separate protein charge variants. Mixed-beds were created by combining a weak base exchanger and a strong base exchanger that were each specifically selected to generate an induced $\mathrm{pH}$ gradient and to provide good mass transfer and selectivity for proteins, respectively. AG 4-X4, a weak base exchanger, was used for this study because it has small pores that exclude proteins and an extremely high weak base ligand content that allows for the creation of induced $\mathrm{pH}$ gradients of useful durations with as little as a $10 \%$ mixed-bed. On the other hand, a number of strong base exchangers were deemed acceptable for use in mixed-beds. Ultimately, SOURCE $30 \mathrm{Q}$ was selected for further study as the mixed-bed strong base exchanger because it showed good selectivity and possesses large pores and a small particle size that improve mass transfer and resolution. Additionally, the disparate particle size between the two resins provided a worst case scenario for studies which demonstrated that the resins are uniformly distributed within a mixed-bed.

Because each of the resins is specifically selected to perform a single function, both process optimization and modeling are simplified, as each phase can be treated independently. A local equilibrium model was developed for induced $\mathrm{pH}$ gradients generated on mixed-beds and was based on the $\mathrm{pK}_{\mathrm{a}}$ for the amine buffering species and the ion exchange equilibria of the counterions and the weak ligands within the resin. Protein retention on the strong base exchanger was described using the Steric Mass 
Action (SMA) model and an assumed linear driving force (LDF) model. In both cases, the models required a newly described expression that accounts for the different phase ratios experienced by the proteins and ions within the column. Modeling parameters were determined experimentally using simple techniques that evaluated each resin separately. The models developed for $\mathrm{pH}$ gradient generation and protein retention were combined, creating a single, numerically solved model that simultaneously describes the step induced $\mathrm{pH}$ gradient and the retention of proteins within it.

Experiments conducted using mixed-beds of AG 4-X4 and SOURCE 30Q demonstrated the ability to resolve the native form and charge variants of a mAb at low protein load conditions $(<1 \mathrm{mg} / \mathrm{ml}$ bed). Increasing the protein load on the column caused earlier elution and an apparent loss of resolution. However, HPLC analysis of eluate fractions for moderate protein loads $(<11 \mathrm{mg} / \mathrm{ml}$ bed) show that good purity can be achieved by cutting the elution peak appropriately. At fully overloaded conditions $(>15$ $\mathrm{mg} / \mathrm{ml}$ bed), resolution is decreased significantly, indicating that this process would be best suited for polishing applications.

A mixed-bed column approach using strong and weak anion exchangers has been shown to be a robust and predictable method for separating protein charge variants at loads appropriate for preparative scale production. Although this technique provides several advantages in terms of resolution, simplicity, and predictability over standard ion exchange chromatography for the purification of charge variants, there are several limitations that must be addressed. First, the non-interacting amine buffers used in this work have temperature sensitive $\mathrm{pK}_{\mathrm{a}} \mathrm{s}$ that can alter the duration of the induced $\mathrm{pH}$ gradient, affecting resolution. Second, the duration of the gradients presented here would 
generally be too long for preparative processes. Finally, the distribution of resins within the mixed-bed could be difficult to standardize and reproduce when packing large-scale columns. In general, these limitations could be overcome with the development of resins specifically designed for mixed-bed applications. The production of weak and strong base materials with the same base matrix and bead size, but with appropriate pore sizing and ligand concentrations, would eliminate any difficulties in packing columns. Additionally, the appropriate choice of weak base ligands with differing $\mathrm{pK}_{\mathrm{a}} \mathrm{s}$ would provide a means to tune the $\mathrm{pH}$ gradient to improve resolution, increase robustness, and reduce elution time.

This work shows that the mixed-bed approach can be a powerful tool for the separation of protein charge variants. The ability to select and characterize each resin phase individually creates a highly flexible system where the resolution, capacity, and duration can be optimized. The model developed here provides a predictive capability for both low and high protein load conditions that minimizes the experimental studies required to establish an optimal separation. Additionally, this model could be used to help design materials better suited to mixed-bed applications.

\subsection{Future work}

The model presented here fully describes the step-induced $\mathrm{pH}$ gradient generation and protein charge variant resolution achieved by using mixed-beds of strong anion exchangers, and the weak anion exchange resin AG 4-X4. However, the mixed-bed concept could be extended in several interesting ways that could improve the purification of proteins. 
The strong and weak phases function independently, so it would be useful to evaluate the use of induced $\mathrm{pH}$ gradients with resins having different functionalities in place of the strong base material. Changes in $\mathrm{pH}$ can affect both the charge and hydrophobicity of proteins, so the use of mixed-mode materials, which contain ligands with multiple mechanisms for interaction, including hydrophobic interactions, could provide beneficial selectivities. In addition to protein charge variants, this approach could provide an improved method for the removal of protein aggregates, which often have a different degree of hydrophobic interaction than native proteins.

In addition to work with mixed-mode anion exchangers, the entire mixed-bed approach should be extended to cation exchangers. Mixed-beds of strong and weak acid resins would function in a manner analogous to the anion exchangers, with the major difference being that the proteins would bind at low $\mathrm{pH}$ and elute as the $\mathrm{pH}$ increases. The numerical model for anion exchangers would require minimal modification to account for the differences in the expressions for ion exchange equilibria for weak cation exchangers. As with the anion exchange mixed-bed, there are also a number of mixedmode cation exchange materials that could be studied in place of the strong cation exchange phase.

Finally, the scope of this study was restricted due to the limited number of suitable weak anion exchange materials commercially available. A great deal of benefit could be achieved by the development of additional weak stationary phases with the appropriate pore structure and ligand concentration. In particular, the use of multiple weak ligand species, with differing $\mathrm{pK}_{\mathrm{a}} \mathrm{s}$, would provide a more robust and tuneable method for generating step-induced $\mathrm{pH}$ gradients. 


\section{Appendix 1}

\section{Evaluation of stationary phases for mixed-bed applications}

\section{I.1. Introduction}

Development of a mixed-bed column of strong and weak anion exchange resins for the generation of induced $\mathrm{pH}$ gradients requires the selection of materials with specific characteristics. The strong base exchanger must have large pores for good protein mass transfer and ligands that have a charge independent of $\mathrm{pH}$. In particular, the strong base exchanger should have negligible weak base ligands, which would provide an uncharacterized secondary binding affinity for proteins and change the shape and duration of induced $\mathrm{pH}$ gradients. On the other hand, the weak base resin should have very small pores that exclude proteins and a high concentration of weak base ligands that minimize the amount of weak resin required within the mixed-bed.

The protocol in Figure I.1 was developed for the systematic evaluation of anion exchange materials as possible mixed-bed components. This protocol is based on three experimental techniques, two of which determine suitability for mixed-bed applications, while the third provides information important for modeling. Inverse size exclusion chromatography (iSEC) was used to determine the particle porosities, bed porosities, and average pore size. Potentiometric titrations were used to determine the total weak base ligand concentration for each material, and ligand deprotonation $\mathrm{pK}_{\mathrm{a}}$ values. Finally, a particle size distribution was determined from visible light microscopy images. Failure to meet a specification resulted in the exclusion of the material from further study. 


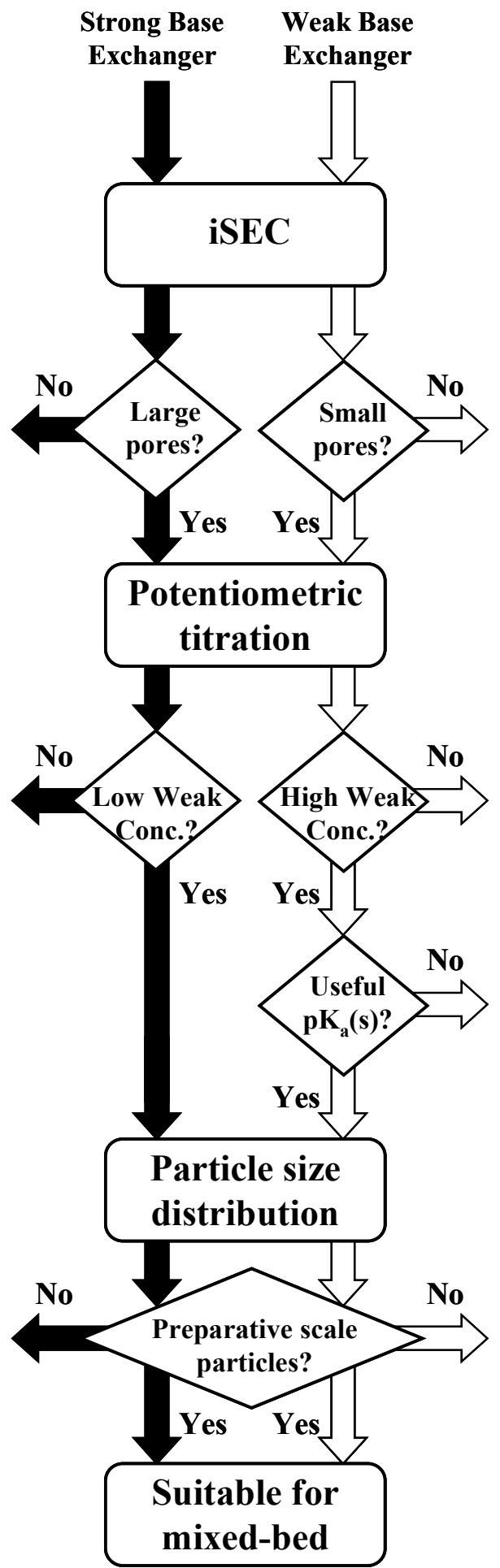

Figure I.1 - Decision tree for evaluating resins for mixed-bed applications based on simple experiments. A "No" response excluded a material from further consideration for use in mixed-bed columns. 


\section{I.2. Experimental methods}

I.2.1. Inverse size exclusion chromatography (iSEC)

iSEC was used to establish the pore size, extraparticle porosity, and intraparticle porosity for each stationary phase. In iSEC, pulse injections of a series of non-interacting dextran probes (Table I.1) are eluted through the column under non-binding conditions. First moment analysis of the resultant peaks is used to determine the distribution coefficient $\left(K_{D}\right)$ from the following expression

$$
K_{D}=\frac{V_{R} / V_{c o l}-\varepsilon}{1-\varepsilon}
$$

where, $V_{R}$ is the retention volume, $\varepsilon$ is the extraparticle porosity, and $V_{c o l}$ is the column volume. The $K_{D}$ values for probes with different molecular size can then be used to determine an effective pore size. In this work, glucose (hydrodynamic radius, $r_{h}=0.36$ $\mathrm{nm})$ and dextran polymers with molecular mass from $4 \mathrm{kDa}\left(r_{h}=1.68 \mathrm{~nm}\right)$ to $2000 \mathrm{kDa}$ $\left(r_{h}=37.1 \mathrm{~nm}\right)$ were used as probes.

Porosity and pore size were determined from the $K_{D}$ values calculated according to Eq I.1. Assuming a cylindrical pore geometry, $K_{D}$ is related to the pore radius as follows (1-3):

$$
K_{D}=\varepsilon_{p}\left(1-\frac{r_{m}}{r_{\text {pore }}}\right)^{2}
$$

where $\varepsilon_{p}$ is the intraparticle porosity and $r_{m}$ is the probe radius. For this work, $\varepsilon$ was determined either from the retention volume of $2000 \mathrm{kDa}$ dextran (for the smaller pore 
Table I.1 - Dextran probes for iSEC experiments.

\begin{tabular}{lcc}
\hline Probe & $\begin{array}{c}\text { Molecular weight } \\
(\mathrm{Da})\end{array}$ & $\begin{array}{c}\text { Hydrodynamic } \\
\text { radius }-\mathrm{r}_{\mathrm{h}}(\mathrm{nm})\end{array}$ \\
\hline Glucose & 181 & 0.4 \\
$4 \mathrm{kDa}$ & 4,000 & 1.7 \\
$10 \mathrm{kDa}$ & 10,000 & 2.7 \\
$40 \mathrm{kDa}$ & 40,000 & 7.0 \\
$500 \mathrm{kDa}$ & 500,000 & 18.6 \\
$2000 \mathrm{kDa}$ & $2,000,000$ & 37.1 \\
\hline
\end{tabular}


matrices) or from column pressure-flow curves using the Kozeny-Carman equation (4). $\varepsilon_{p}$ and $r_{m}$ were then determined by linear regression of the plot of $\sqrt{K_{D}}$ versus $r_{m}$.

\section{I.2.2. Potentiometric titrations}

Potentiometric titrations were used to determine the weak base content and deprotonation equilibrium constant of each resin. The resin samples were first equilibrated at $\mathrm{pH} 11$ to deprotonate all weak base groups, and then titrated with $\mathrm{HCl}$ while monitoring the $\mathrm{pH}$. Sloping regions of the titration profile indicate buffering capacity while plateaus indicate the saturation of a particular set of weak sites. The buffering regions are described using one or more experimentally determined $\mathrm{pKa}$ values.

The model developed by Pabst et al. (5) was used to describe the potentiometric titration curves. The following relationships can be written about the experimental system.

\section{Electroneutrality -}

$$
C_{\mathrm{Cl}^{-}}+C_{\mathrm{OH}^{-}}=\mathrm{C}_{\mathrm{Na}^{+}}+C_{\mathrm{H}^{+}}
$$

Donnan equilibrium -,

$$
q_{C l^{-}} q_{H^{+}}=C_{C l^{-}} C_{H^{+}}
$$

Deprotonation equilibrium constant -

$$
K_{a, R}=\frac{q_{R} q_{H^{+}}}{q_{R H^{+}}}
$$

The Donnan equilibrium relationship describes the partitioning of equal charge counterions between the solution and the positively charged resin phase. The deprotonation constant, $K_{a, R}$, describes the proton loss for the weak base groups $\left(\mathrm{RH}^{+}\right)$ which yields a neutral group (R). The total concentration of weak base groups, $q_{0}$, is the sum of the concentrations of the protonated and deprotonated groups. 


$$
q_{0}=q_{R H^{+}}+q_{R}
$$

In practice, $q_{\mathrm{OH}^{-}}<<q_{C l^{-}}(6)$, so that $q_{C L^{-}} \approx q_{R H^{+}}$. The final result is obtained by combining Eqs I.3-I.6 and is as follows:

$$
q_{C l^{-}}=\frac{1}{2}\left[\frac{-C_{H^{+}} C_{C l^{-}}}{K_{a, R}}+\sqrt{\left(\frac{C_{H^{+}} C_{C l^{-}}}{K_{a, R}}\right)^{2}+4\left(\frac{q_{0} C_{H^{+}} C_{C l^{-}}}{K_{a, R}}\right)}\right]
$$

This equation shows that the amount of chloride in the resin depends on the product of the chloride and hydrogen ion concentrations in solution.

\section{I.2.3. Particle size distribution (PSD)}

Particle size was determined by analyzing optical microscopy images of several hundred particles of each material using ImageJ software. The images were converted to a binary representation and then the areas of individual particles were converted to radii which were used to calculate particle volume. Because of their high transparency, geltype resins, such as Sepharose, required the use of dye or additional image processing steps to analyze visually, while raw images of the harder and more opaque materials such as UNOsphere were made binary without further treatment.

\section{I.3. Results and discussion}

I.3.1. Inverse size exclusion chromatography (iSEC)

Figures I.2 - I.4 show the iSEC results obtained for all the materials tested for use as either weak or strong base materials in mixed-bed applications. The values determined for the porosity and pore size are included in Table I.2. For materials like SOURCE 30Q and UNOsphere DQ that have large pores, we see a wide distribution of retention times 

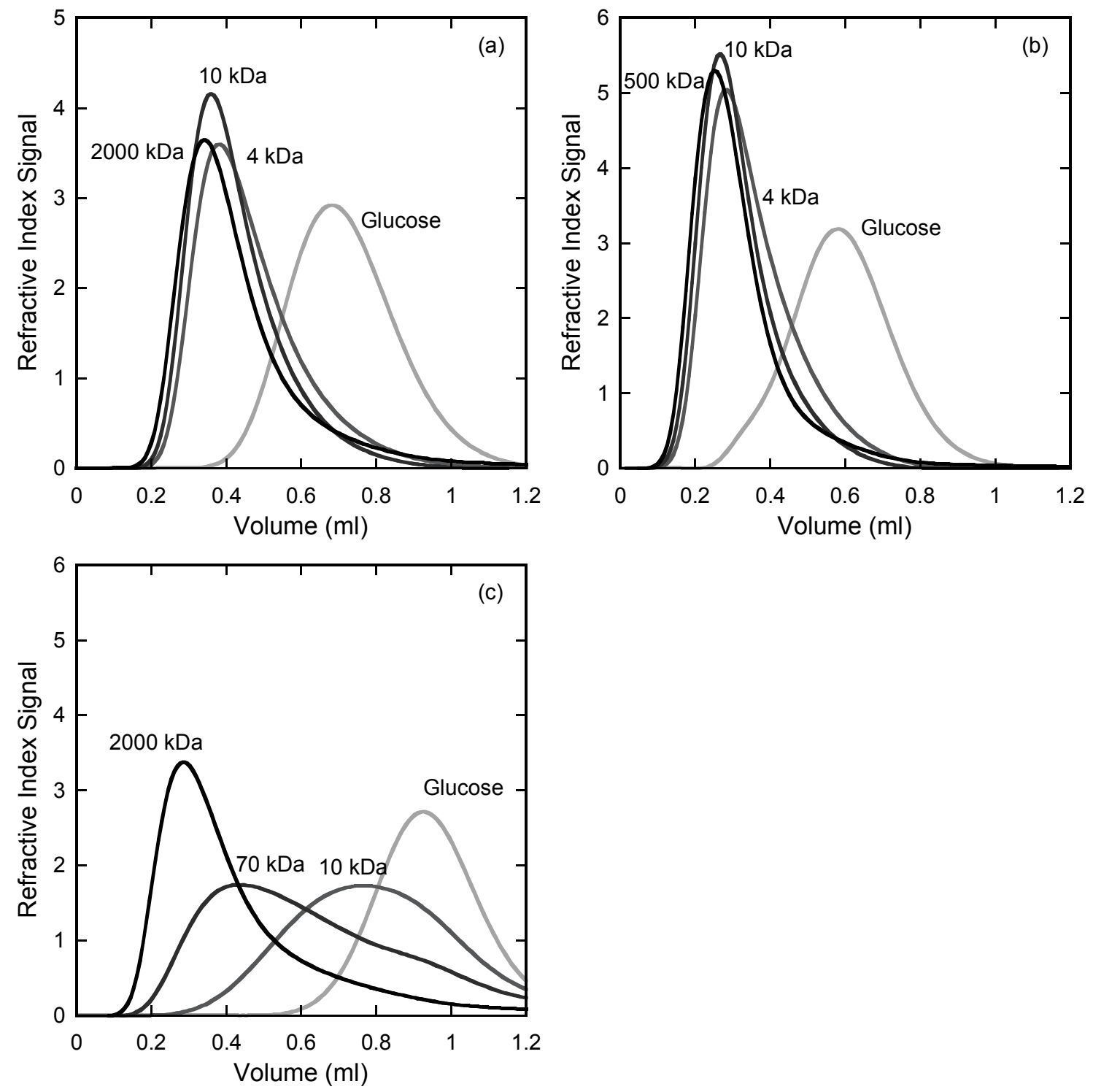

Figure I.2 - iSEC elution profiles for weak base exchange resins (a) A847, (b) AG 4-X4, and (c) DEAE Sepharose FF, tested with non-interacting dextran probes using $0.5 \mathrm{~cm} \times 5.0 \mathrm{~cm}$ columns and $20 \mathrm{mM}$ Tris/ $\mathrm{Cl}^{-}$buffer at $\mathrm{pH}$ 7.0. 

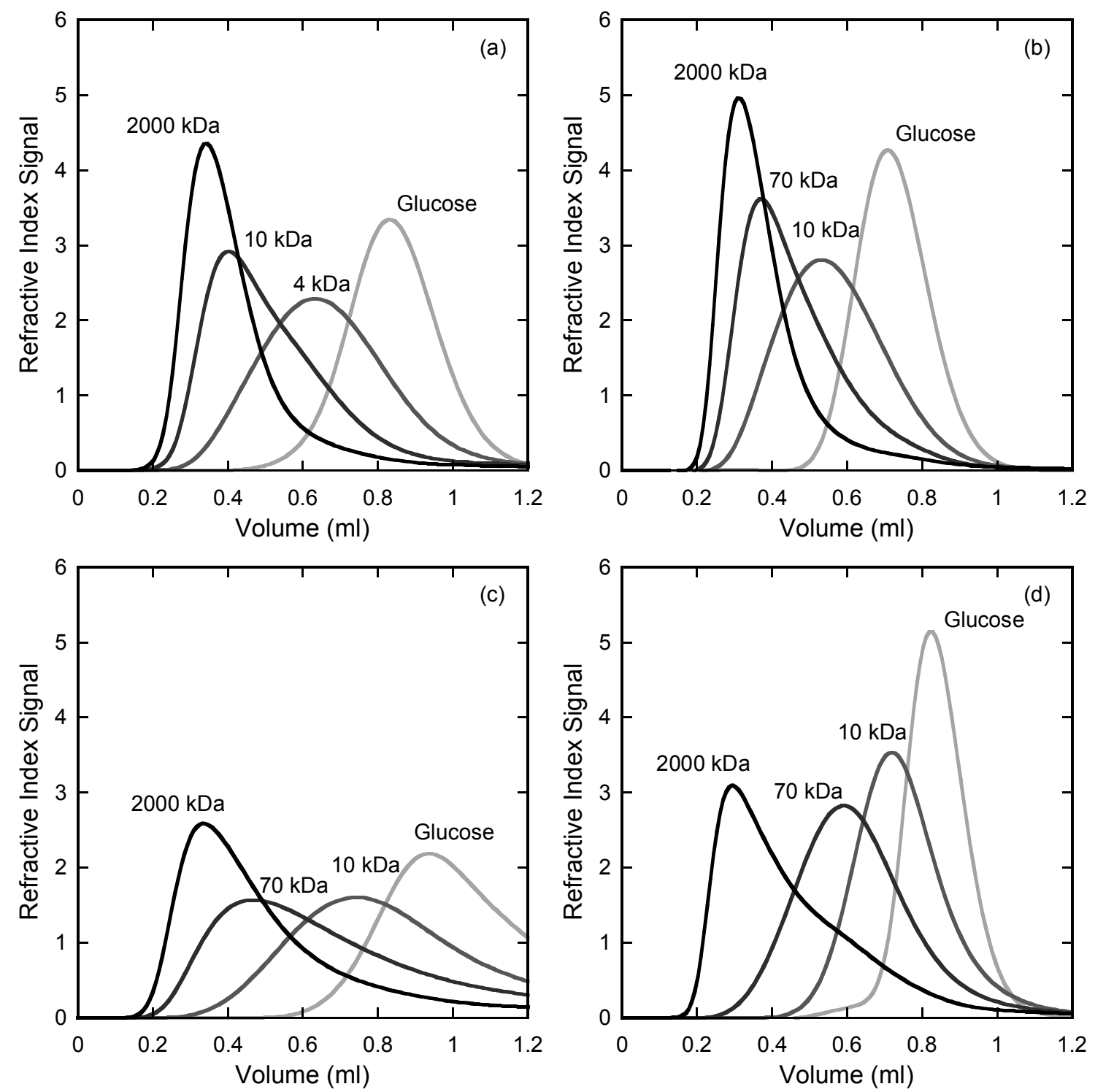

Figure I.3 - iSEC elution profiles for strong base exchange resins (a) Nuvia Q, (b) SuperQ 650, (c) Q Sepharose FF, and (d) Q Sepharose HP, tested with non-interacting dextran probes using $0.5 \mathrm{~cm} \times 5.0 \mathrm{~cm}$ columns and $20 \mathrm{mM}$ Tris/Cl- buffer at $\mathrm{pH}$ 7.0. 

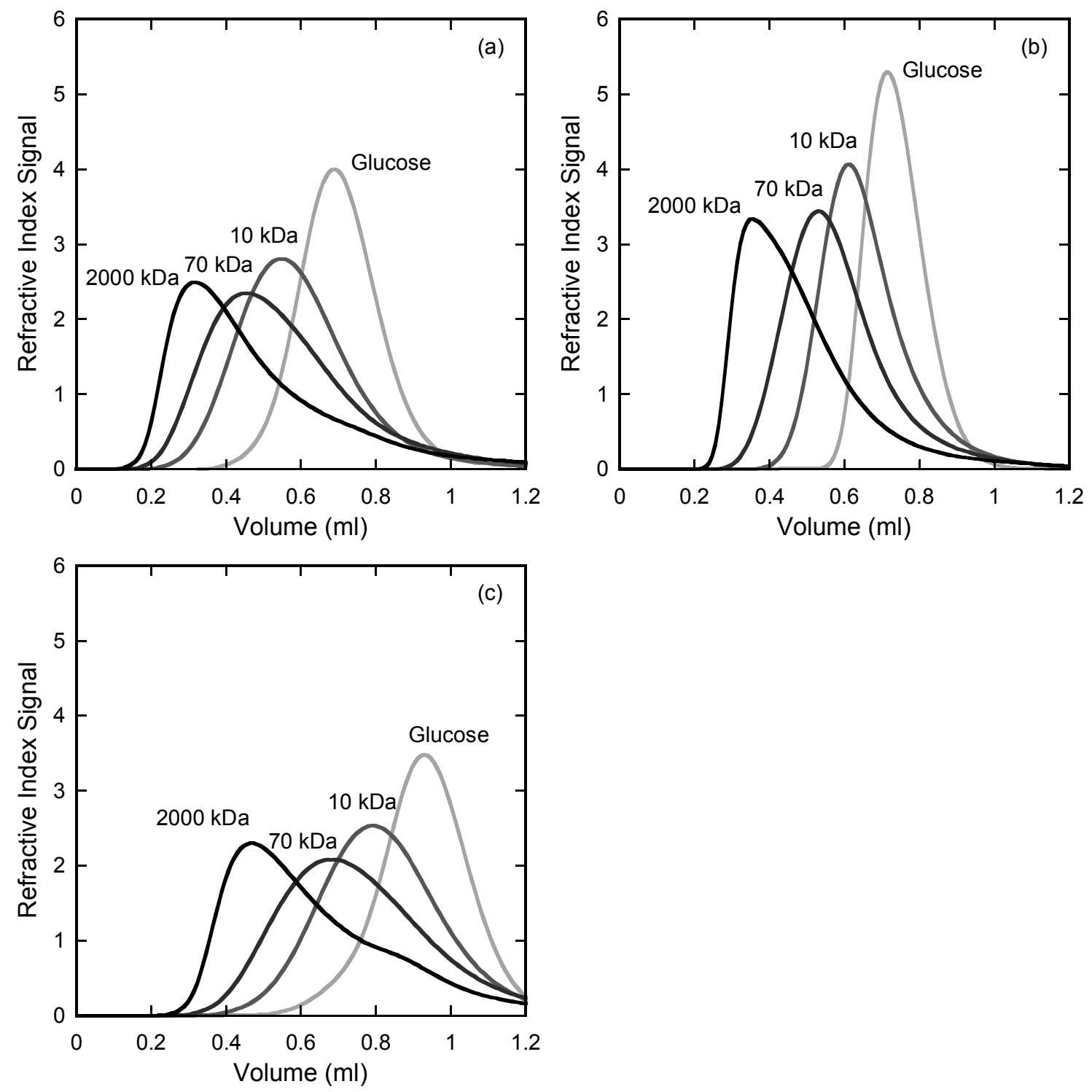

Figure I.4 - iSEC elution profiles for strong base exchange resins (a) Macro-Prep High Q, (b) SOURCE $30 \mathrm{Q}$, and (c) UNOsphere DQ, tested with non-interacting dextran probes using $0.5 \mathrm{~cm} \times 5.0 \mathrm{~cm}$ columns and $20 \mathrm{mM}$ Tris $/ \mathrm{Cl}^{-}$buffer at $\mathrm{pH}$ 7.0. 
Table I.2 - Porosity and pore size as determined from iSEC studies

\begin{tabular}{lcc}
\hline Material & Porosity $\left(\varepsilon_{p}\right)^{\#}$ & $\begin{array}{c}\text { Size exclusion } \\
\text { limit (nm)* }\end{array}$ \\
\hline A847 & 0.42 & $<2$ \\
AG 4-X4 & 0.44 & $<2$ \\
DEAE Sepharose FF & 0.92 & 20 \\
Nuvia Q & 0.69 & 7 \\
SuperQ 650 & 0.55 & 7 \\
Q Sepharose FF & 0.92 & 20 \\
Q Sepharose HP & 0.76 & 37 \\
Macro-Prep High Q & 0.67 & $>40$ \\
SOURCE 30Q & 0.63 & $>40$ \\
UNOsphere Diol Q & 0.80 & $>40$
\end{tabular}

\# Based on glucose

$*$ Hydrodynamic radius of dextran giving $K_{D}=0$ 
for the various probes, while materials like Nuvia Q and AG 4-X4 exclude a majority of the probes indicating smaller pores. In this case, the apparent small pore size for Nuvia Q and SuperQ 650 are the result of charged polymeric extenders within the pores that exclude neutral molecules while allowing rapid transport of appropriately charged proteins (7).

The pore sizes determined in these experiments indicate that several of the materials first investigated are not well suited to a mixed-bed design. DEAE Sepharose FF is a weak anion exchanger that has been shown to generate induced $\mathrm{pH}$ gradients (5), but the pore size is more than three times the radius of mAbs, indicating that proteins would have significant access to pores. All of the strong base exchangers have pores large enough to allow the entrance of mAbs, however Q Sepharose FF has pores that are 3-4 times smaller than the other materials. This indicates that mass transfer would be slower in Q Sepharose FF, so the other materials would be better suited to a mixed-bed application.

\section{I.3.2. Potentiometric titrations}

Figure I.5 shows the potentiometric titrations for (a) weak and (b) strong anion exchange materials. All of the strong Q matrices except for Macro-Prep High Q (Figure I.5b) have titration curves near the blank, indicating very little weak base content. Even DEAE Sepharose FF, which is a weak base resin, has a relatively low weak base content. On the other hand, the very high plateaus for A847 and AG 4-X4 indicate very large weak base capacities, 1-2 orders of magnitude greater than the strong materials. When coupled with the small pores found for both resins, both would be ideal for our mixed- 

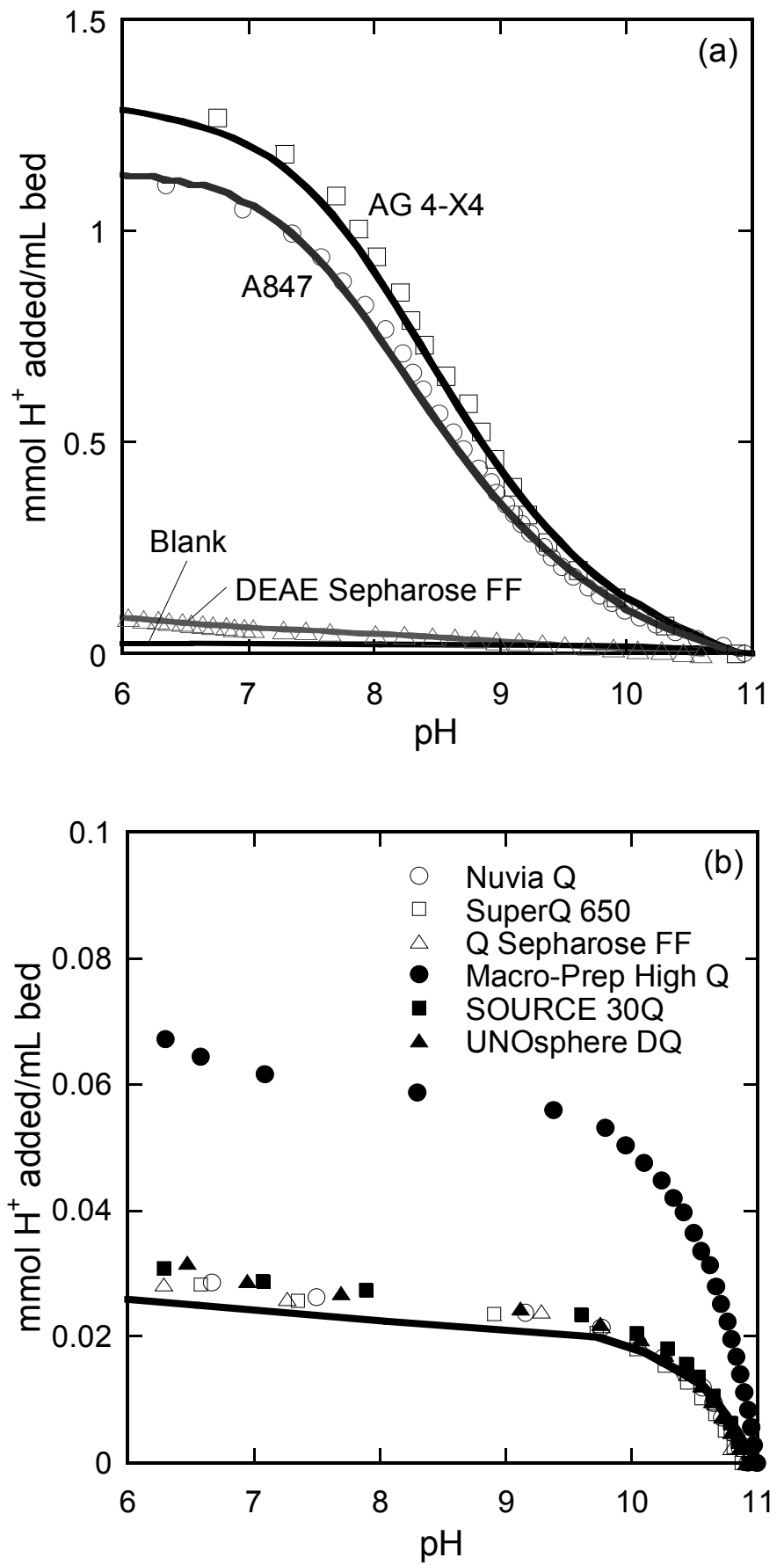

Figure I.5 - Potentiometric titrations for (a) weak and (b) strong anion exchange media 
Table I.3 - Weak ligand concentrations and $\mathrm{pK}_{\mathrm{a}} \mathrm{s}$ determined by potentiometric titration

\begin{tabular}{lcc}
\hline Material & $\begin{array}{c}\text { Weak base content } q_{0} \\
(\mathrm{mmol} / \mathrm{ml} \text { bed })\end{array}$ & $\mathrm{pKa}$ \\
\hline A847 & 1.29 & 9.7 \\
AG 4-X4 & 1.46 & 9.8 \\
DEAE Sepharose FF & 0.11 & $9.0,8.2$ \\
Nuvia Q & 0.02 & 9.4 \\
SuperQ 650 & 0.02 & 9.0 \\
Q Sepharose FF & 0.02 & 10.0 \\
Macro-Prep High Q & 0.11 & 11.0 \\
SOURCE 30Q & 0.01 & 9.0 \\
UNOsphere Diol Q & 0.01 & 9.0 \\
\hline
\end{tabular}


bed system. The reason for the high weak base contents in A847 and AG4X4 is that these are gel-type polymeric resins without macroporosity. As a result, the polymer content is very high giving base capacities comparable with those of traditional ion exchange resins used in water treatment applications.

Table I.3 shows the weak ligand concentrations and pKas used to fit the potentiometric titration curves. Both A847 and AG 4-X4 had weak ligand concentrations much greater than any other material, and $\mathrm{pK}_{\mathrm{a}} \mathrm{s}$ that indicate they would have a useful buffering range for separating proteins at $\mathrm{pH}>7$. However, because both materials have comparable $\mathrm{pK}_{\mathrm{a}}$ values, $\mathrm{AG} 4-\mathrm{X} 4$ was selected for further study due to a higher overall ligand concentration. With the exception of Macro-Prep High Q, the strong anion exchangers have low weak base content, meaning they would be well-suited for use in a mixed-bed.

I.3.3. Particle size distribution (PSD)

Figure I.6 shows the particle size distributions for the ion exchange resins investigated in this work. The highly irregular shapes of the A847 and AG 4-X4 prevented analysis of the particle size distribution by the standard method. By observation, the largest pieces of AG 4-X4 have a longest dimension of about $200 \mu \mathrm{m}$ while the smallest are about $50 \mu \mathrm{m}$. A847 had a larger distribution, with pieces up to 300 $\mu \mathrm{m}$. The particle size distributions shown in Figure I.6 indicate that there is a large variance in the strong AEX resins used. The gel-type Q Sepharose FF has large particles with a wide size distribution while UNOsphere Diol Q has a smaller average size and much narrower distribution. Source $30 \mathrm{Q}$ has the smallest average size and is essentially monodispersed. 

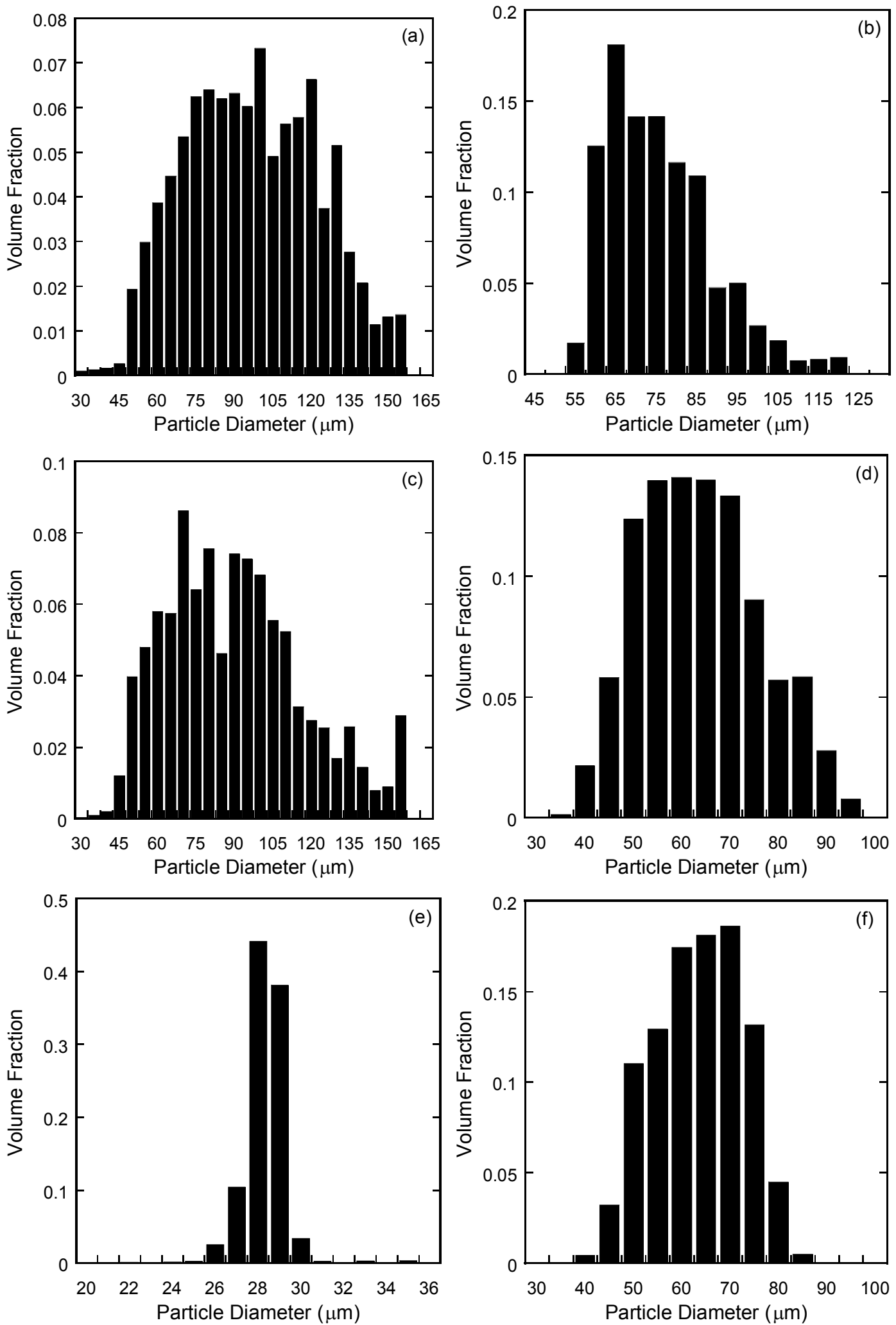

Figure I.6 - Particle size distributions determined by microphotograph analysis for (a) DEAE Sepharose FF, (b) Nuvia Q, (c) Q Sepharose FF, (d) Macro-Prep High Q, (e) SOURCE 30Q, and (f) UNOsphere DQ. 
All materials investigated here had particle sizes appropriate for preparative scale chromatography. Based on the immobilized mixed-bed data presented in Chapter 2, the difference in particle size doesn't appear to affect the distribution of materials within a mixed-bed. However, packing methods for large scale columns may require that the strong and weak base materials have similar size distributions and flow characteristics. In this case, the PSD would lead to the exclusion of dissimilar materials from further study.

\section{I.3.4. Selection of materials}

The data from these three experiments is used in conjunction with the decision tree from Figure I.1 to determine which materials are useful for continued study. For instance, iSEC results exclude the DEAE Sepharose FF from use as a weak phase material and indicate that Q Sepharose FF is less favorable as a strong phase material due to a relatively small average pore size. Additionally, the materials with charged surface extenders (Nuvia Q and SuperQ 650) were removed from consideration due to elution mass transfer limitations resulting from the sterically hindered pores. The potentiometric titrations showed that A847, despite having a high weak ligand capacity, had a lower capacity and similar pKa value to AG 4-X4, making AG 4-X4 the more useful material. On the other hand, Macro-Prep High Q has a significant weak ligand concentration, so would not be suitable for mixed-bed applications. Finally, no specific selection criteria were used from the particle size distribution for these small scale experiments, however this would be a deciding factor for preparative scale columns which are often packed by gravity settling. 


\section{I.4. Conclusions}

The use of mixed-bed columns of strong and weak anion exchange resins to generate induced $\mathrm{pH}$ gradients for protein purification requires a systematic approach to select materials. Both strong and weak base materials were evaluated using the same series of simple experiments to determine pore size, weak ligand concentration, deprotonation $\mathrm{pK}_{\mathrm{a}}$, and particle size distribution. Acceptance criteria for each phase differed, with large pores $\left(r_{p}>15 \mu m\right)$ and low weak base ligand concentrations required for the strong base materials and small pores $\left(r_{p} \leq 5 \mu m\right)$ and high weak base ligand concentrations needed for the weak base material. Based on this approach, AG 4-X4 was selected as the weak base component for further mixed-bed experiments. On the other hand, several strong base exchangers were determined to be suitable for mixed-bed applications. Selection of a single material requires additional experiments with the protein system of interest to determine capacity and selectivity for the desired product. In this way we can select a protein/strong base resin combination that best optimizes the purity and recovery. By selecting a cohort of suitable strong base materials that have differing selectivities, it is possible to improve the flexibility of the mixed-bed approach and makes it a simple matter to apply it to other protein systems. 


\section{I.5. References}

1. Hagel, L.; Ostberg, M. \& Andersson, T. (1996) Apparent pore size distributions of chromatography media. J. Chromatogr. A, 743: 33-42.

2. Yau, W. W.; Kirkland, J. J. \& D, B. D. (1979) Modern size-exclusion liquid chromatography: practice of gel permeation and gel filtration chromatography. Wiley

3. Ubiera, A. R. \& Carta, G. (2006) Radiotracer measurements of protein mass transfer: kinetics in ion exchange media. Biotechnol. J., 1: 665-674.

4. Carta, G.; Gregory, M. E.; Kirwan, D. J. \& Massaldi, H. A. (1992) Chromatography with permeable supports: theory and comparison with experiments. Sep. Technol., 2: 62-72.

5. Pabst, T. M. et al. (2008) Separation of Protein Charge Variants with Induced pH Gradients Using Anion Exchange Chromatographic Columns. Biotechnol. Prog., 24: 1096-1106.

6. Helfferich, F. (1962) Ion Exchange; McGraw-Hill Book Company, Inc.: New York, United States

7. Perez Almodovar, E. X. (2012) Protein adsorption and transport kinetics in novel stationary phases for protein chromatography based on the UNOsphere architecture. 225. 


\section{Appendix 2}

\section{Comparison of mixed-bed and layered-bed columns}

\section{II.1. Introduction}

The use of $\mathrm{pH}$ gradients has been shown to improve the resolution of protein charge variants when used with ion exchange chromatography (1-3). This improvement in resolution is attributed to the inherent differences between elution driven by ionic strength and that by changing $\mathrm{pH}$ (4) (Figure 2.2). Protein elution achieved by increasing the ionic strength is the result of increased shielding of attractive electrostatic forces between the charged ligands and proteins. On the other hand, protein elution achieved by decreasing the $\mathrm{pH}$ on an anion exchanger is the result of increasing the net positive charge of the bound proteins, eventually leading to electrostatic repulsion overcoming attraction. Because this approach is based on the changing charge of the proteins themselves, $\mathrm{pH}$ gradients are well suited to the separation of protein charge variants.

The two ways of implementing $\mathrm{pH}$ gradients on chromatography columns are to either create an externally generated $\mathrm{pH}$ gradient by mixing two or more buffers in the proper ratio, or to use a mobile and stationary phase combination that creates a retained $\mathrm{pH}$ gradient in response to a step change in buffer composition. Externally generated $\mathrm{pH}$ gradients move at the mobile phase velocity so that at any given time, the difference in

$\mathrm{pH}$ between the column inlet and outlet is relatively small. As a result, the slow moving proteins eluted by externally generated gradients are not focused and produce relatively broad peaks. On the other hand, the equilibrium-based interactions that produce retained $\mathrm{pH}$ gradients occur at rates slower than the mobile phase velocity, so that a standing $\mathrm{pH}$ 
wave is produced with a large $\mathrm{pH}$ difference between the column inlet and outlet. In this way, eluting proteins are able to effectively focus at a specific $\mathrm{pH}$, resulting in sharper peaks and improved resolution.

In order to confirm the expected behavior of both the externally generated and induced $\mathrm{pH}$ gradients, two columns were packed, one with a mixed-bed (10\% AG 4-X4 / 90\% SOURCE 30Q) and the other with a layered-bed (with AG 4-X4 at the top and SOURCE 30 Q at the bottom) with the same masses for each component material. Experiments were conducted with both columns using step-induced $\mathrm{pH}$ gradients to separate $\mathrm{mAb}$ charge variants. The $\mathrm{pH}$ gradient generated for each column should be temporally identical, while the gradient is retained in the mixed-bed and unretained in the layered-bed. In this way, the inherent differences between the two implementations of $\mathrm{pH}$ gradients should be apparent.

\section{II.2. Experimental methods}

\section{II.2.1. Columns}

Two sets of dry SOURCE 30Q (1.083 g each) and AG 4-X4 (0.083 g each) samples were massed and rehydrated in a $\mathrm{pH} 7.0,10 \mathrm{mM}$ phosphate buffer with $1 \mathrm{M}$ sodium chloride. One set of SOURCE 30Q and AG 4-X4 samples were combined into a single slurry and packed into a 5x200 Tricorn column (GE Healthcare Piscataway, NJ, USA) using the method for mixed-beds described in Chapter 2. The second pair of samples were packed sequentially (Figure II.1), with the SOURCE 30Q being packed first in the bottom of the column at $10 \mathrm{ml} / \mathrm{min}$, and then packing the $\mathrm{AG} 4-\mathrm{X} 4$ on top of the SOURCE 30Q at a reduced flow rate of $4 \mathrm{ml} / \mathrm{min}$. A fiberglass frit was placed 


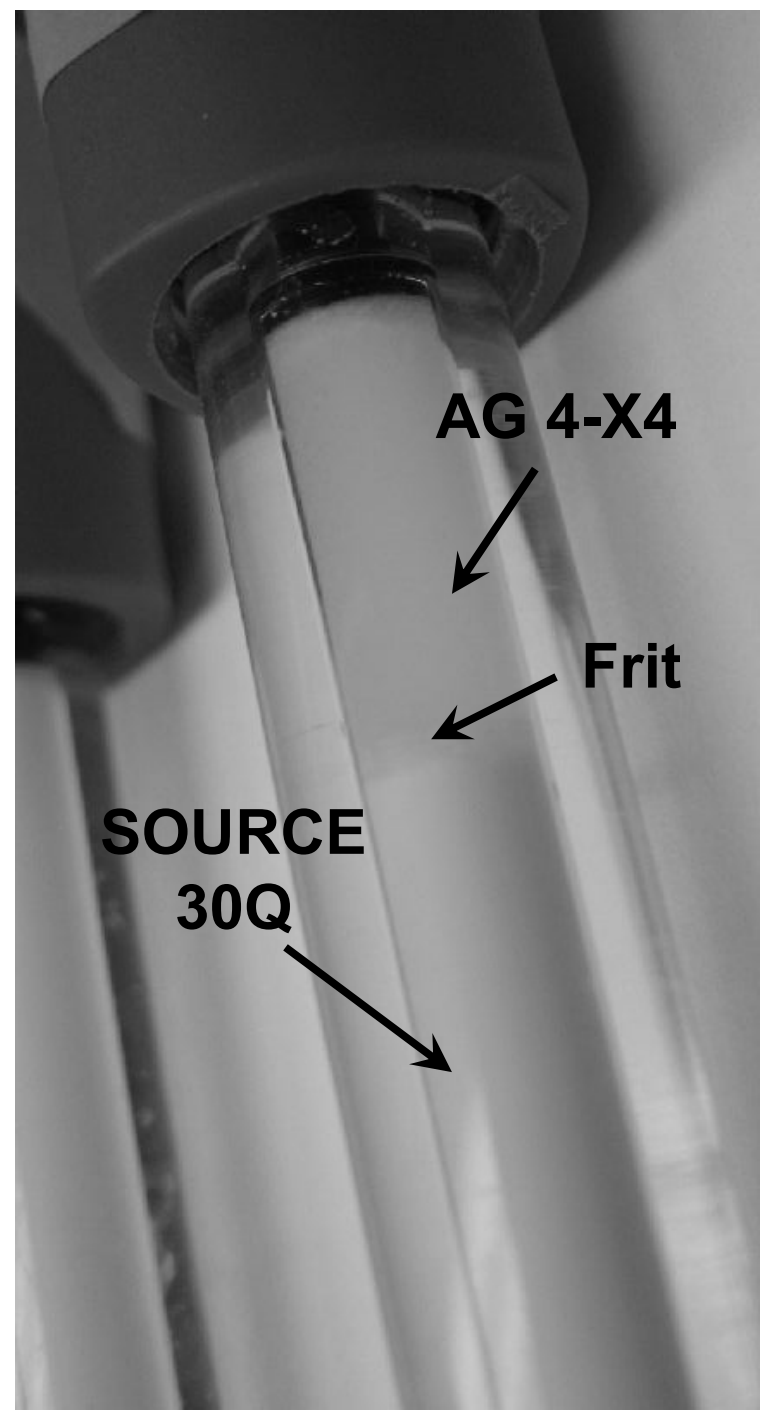

Figure II.1 - Image of a layered-bed column, with a $1.9 \mathrm{~cm}$ bed of AG 4-X4 packed on top of a $18.5 \mathrm{~cm}$ bed of SOURCE 30Q. The two sections are separated by a fiberglass frit to prevent resin mixing and ensure a flat transition between the two. 
between the two beds to prevent resin mixing and ensure a flat transition between sections of the column. The resulting columns had comparable bed heights, with the layered-bed having a slightly greater height due to the additional frit.

II.2.2. Step-induced $\mathrm{pH}$ gradient separations of $\mathrm{mAb}$ charge variants

Experiments were conducted with both columns to separate mAb charge variants using $\mathrm{pH} 9$ to $\mathrm{pH} 7$ steps with two different buffer conditions. The buffers tested were 35 $\mathrm{mM}$ and $15 \mathrm{mM}$ chloride with $95 \%$ ethanolamine and 5\% Tris. In an effort to minimize variability, a single preparation of each buffer was used to test both columns. A mAb sample of $2 \mathrm{mg} / \mathrm{ml}$ bed was used at each condition and a constant linear flow rate of 300 $\mathrm{cm} / \mathrm{hr}$ was used for all experiments. The elution from each experiment was collected in 1 CV fractions for offline $\mathrm{pH}$ analysis.

\section{II.3. Results and discussion}

Figure II.2 shows the elution profiles for both the mixed-bed and the layered-bed columns using $35 \mathrm{mM}$ chloride buffers. As expected for two columns with identical quantities of weak resin, the step-induced $\mathrm{pH}$ gradients generated by the two beds are comparable. This result confirms the assumption that local equilibrium is achieved for ions in the column, even in the small pores of AG 4-X4. On the other hand, the elution profiles for the $\mathrm{mAb}$ are quite different, with the layered-bed producing a shorter and broader peak that elutes about $5 \mathrm{CV}$ later than the mixed-bed peak. In addition to eluting earlier with a sharper peak, the mixed-bed elution profile presents a shoulder on the tail of the curve, indicating the presence of the deamidated charge variant. No shoulder is apparent on the layered-bed elution profile. 


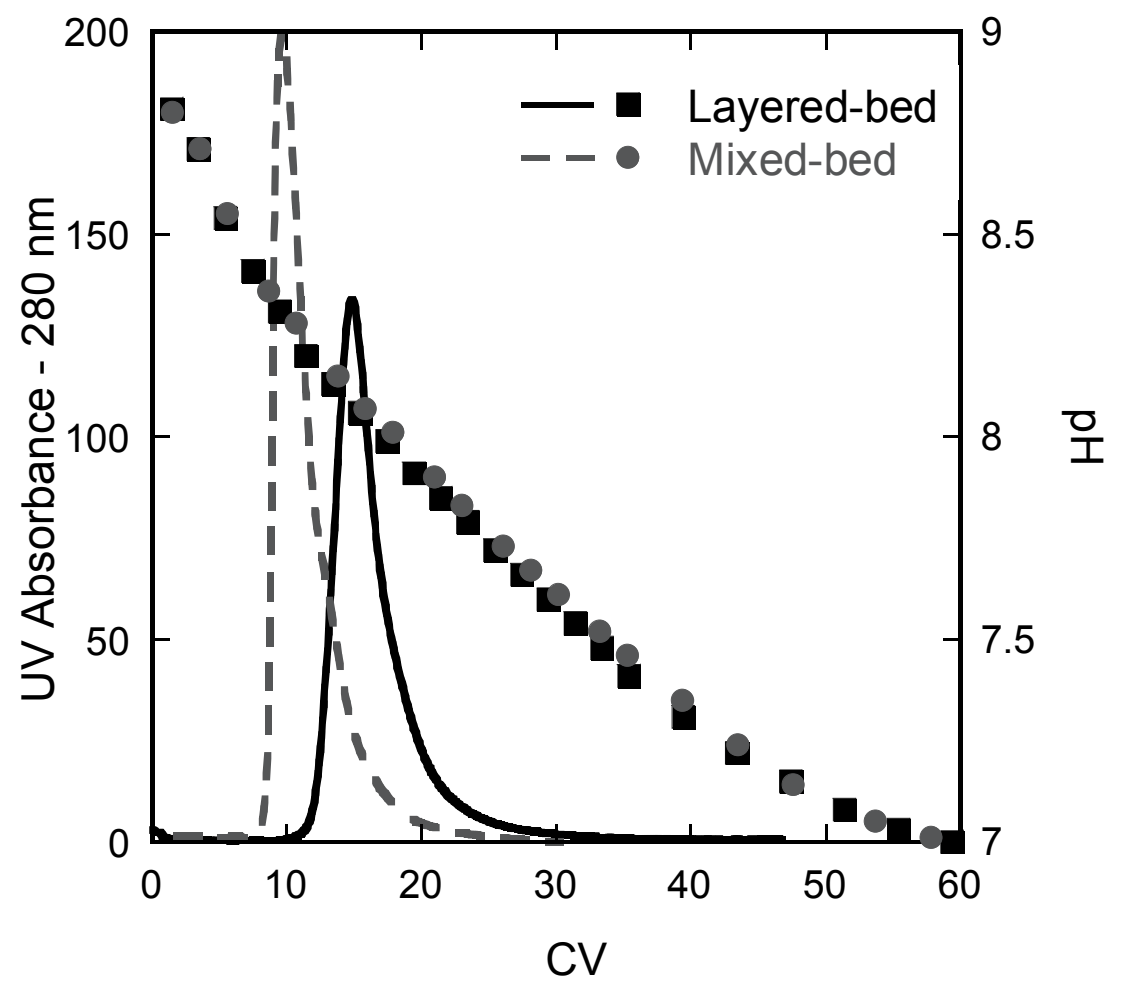

Figure II.2 - Comparison of the $\mathrm{pH}$ gradient elution behavior for a $\mathrm{mAb}$ in two columns with identical masses of two materials, 10\% AG 4-X4 / 90\% SOURCE 30Q, with the materials mixed in one column and layered in the other. The induced $\mathrm{pH}$ gradient was created by a step change from $\mathrm{pH} 9$ to $\mathrm{pH} 7 \mathrm{using}$ a 35 $\mathrm{mM}$ chloride buffer with $95 \%$ ethanolamine and $5 \%$ Tris. 
Figure II.3 shows the elution profiles for both the mixed-bed and layered-bed columns using $15 \mathrm{mM}$ chloride buffers. The $\mathrm{pH}$ gradients, though more shallow than those seen in the $35 \mathrm{mM}$ experiments, are still comparable for the mixed-bed and layeredbed columns. The shallower gradient resulted in later elution for both columns, and also increased the difference in $\mathrm{mAb}$ retention. In this case, the mixed-bed eluted about $20 \mathrm{CV}$ earlier than the layered-bed. The mixed-bed produced a much sharper peak with a clearly defined second peak for the variant. The broader peak from the layered-bed shows a welldefined shoulder, but does not present a clear second peak for the variant.

Figure II.4 shows the evolution of the $\mathrm{pH}$ gradient within the column as a function of time for the layered-bed and mixed-bed columns. The mixed-bed $\mathrm{pH}$ profile was generated by the numerical model discussed in Chapter 2. Modeling the $\mathrm{pH}$ gradient for the layered-bed was based on using the analytical $\mathrm{pH}$ gradient model (Chapter 2) to simulate a $1.9 \mathrm{~cm} \mathrm{AG} \mathrm{4-X4} \mathrm{column,} \mathrm{with} \mathrm{the} \mathrm{output} \mathrm{adjusted} \mathrm{for} \mathrm{the} \mathrm{actual} \mathrm{layered-bed}$ column volume. Because the $\mathrm{pH}$ gradient is unretained, any given $\mathrm{pH}$ value has a residence time of about $1 \mathrm{CV}$, meaning the inlet $\mathrm{pH}$ corresponding to a given outlet $\mathrm{pH}$ can be estimated by looking at the outlet $\mathrm{pH} 1 \mathrm{CV}$ later. 


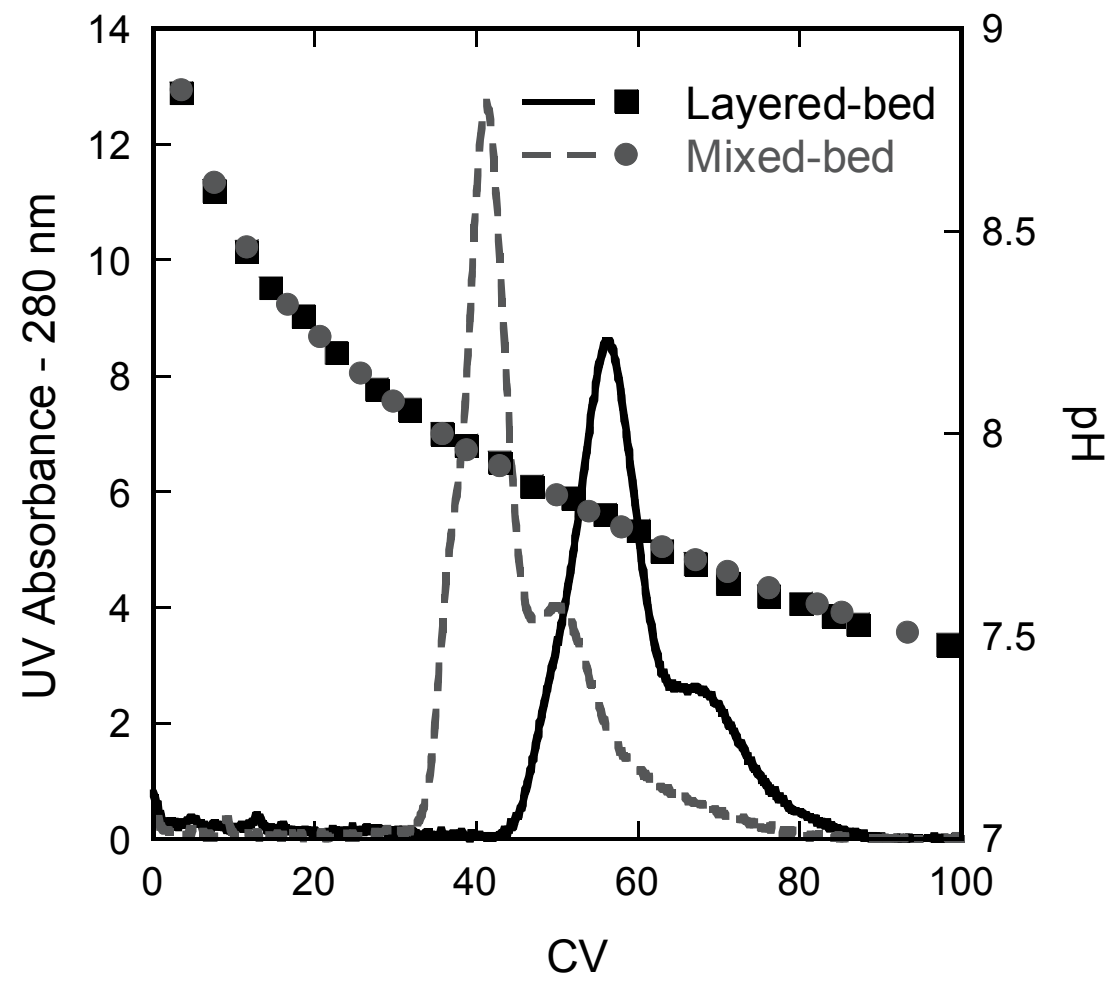

Figure II.3 - Comparison of the $\mathrm{pH}$ gradient elution behavior for a $\mathrm{mAb}$ in two columns with identical masses of two materials, 10\% AG 4-X4 / 90\% SOURCE 30Q, with the materials mixed in one column and layered in the other. The induced $\mathrm{pH}$ gradient was created by a step change from $\mathrm{pH} 9$ to $\mathrm{pH} 7 \mathrm{using}$ a 15 $\mathrm{mM}$ chloride buffer with $95 \%$ ethanolamine and $5 \%$ Tris. 


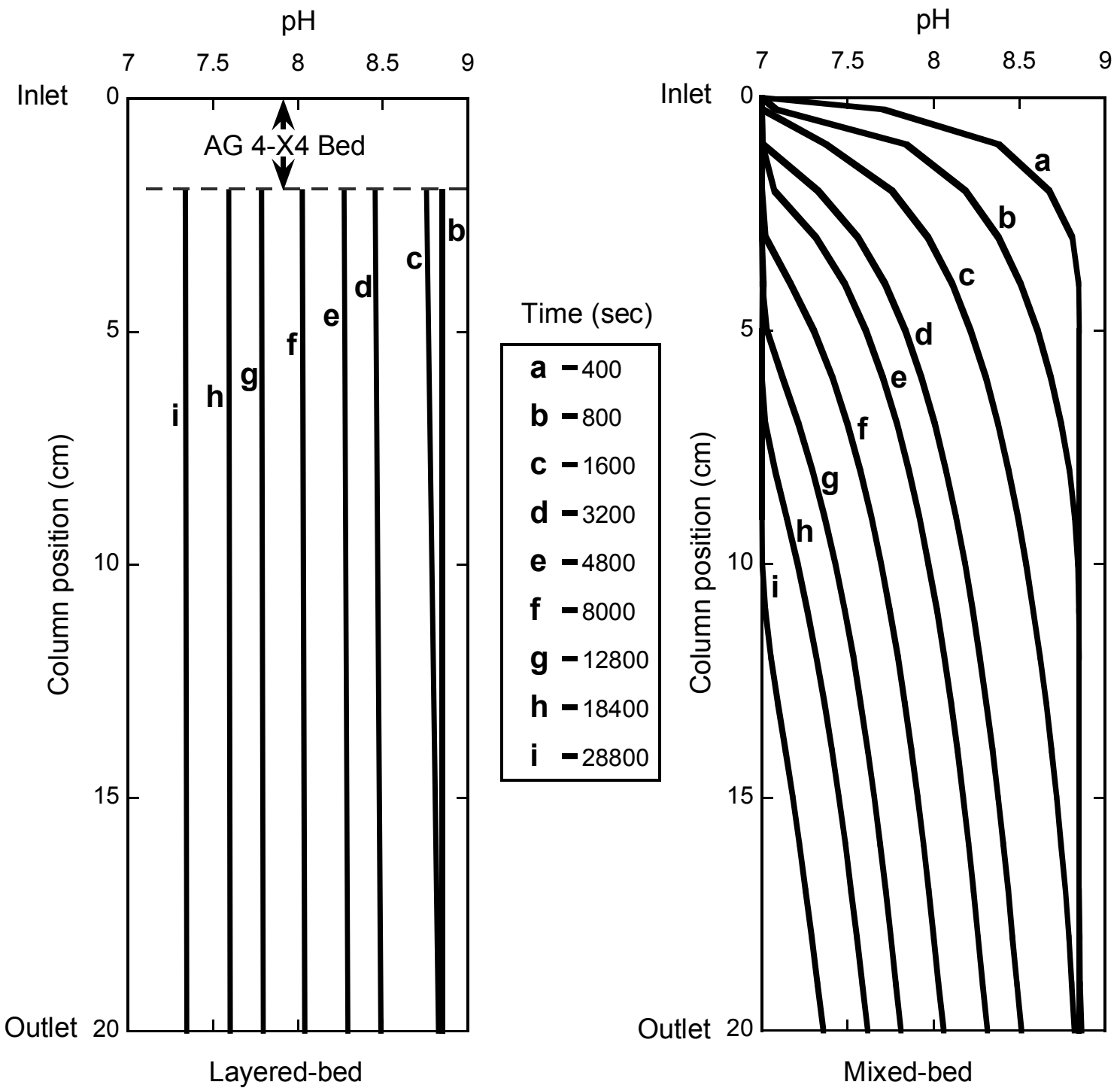

Figure II.4 - Model predicted column pH profiles for a layered-bed (AG 4-X4 followed by SOURCE 30Q) and a mixed-bed using identical masses of each component resin. The $\mathrm{pH}$ waves are based on a $10 \%$ AG 4$\mathrm{X} 4$ concentration in each column and occur after a $\mathrm{pH} 9$ to $\mathrm{pH} 7$ step in $15 \mathrm{mM}$ chloride buffer with $95 \%$ ethanolamine and $5 \%$ Tris. 
The $\mathrm{pH}$ waves for the mixed-bed column are generally non-linear and provide a much greater slope between the inlet and outlet than the layered-bed, with this difference persisting throughout the entire $\mathrm{pH}$ gradient. On the other hand, the layered-bed obviously produces a series of shallow, near-parallel $\mathrm{pH}$ waves. Despite having much different internal $\mathrm{pH}$ profiles, the outlet $\mathrm{pH}$ as a function of time is the same for both columns. This difference in the $\mathrm{pH}$ gradients qualitatively predicts the experimentally observed protein retention behavior. The early elution of protein in the mixed-bed column occurs as a result of the steep standing $\mathrm{pH}$ wave established along the column. Protein bound at the top of the mixed-bed column is protonated and begins to move at the onset of the step to low $\mathrm{pH}$ buffer, reattaching further down the column where higher $\mathrm{pH}$ deprotonates the protein and encourages binding. As the protein focuses at a $\mathrm{pH}$ value along the gradient, this continuous release/bind cycle leads to a large number of theoretical plates, increasing resolution. At the same time, the lower $\mathrm{pH}$ of the progressing wave focuses the protein in the bottom of the column where it will elute quickly once the $\mathrm{pH}$ decreases sufficiently. On the other hand, the protein bound at the top of the layered-bed will remain attached there until the decrease in $\mathrm{pH}$ causes the proteins to become protonated enough to begin moving. However, significant electrostatic interactions would still be present, leading to a slow rate of elution that gradually increases as the $\mathrm{pH}$ continues to decline. If we assume that the $\mathrm{mAb}$ begins to elute around the $\mathrm{pI}$ of 8.2 , then $\mathrm{pH}$ profiles for the two columns dictate that the mAb will be concentrated in the bottom $7 \mathrm{~cm}$ of the mixed-bed where it can elute almost immediately, and at the top of the layered-bed where it still must elute the full length of the column under conditions where significant interactions still exist. 


\section{II.4. Conclusions}

Two columns, a mixed-bed and a layered-bed, were packed with identical masses of AG 4-X4 and SOURCE 30Q. Experiments were conducted to determine if stepinduced $\mathrm{pH}$ gradients created on mixed-bed columns of strong and weak anion exchange resins will provide sharper peaks and better resolution than externally generated $\mathrm{pH}$ gradients. While both columns produced temporally identical $\mathrm{pH}$ gradients, it is apparent that the mixed-bed and layered-bed approaches have functional differences that change the effective retention of proteins within those gradients. As hypothesized, the mixed-bed produces sharper peaks with better resolution than the layered-bed column. The improvement in protein concentration and resolution is the result of sharp standing $\mathrm{pH}$ waves in the mixed-bed that focus protein toward the bottom of the column where it elutes quickly. This is in contrast to the layered-bed column, where protein remains bound at the top of the column until the $\mathrm{pH}$ decreases enough for the protein to begin moving. The combination of the slow-moving protein and fast moving $\mathrm{pH}$ gradient mean the protein will require a significant amount of time to elute through the entire column, and will be unable to focus along the $\mathrm{pH}$ gradient. 


\section{II.5. References}

1. Pabst, T. M. et al. (2008) Separation of Protein Charge Variants with Induced pH Gradients Using Anion Exchange Chromatographic Columns. Biotechnol. Prog., 24: 1096-1106.

2. Zhang, L.; Patapoff, T.; Farnan, D. \& Zhang, B. (2013) Improving pH gradient cation-exchange chromatography of monoclonal antibodies by controlling ionic strength. J. Chromatogr. A, 1272: 56-64.

3. Kang, X. \& Frey, D. D. (2004) Chromatofocusing of peptides and proteins using linear $\mathrm{pH}$ gradients formed on strong ion-exchange adsorbents. Biotechnol. Bioeng., 87: 376-87.

4. Vetter, T. A.; Ferreira, G.; Robbins, D. \& Carta, G. (2014) Mixed-Beds of Strong and Weak Anion Exchange Resins for Protein Separations with Step-Induced $\mathrm{pH}$ Gradients. Sep. Sci. Technol., 49: 477-489. 